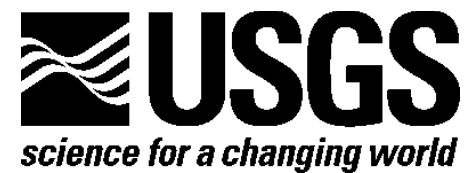

Geology and Geophysics Applied to Groundwater Hydrology at Fort Irwin, California

David C. Buesch, Editor

\title{
Laboratory Electrical Resistivity Analysis of Geologic Samples from Fort Irwin, California
}

By Benjamin R. Bloss and Paul A. Bedrosian

Open-File Report 2013-1024-E

U.S. Department of the Interior

U.S. Geological Survey 


\section{U.S. Department of the Interior \\ SALLY JEWELL, Secretary}

\section{U.S. Geological Survey \\ Suzette M. Kimball, Acting Director}

U.S. Geological Survey, Reston, Virginia: 2015

For more information on the USGS—-the Federal source for science about the Earth,

its natural and living resources, natural hazards, and the environment-visit

http://www.usgs.gov or call 1-888-ASK-USGS

For an overview of USGS information products, including maps, imagery, and publications, visit http://www.usgs.gov/pubprod

To order this and other USGS information products, visit http://store.usgs.gov

Any use of trade, firm, or product names is for descriptive purposes only and does not imply endorsement by the U.S. Government.

Although this information product, for the most part, is in the public domain, it also may contain copyrighted materials as noted in the text. Permission to reproduce copyrighted items must be secured from the copyright owner.

Suggested citation:

Bloss, B.R., and Bedrosian, P.A, 2015, Laboratory electrical resistivity analysis of geologic samples from Fort Irwin, California, chap. E of Buesch, D.C., ed., Geology and geophysics applied to groundwater hydrology at Fort Irwin, California: U.S. Geological Survey Open-file Report 2013-1024, 104 p., http://dx.doi.org/10.3133/ofr20131024E. 


\section{Acknowledgments}

Sample collection was undertaken as part of an integrated program funded by the Fort Irwin National Training Center. All laboratory resistivity measurements were carried out in the U.S. Geological Survey (USGS)

Petrophysics Laboratory in Denver, Colorado. Joseph Nawikas is thanked for collecting many of the surface samples. Thanks to Robert Horton for guidance and assistance in measurement techniques and data reduction. Bill Benzel is thanked for running XRD analysis on select drill-core and surface sediment samples, the results of which informed our interpretation. Eric Anderson provided the petrologic description for all samples. Discussions with Chris Menges, David Miller, David Buesch, and Jill Densmore provided the geologic and hydrologic context for this work. Thanks to Robert Horton and Lyndsay Ball for constructive reviews of this manuscript. A hearty thanks goes to Carole Kaouane of École Polytechnique de Montréal for many discussions on laboratory setup and data interpretation as well as a technical review of this document. 


\section{Contents}

Abstract

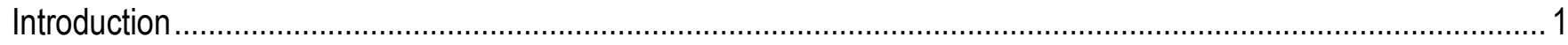

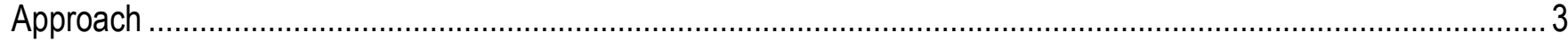

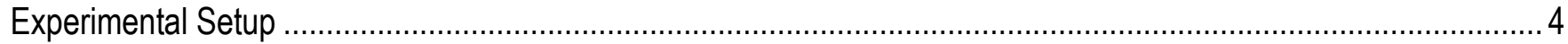

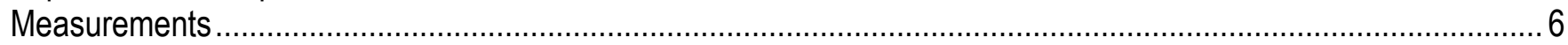

Sources of Error

Representing Complex Resistivity ......................................................................................................

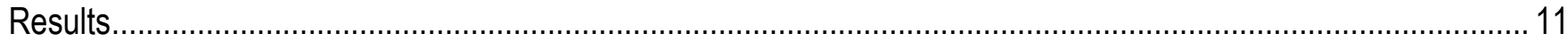

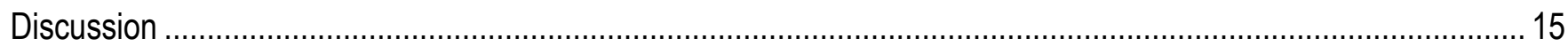

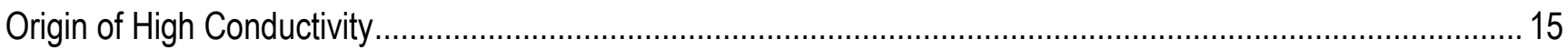

Correlation with Ground TEM Models .............................................................................................. 16

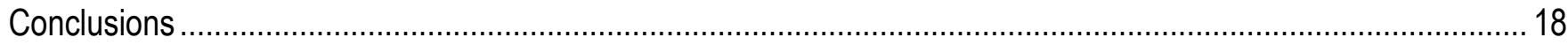

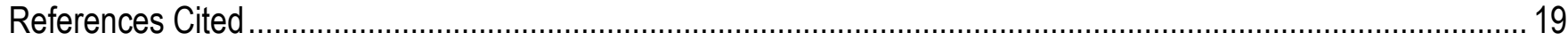

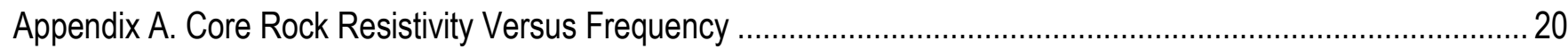

Appendix B. Core Sediment Resistivity Versus Frequency ................................................................................. 46

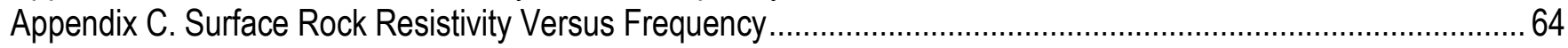

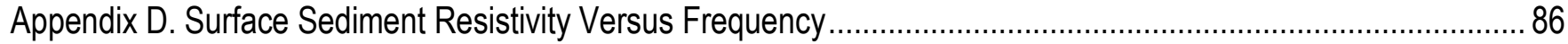

Appendix E. Laboratory Borehole Resistivity Comparison to TEM and Downhole Resistivity Logs........................... 95

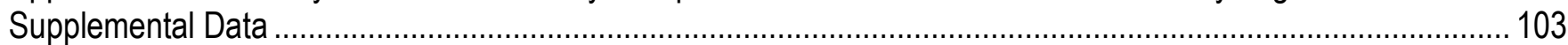

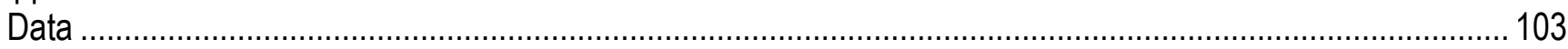

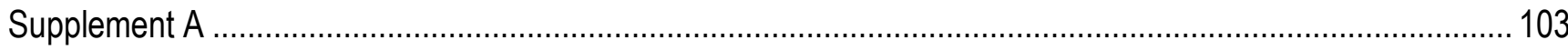

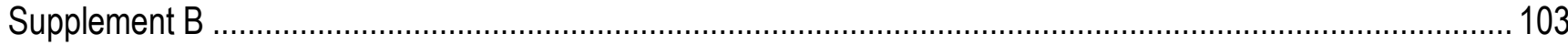

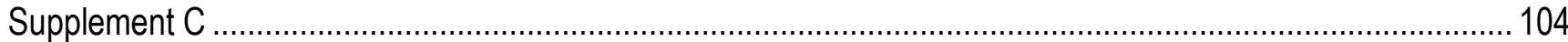

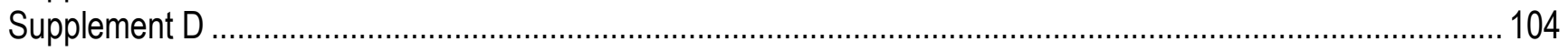

\section{Figures}

1. Map of Fort Irwin National Training Center, California, showing boreholes used in this report, sample sites, time-domain electromagnetic sites, and known faults.

2. Photographs showing the sample holder used for sediments. A, Disassembled sediment sample holder. $B$, Assembled sediment sample holder attached to the LCR (inductance, capacitance, resistance) test leads . 5

3. Photographs showing the sample holder used for hard rocks. $A$, Disassembled rock sample clamp. $B$, Assembled rock sample clamp attached to the LCR (inductance, capacitance, resistance) test leads. ........6

4. Simple frequency-dependant circuit diagram representative of many geologic samples.............................. 8

5. Complex impedance plots of the Mio4b surface sediment sample, where $Z^{\prime \prime}$ is the imaginary component and $Z$ 'is the real component ................................................................................................. 9

6. Bode phase plots of the three states of saturation for surface rock sample Crash-4a-weld_R. Plots presented are dry state, humid state, and submerged state............................................................. 11

7. Graph showing resistivity versus frequency for core sediment sample CRTH1-2C-2 .............................. 12

8. Graph showing resistivity versus frequency for core rock sample GOLD2-2c-1T_R ............................... 13

9. Histograms showing resistivity of all core sediment samples. Top panel represents the as-received state; second panel represents the saturated state

10. Graph showing resistivity comparison for samples from borehole LLO4, time-domain electromagnetic (TEM) sounding LN2, and long-normal borehole resistivity log. 


\section{Tables}

1. Borehole locations, nearest time-domain electromagnetic (TEM) sounding locations, and distance in meters between boreholes and nearest TEM soundings.................................................................... 16 


\section{Conversion Factors}

Inch/Pound to SI

\begin{tabular}{|c|c|c|}
\hline Multiply & By & To obtain \\
\hline inch (in.) & 2.54 & centimeter $(\mathrm{cm})$ \\
\hline square inch $\left(\right.$ in $\left.^{2}\right)$ & 6.452 & square centimeter $\left(\mathrm{cm}^{2}\right)$ \\
\hline pound per square inch $\left(\mathrm{lb} / \mathrm{in}^{2}\right)$ & 6.895 & kilopascal $(\mathrm{kPa})$ \\
\hline
\end{tabular}

SI to Inch/Pound

\begin{tabular}{|c|c|c|}
\hline Multiply & By & To obtain \\
\hline centimeter $(\mathrm{cm})$ & 0.3937 & inch (in.) \\
\hline meter $(\mathrm{m})$ & 3.281 & foot $(\mathrm{ft})$ \\
\hline
\end{tabular}

Temperature in degrees Celsius $\left({ }^{\circ} \mathrm{C}\right)$ may be converted to degrees Fahrenheit $\left({ }^{\circ} \mathrm{F}\right)$ as ${ }^{\circ} \mathrm{F}=\left(1.8 \times{ }^{\circ} \mathrm{C}\right)+32$.

\section{Datum}

Vertical coordinate information is referenced North American Vertical Datum of 1988 (NAVD88).

Horizontal coordinate information is referenced to the World Geodetic System of 1984 (WGS 84).

Altitude, as used in this report, refers to distance above the vertical datum.

\section{Abbreviations}

[Listed in order of appearance.]

USGS U.S. Geological Survey

$\Omega \cdot \mathrm{m} \quad$ ohm-meter

TEM time-domain electromagnetics

NTC National Training Center

m meter

$\mathrm{cm} \quad$ centimeter

in. inch

$\rho \quad$ electrical resistivity

TDS total dissolved solids

f frequency

$\mathrm{Hz} \quad$ hertz

$\mathrm{kHz} \quad$ kilohertz

$|Z| \quad$ electrical impedance amplitude

$\varphi \quad$ phase

$Z^{*} \quad$ complex electrical impedance 


$\begin{array}{ll}Z^{\prime} & \text { real component of the complex electrical impedance } \\ Z^{\prime \prime} & \text { imaginary component of the complex electrical impedance } \\ e & \text { Euler's number } \\ i & \text { imaginary unit } \\ \text { LCR } & \text { inductance, capacitance, resistance } \\ \text { ZOA } & \text { zero offset adjustment } \\ \text { mrad } & \text { milliradians } \\ \text { AR } & \text { as-received } \\ \text { WA } & \text { water-added } \\ \text { psi } & \text { pounds per square inch } \\ { }^{\circ} \mathrm{C} & \text { degrees Celsius } \\ K & \text { geometrical factor } \\ A & \text { area } \\ L & \text { length } \\ Z_{b} & \text { bulk impedance element } \\ C_{d l} & \text { double layer capacitor } \\ Z_{c t} & \text { charge transfer impedance element } \\ W & \text { Warburg impedance element } \\ \text { DC } & \text { Direct Current } \\ \text { XRD } & \text { X-ray diffraction } \\ \text { UTM } & \text { Universal Transverse Mercator, zone 11 } \\ \text { BH } & \text { borehole }\end{array}$




\title{
Laboratory Electrical Resistivity Analysis of Geologic Samples from Fort Irwin, California
}

\author{
By Benjamin R. Bloss and Paul A. Bedrosian
}

\begin{abstract}
Correlating laboratory resistivity measurements with geophysical resistivity models helps constrain these models to the geology and lithology of an area. Throughout the Fort Irwin National Training Center area, 111 samples from both cored boreholes and surface outcrops were collected and processed for laboratory measurements. These samples represent various lithologic types that include plutonic and metamorphic (basement) rocks, lava flows, consolidated sedimentary rocks, and unconsolidated sedimentary deposits that formed in a series of intermountain basins. Basement rocks, lava flows, and some lithified tuffs are generally resistive $(\geq 100 \mathrm{ohm}-\mathrm{meters}[\Omega \cdot \mathrm{m}])$ when saturated. Saturated unconsolidated samples are moderately conductive to conductive, with resistivities generally less than $100 \Omega \cdot \mathrm{m}$, and many of these samples are less than $50 \Omega \cdot \mathrm{m}$. The unconsolidated samples can further be separated into two broad groups: (1) younger sediments that are moderately conductive, owing to their limited clay content, and (2) older, more conductive sediments with a higher clay content that reflects substantial amounts of originally glassy volcanic ash subsequently altered to clay. The older sediments are believed to be Tertiary. Time-domain electromagnetic (TEM) data were acquired near most of the boreholes, and, on the whole, close agreements between laboratory measurements and resistivity models were found.
\end{abstract}

\section{Introduction}

The Fort Irwin National Training Center (hereafter called NTC) is located in southern California within the Eastern California Shear Zone and Mojave strike-slip province, and most of the NTC is in the east-striking fault domain (fig. 1; Miller and Yount, 2002). The NTC consists of mountains separated by a series of topographic basins floored by volcanic, plutonic, and metamorphic rocks. The complex geologic history of the NTC is described in Miller and others (this volume, chap. B). Miocene and younger sediments within the basins reflect a range of depositional environments, resulting in alluvial, lacustrine, eolian, paludal, and groundwater-discharge deposits. Sediment provenance varies both throughout the NTC and within individual basins; primary sediment sources are grus-rich material derived from Jurassic to Cretaceous granite and volcaniclastic sediments derived from both local and regional sources. The region has further been affected by multiple generations of Cenozoic faulting that includes transverse, thrust, normal, and oblique faults (fig. 1). 


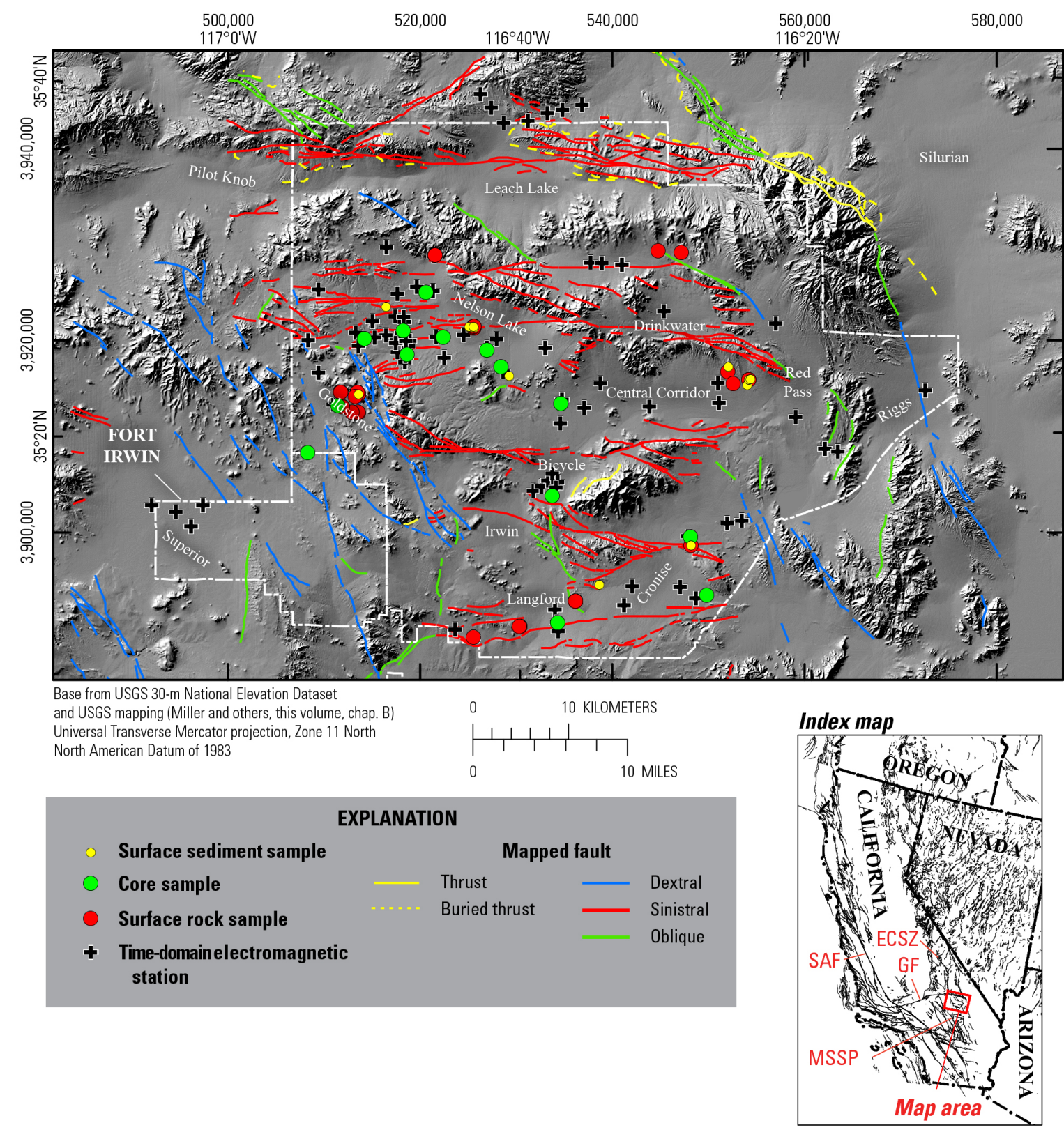

Figure 1. Map of Fort Irwin National Training Center, California, showing boreholes used in this report, sample sites, time-domain electromagnetic sites (Burgess and Bedrosian, this volume, chap. F), and known faults (Miller and others, this volume, chap. B). The index map shows the Eastern California Sheer Zone (ECSZ), the San Andreas Fault (SAF), the Garlock Fault (GF), and the Mojave strike-slip province (MSSP), as well as the map area.

Given the complex geologic and tectonic history, establishing a lithostratigraphic framework from limited borehole samples and geophysical data is challenging (D. Buesch, written commun., 2014). Physical property measurements on surface and borehole sediment samples provide a means to discriminate between different lithologies and aid in the interpretation of geophysical models. Additional measurements on consolidated rock samples offer context for airborne geophysical surveys 
and, in turn, serve as a complement to traditional geologic mapping (Bedrosian and others, this volume, chap. G).

From 2009 to 2012, 21 sites within the NTC have been drilled; 15 of these boreholes have segments of recovered drill core (Kjos and others, 2014), and 14 of these boreholes with recovered drill core have had laboratory resistivity measurements performed on them. (See table 1, appendix E, and supplemental data for a complete list of laboratory-processed borehole drill cores.) Laboratory resistivity measurements on these samples give constraints on the physical properties of basement rocks, lava flows, and lithified sedimentary volcanic rocks, in addition to consolidated sedimentary rocks and unconsolidated sediment deposits. Basement here is defined as plutonic and metamorphic rocks, Mesozoic and older, that are exposed in the ranges and floor the intervening basins. Consolidated is defined herein as sedimentary rocks (volcanic or epiclastic) that are at least partially lithified and capable of retaining shape as a hand sample or core sample.

A sample's bulk electrical resistivity has four contributing factors: (1) mineralogy, (2) porosity, (3) saturation, and (4) conductivity of pore fluid. Laboratory resistivity measurements on samples of representative geology are important in relating geophysical resistivity measurements, both groundbased and airborne, to structure and geology. When borehole samples are available, laboratory resistivity measurements deliver a close approximation to the in situ bulk resistivity, albeit at very different scales than is approximated by borehole geophysical logs and surface-based resistivity soundings. The ability to control saturation in the laboratory environment permits investigation of the effect of water content on sample resistivity. Furthermore, if estimates of water quality are available, we can further constrain the resistivity signature of various lithologies above and below the local water table. These signatures can be used to constrain ground-based and airborne resistivity models (Bedrosian and others, this volume, chap. G; Burgess and Bedrosian, this volume, chap. F) and identify changes in lithology and saturation.

\section{Approach}

To evaluate the resistivity of various sedimentary units and basement rocks found throughout the NTC, laboratory resistivity measurements were performed on 54 drill-core and 57 surface samples (see supplemental data for details). The 54 drill-core samples were subdivided into two groups: 34 unconsolidated sediment deposit samples (hereafter known as sediment) and 20 consolidated, lithified, or inherently competent rock samples (hereafter known as rock), which are primarily large clasts within a sedimentary unit (Kjos and others, 2014). The 57 surface samples were likewise separated into 16 sediment samples and 41 rock samples. Note that these classifications are not necessarily based on lithology or geology but on the mechanical properties of the sample. Because of the inherent differences between sediment and rock, these samples were prepared differently for subsequent measurements. Also, the condition of the sample in the laboratory may be considerably different than the condition of the sample in situ. Collection, storage, and preparation of the samples may change the level of compaction, disturb sample-scale sedimentary structure, and alter the moisture content. Each borehole core is composed of several $\sim 1.0$ - to $\sim 1.5$-meter $(\mathrm{m})(\sim 3$ - to $\sim 5$-foot) segments. These cored segments were subdivided into sections that varied in length between 8 and 65 centimeters $(\mathrm{cm})(3$ and 26 inches [in.]). A sample was taken from the top and bottom of each section, except for the extremely short sections that only produced one sample. Core samples may been contaminated by infiltration of drilling fluids; however, samples were chosen that were not in contact with the core housing (thus decreasing the radius) or core cap (through removal of 2 to $3 \mathrm{~cm}$ of material from the core section ends).

Electrical resistivity $(\rho)$ is an intrinsic electrical property, independent of a material's size and shape, that characterizes its opposition to the flow of electric current. In sedimentary environments, the 
dominant factors that determine a sample's bulk $\rho$ are clay content, pore water $\rho$, and the degree of saturation. In the absence of clay, dry materials are typically more resistive than wet materials, and material saturated with water containing low total dissolved solids (TDS) will be more resistive than material saturated with high-TDS water.

Bulk $\rho$, as measured and treated by many geophysical techniques, is considered to be frequency $(f)$ independent. In reality, $\rho$ is frequency dependent. We aim to constrain ground-based time-domain electromagnetic, airborne electromagnetic, and borehole $\rho$ measurements, which are all considered to be low frequency, or low induction number, systems. We characterized $\rho$ through impedance spectroscopy over a frequency bandwidth from 100 hertz $(\mathrm{Hz})$ to 100 kilohertz $(\mathrm{kHz})$. Resistivity anisotropy was not measured and is not considered here.

Impedance spectroscopy consists of measuring the impedance amplitude $(|Z|)$ and the phase $(\varphi)$ of the complex electrical impedance $\left(Z^{*}\right)$. Phase measurements refer to the angle that an observed sine wave lags, or leads, a reference sine wave. For these data, a time-varying current was passed through the sample, and a time-varying voltage was measured. The phase of the received voltage waveform was calculated using the current waveform as a reference. Impedance phase is a measure of energy storage, also called polarization.

$$
Z^{*}=|Z| \mathrm{e}^{\mathrm{i} \varphi}=Z^{\prime}+\mathrm{i} Z^{\prime \prime}
$$

where $\quad Z^{\prime}$ is the real part of the complex impedance, or resistance, in ohms; and $Z$ ”' is the imaginary part of the complex impedance, or reactance, in ohms.

\section{Experimental Setup}

All measurements were made using a Hewlett Packard LCR (inductance, capacitance, resistance) meter controlled via a computer using an in-house LabVIEW interface. The LCR impedance measurements were carried out using two wire-leads and two electrodes in what is commonly referred to as a two-electrode measurement. Each electrode was attached to one current lead. The LCR meter sweeps through a series of measurement frequencies and at each frequency stores the sample's impedance, resistance, and phase measurements. It is worth noting that the LCR meter reports impedance values with the effects of capacitance and inductance included, whereas resistance values are reported with the effects of capacitance and inductance removed.

When making resistivity measurements, the electrical response of the measurement system must be accounted for. The LCR meter, test cables, and samples holders all have an associated impedance caused by stray capacitance, residual inductance, and system resistance. An instrument calibration procedure, referred to as the zero offset adjustment (ZOA), was performed to compensate for these effects. It consists of two parts: An open-circuit ZOA measures stray capacitance and conductance of the test cables with an empty sample holder, and a short-circuit ZOA measures the residual inductance and resistance of the system with the current electrodes shorted. Subsequent measurements automatically compensated for these system-response measurements. Calibration of the LCR meter also included a self-diagnostic test to confirm normal system operation. Finally, a verification procedure was carried out in which parallel, resistor-capacitor circuits with a known resistance, impedance, and phase response were measured. These equivalent circuits provide a means with which to compare measured and theoretical circuit responses.

The accuracy of the LCR meter varies as a function of signal level and measurement frequency. In general, the LCR meter is less accurate at low measured voltages and at high measurement frequencies. The smallest instrument impedance and phase errors occur at low frequencies with low measured impedances (impedance: \pm 0.1 to \pm 0.3 percent; phase: \pm 0.87 milliradians [mrad]), while larger 
instrument errors occur at high frequencies and high measured impedances (impedance: \pm 1 to \pm 3 percent; phase: $\pm 17.45 \mathrm{mrad})$. Very high measured impedance values (>1,000 kilohms) can result in instrument errors as high as \pm 3 to \pm 5 percent. Given the low $\rho$ of many of our samples, the instrument impedance errors generally fell within the range of \pm 0.1 to \pm 3 percent, while instrument phase angle measurement errors were typically within the range of \pm 0.87 to $\pm 17.45 \mathrm{mrad}$.

Sample preparation depended on the degree of lithification. The sample holders used for sediments, both assembled and disassembled, are shown in figure 2. These parallel-plate sample holders consist of two platinum foil electrodes with a clear Plexiglas cylinder sandwiched in between. The cylinders are $5.08 \mathrm{~cm}(2.00 \mathrm{in}$.) in length with an inner diameter of $4.45 \mathrm{~cm}(1.75 \mathrm{in}$.). The current electrodes are $0.0127-\mathrm{cm}(0.005$-in.) thick, bright platinum foil. Each electrode is backed with a $0.32-\mathrm{cm}$ $(1 / 8$-in.) thick, hard rubber pad, which, in turn, is backed with a rigid, $1.27-\mathrm{cm}(1 / 2-$ in. $)$ thick, plastic tile. The entire sample holder assembly is held together with a bar clamp. To ease the filling of the sample holder, an electrode is glued to one end of the Plexiglas cylinder with a silicon rubber adhesive. Fixing the electrode and the Plexiglas cylinder together also allows the sample holder to be watertight until the clamp can apply pressure.
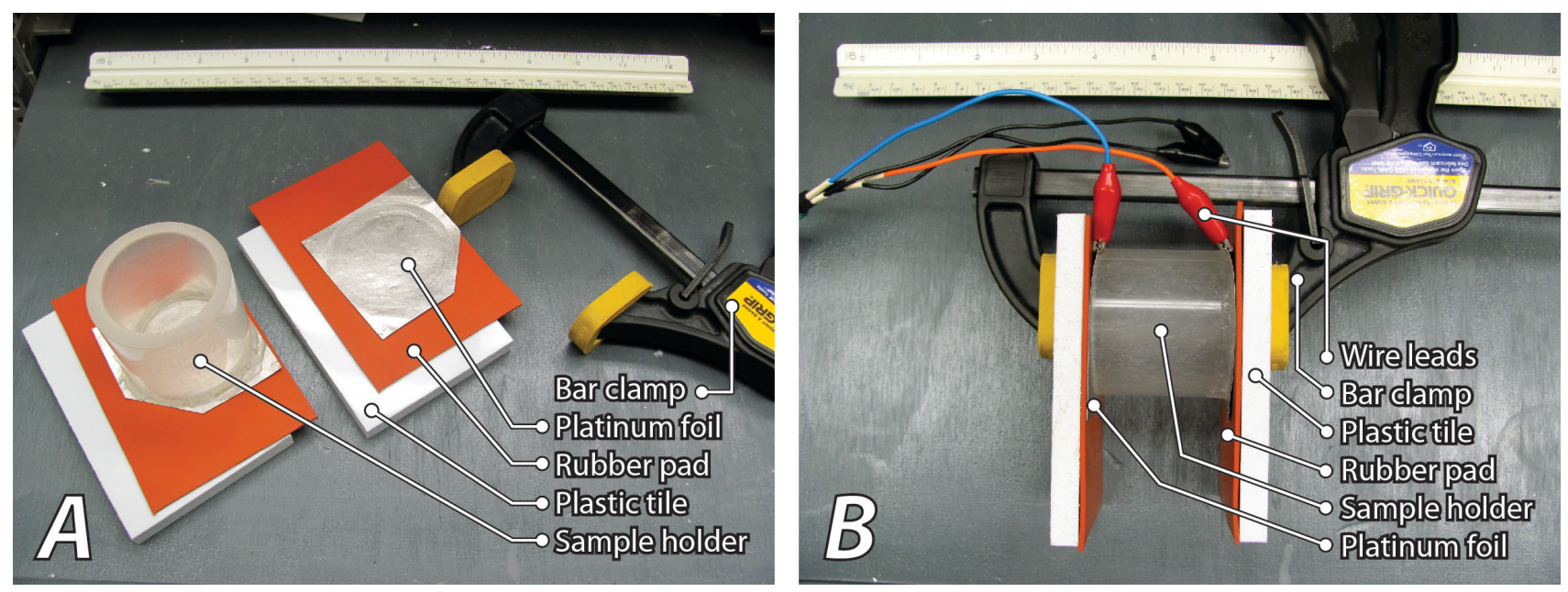

Figure 2. Photographs showing the sample holder used for sediments. A, Disassembled sediment sample holder. $B$, Assembled sediment sample holder (empty) attached to the LCR (inductance, capacitance, resistance) test leads.

Hard-rock samples were slabbed prior to measurement to obtain two parallel surfaces. Each slab was cut to an approximate thickness of $1.91 \mathrm{~cm} \mathrm{(3/4} \mathrm{in.).} \mathrm{The} \mathrm{electrodes} \mathrm{were} \mathrm{a} 0.32-\mathrm{cm}(1 / 8$-in.) thick, hard rubber pad wrapped in aluminum foil, which was, in turn, backed with a rigid, $1.27-\mathrm{cm}(1 / 2-\mathrm{in}$.) thick, plastic tile. The rock slab and electrodes were held together with a bar clamp. The sample clamp disassembled and assembled is shown in figure 3 . 

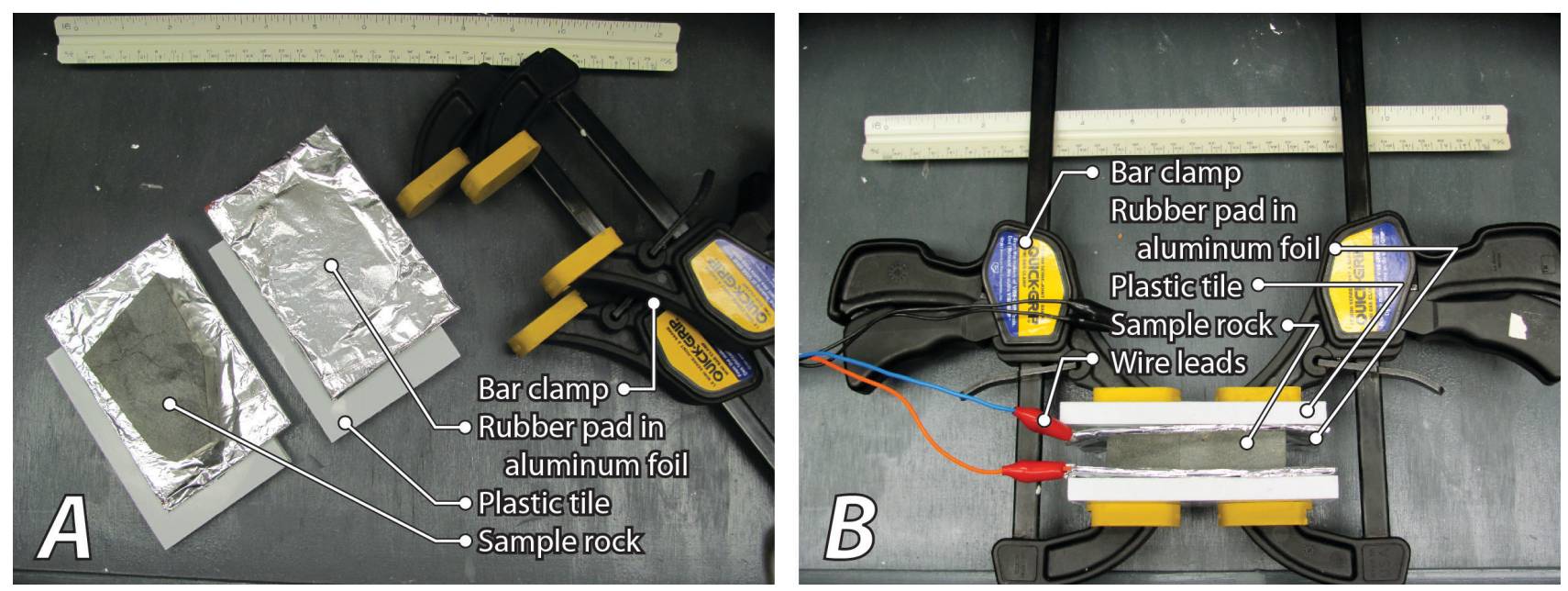

Figure 3. Photographs showing the sample holder used for hard rocks. A, Disassembled rock sample clamp (with sample slabbed rock). B, Assembled rock sample clamp (with sample slabbed rock) attached to the LCR (inductance, capacitance, resistance) test leads.

Geometrical factors were calculated by measuring sample dimensions (thickness and crosssectional areas for slabs, diameter and height of sample holder for sediments) using a dial caliper with 0.0254 -millimeter (0.001-in.) resolution and by visually verifying complete contact between each of the sample's areas and their respective electrodes. The cross-sectional areas were calculated by digitally scanning the rocks at 300 pixels-per-inch, counting the pixels, and multiplying by pixel area (1/90000 square inches). The transparent Plexiglas sample holder permits visual inspection of the sampleelectrode contact.

\section{Measurements}

Sediment samples were typically measured twice: once in as-received (AR) condition, and once after deionized water was added (WA) to saturate the sample. This AR to WA measurement series often produces a broad range of $\rho$ and $\varphi$ values, indicating the degree to which electrical properties vary as a function of water content. Surface sediment samples were generally received very dry, whereas the core sediment samples were generally received fully saturated. Many samples from the core sediment sample group could only be measured in their AR state due to an inability to add more water. For the AR measurement, the sample holder was filled and packed with a representative sample from the sample container. For the samples that were able to have water added to them, a WA measurement was conducted by adding deionized water to a sample already mounted in the sample holder. To increase the amount of water imbibed by the sample, the wetted sample was placed in a vacuum jar and the vacuum pressure cycled from 0 to 15 pounds-per-square-inch (psi) several times. The process of adding water and applying a vacuum was repeated until the sample was visibly saturated and transient effects (bubbling, swelling) had stopped. Starting from the sample's AR state, the volume of water added to the sample was recorded by weight, providing a minimum estimate of sample porosity. Many of the samples expanded when water was added, requiring removal of material from the sample holder, thus further skewing the porosity estimates. The minimum porosity estimates are expected to significantly underestimate the true porosity of the core samples, but are thought to be comparable to the true porosity for all other samples. 
The slabbed rock samples were generally measured four times: (1) once in their AR condition, (2) once fully dried in an oven at 100 degrees celcius $\left({ }^{\circ} \mathrm{C}\right)$ while under a vacuum at 15 psi (dry measurement), (3) once after extensive exposure to a 100-percent relative humidity environment (humid measurement), and (4) after being submersed in deionized water with all air removed under vacuum (submerged measurement). For the surface samples, the AR measurements were omitted, owing to environmental changes during the time between collection and processing. In general, the AR measurements typically have resistivity values that fall in between the dry and humid measurements.

Impedance measurements were converted to resistance by the LCR meter, which took into account the effects of capacitance and inductance; both resistance and impedance datasets were saved. Resistance data were converted to resistivity using a geometrical factor $(K)$ based on the effective area $(A)$ of the electrodes and the length or thickness $(L)$ of the sample holder or slabbed rock. Note that errors in $K$ contribute to errors in $\rho$ values; a 1-percent error in the geometrical factor produces a 1percent error in the resistivity value.

$$
\begin{gathered}
\rho=K R, \text { where } \\
K=\frac{\sqrt{A_{1} A_{2}}}{L}
\end{gathered}
$$

and $\quad K \quad$ is the sample's geometrical factor in meters,

$A_{1,2} \quad$ are the sample's effective cross-sectional areas in contact with each electrode in square meters,

$L \quad$ is thickness or height of the sample in meters,

$\rho \quad$ is resistivity in $\Omega \cdot \mathrm{m}$, and

$R \quad$ is the resistance, as reported, in ohms.

\section{Sources of Error}

The LCR meter has an upper and lower limit to its measurement range. Occasionally, a sample was found to be too resistive to measure given the finite input impedance of the LCR meter. Typically, this is observed when the resistance of the sample exceeds 19.999 megaohms. Where observed, these measurements are flagged as -99999 in the supplemental data. Electrode impedance effects at the electrode-sample interface may further complicate two-electrode impedance and resistance measurements. These effects are most prominent at low frequencies, where they tend to increase the observed impedance amplitude measurement and alter the impedance phase, ultimately altering the resistance measurement. The effect on impedance is most pronounced in dry, resistive samples, whereas distortion in the phase measurement, associated with electrode polarization, is strongest in wet, conductive samples. These effects can often be observed at low frequencies on a complex impedance plot, which is discussed further in the next section.

\section{Representing Complex Resistivity}

Complex impedance plots allow us to dissect the complex, frequency-dependent impedance into its component pieces. Simplified electronic circuits (for example, fig. 4) can model the complex impedance of many earth materials. 


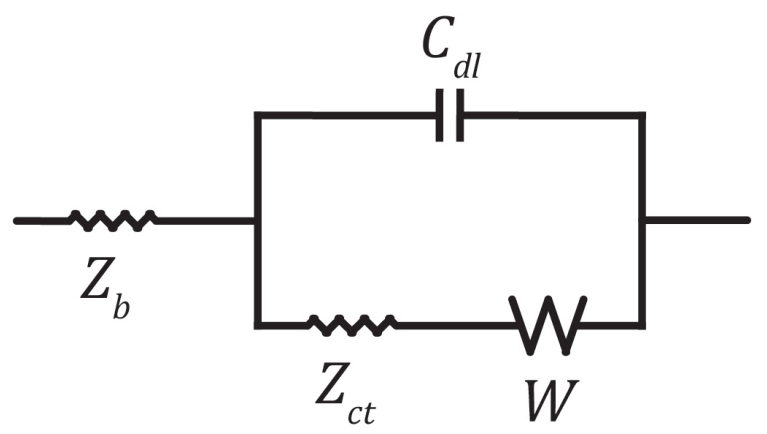

$Z_{b} \quad$ is the bulk impedance element of the sample,

$C_{d l} \quad$ is the double layer capacitor,

$Z_{c t} \quad$ is the charge transfer impedance element of the sample, and

$W \quad$ is the Warburg impedance element of the sample (inversely proportional to $\sqrt{f}$ ).

Figure 4. Simple frequency-dependant circuit diagram representative of many geologic samples. Equivalent circuit models exist that would produce the same complex impedance versus frequency behavior. At low frequencies $(f)$, the capacitor is open, and the primary current path is through $Z_{c t}$ and $W$. At high $f$, the capacitor is shorted, and the primary current path is through $C_{d l}$.

The impedance element, $Z_{b}$, represents the frequency-independent sample impedance and is an intrinsic property dependent upon the type and number density of charge carriers and their ionic mobilities. The two parallel branches of the circuit represent two different paths by which current can be carried across the sample-electrode contact. A faradaic conduction path involves electrochemical charge transfer via a combination of oxidation and reduction and ionic diffusion across the interface. Current can also be passed via a non-faradaic, electrokinetic path associated with the capacitance of the fixed and diffuse layers at the sample-electrode interface. The electrokinetic conduction pathway is much faster and tends to carry more of the current at high frequencies compared to the faradaic conduction pathway. This electrokinetic pathway is represented by the double-layer capacitor, $C_{d l}$, in figure 4 . The faradaic conduction path contains both a charge transfer impedance, $Z_{c t}$, associated with a kinetically controlled charge transfer mechanism, and the Warburg impedance, $W$, associated with ionic diffusion across the interface (Flekkøy, 2013). The Warburg impedance is unique in that it cannot be represented by a traditional circuit element. Its magnitude varies inversely with $\sqrt{f}$, and it has a constant phase of $\frac{\pi}{4}$ radians; that is, it approximates a straight line at low frequencies on a complex impedance plot (fig. 5). 

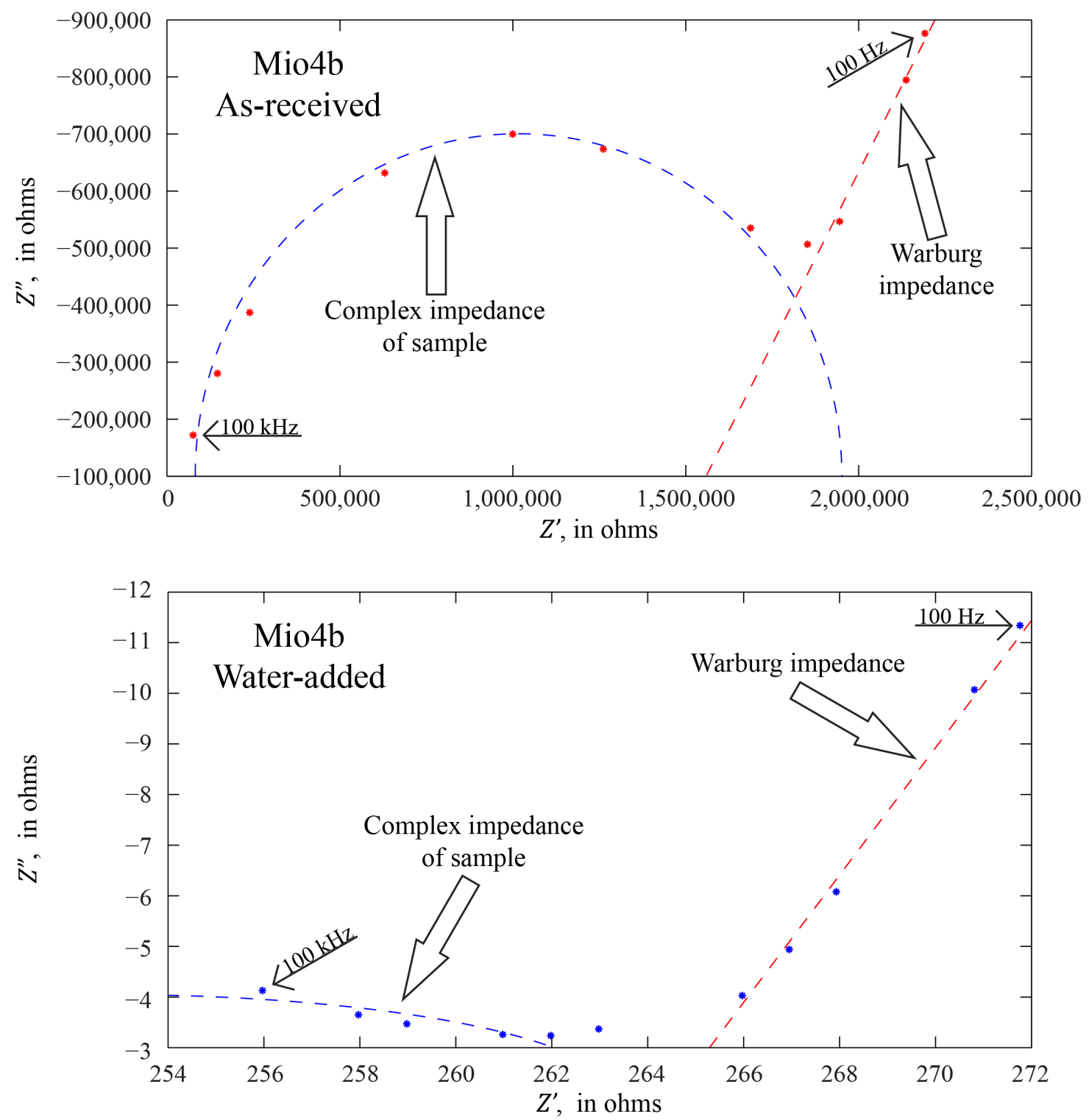

* As-received data point

* Water-added data point

- - - Interpolated curve fitting the sample's complex impedance

- - - Interpolated line fitting the Warbug impedance

$Z^{\prime} \quad$ is resistance (real part of complex impedance)

$Z^{\prime \prime}$ is reactance (imaginary part of complex impedance)

Figure 5. Complex impedance plots of the Mio4b surface sediment sample, where $Z^{\prime \prime}$ is the imaginary component and $Z^{\prime}$ is the real component. The Warburg impedance (the polarization effect - red dashed line) dominates at low frequencies $(100 \mathrm{~Hz})$, while the complex impedance arcs (blue dashed line) represent different conduction mechanisms within the sample.

The correspondence between the complex impedance plots in figure 5 and the equivalent circuit in figure 4 can be considered as follows. At high frequencies $(100 \mathrm{kHz})$, the capacitor ( $C_{d l}$ in fig. 4$)$ is 
shorted, and the complex impedance becomes purely a function of the capacitor and the bulk impedance element $\left(C_{d l}\right.$ and $Z_{b}$ in fig. 4$)$. As the input frequency is lowered, the capacitor's ability to transmit current is reduced, allowing current to flow through the other impedance elements and traces out the arc in the complex impedance plots (dashed blue lines in fig. 5). At very low frequencies, the capacitor $\left(C_{d l}\right.$ in fig. 4) is open, forcing current to pass solely through the three impedance elements $\left(Z_{b}, Z_{c t}\right.$, and $W$ in fig. 4), including the constant-phase Warburg impedance, the influence of which dominates at the lowest frequencies $(100 \mathrm{~Hz})$. Samples with additional mechanisms for ionic charge transfer (conduction mechanisms) can be described by additional $Z_{c t}$ and $C_{d l}$ circuit elements and can exhibit multiple arcs in a complex impedance plot. In closing, we note that the intercepts of the complex impedance arc with the real axis are of special significance- the low frequency intercept defines the direct-current (DC), or 0 $\mathrm{Hz}$, sample resistance, while the width of the semicircle is related to the frequency dependence of the dielectric constant of the sample, and the high frequency intercept relates to the $Z_{b}$ of the sample. When relating laboratory measurements to field measurements, the lower frequency $\rho$ measurements often reflect both sample and electrode effects. At higher frequencies, the real impedance component $(Z)$ measurements are most comparable to field $\rho$ measurements.

One other aspect of evaluating complex impedance data comes from evaluating the phase relationship with the measured $\rho$. A peak in the phase often corresponds with the greatest slope on a resistivity versus frequency plot. Many of our dry rock samples exhibited relatively high, yet consistent, phase values. When phase is plotted against frequency (a Bode phase plot), a flat curve suggests the conduction mode is largely frequency independent, while a phase peak suggests the center frequency of one conduction mechanism. Owing to the narrow bandwith of the measured frequencies, we were unable to identify many conduction mechanism bandwidths. Phase data varies with the degree of saturation of a sample, indicating that the modes of conduction are also related to water content (for example, fig. 6). We present only one example in figure 6; however, all phase data are released in the supplemental data. 

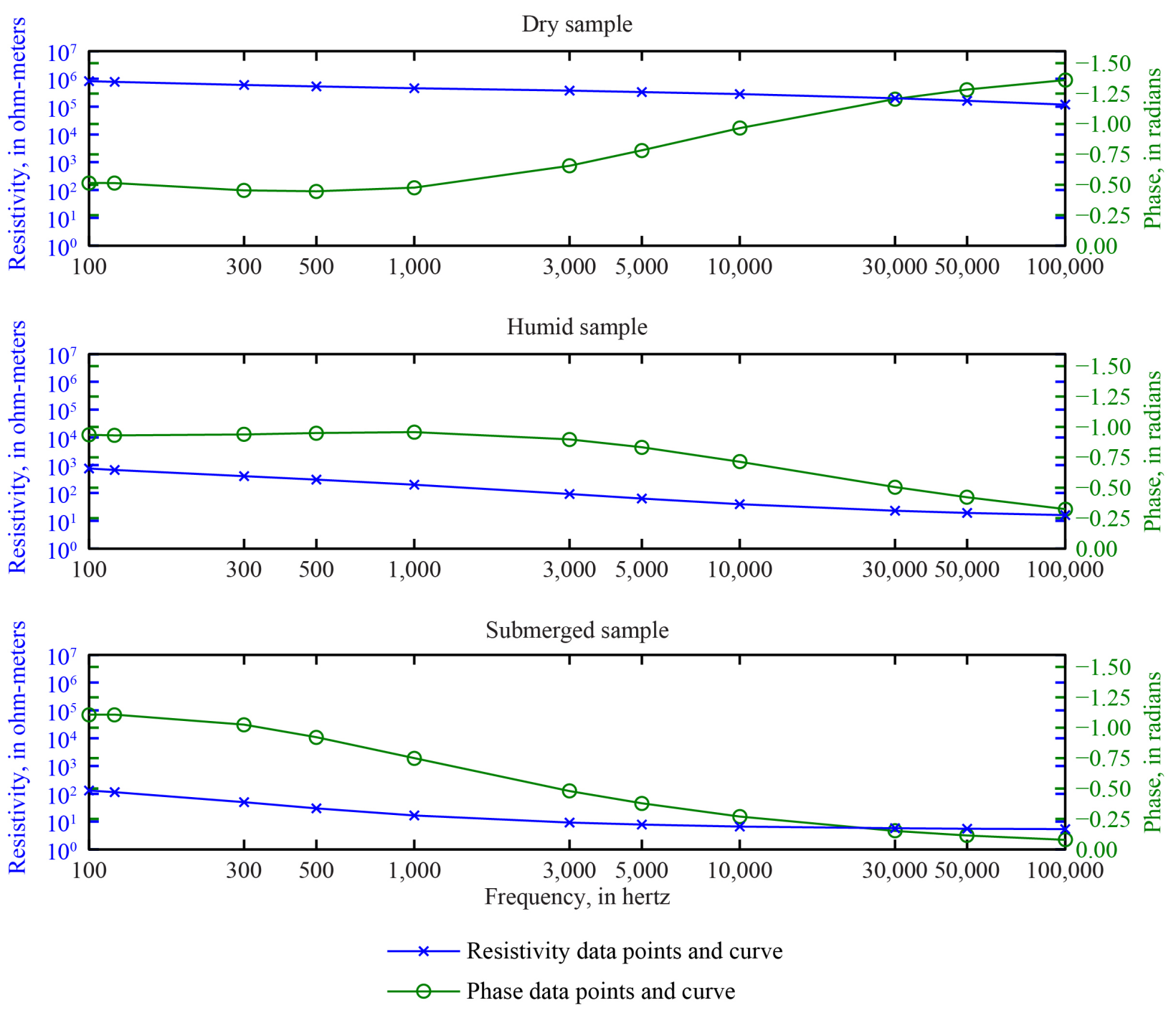

Figure 6. Bode phase plots of the three states of saturation for surface rock sample Crash-4a-weld_R. Plots presented, from top down, are dry state, humid state, and submerged state. Resistivity data (blue curve) align with the left axes, and phase data (green curves) align with the right axes.

\section{Results}

We grouped the samples into the following categories, also reflected in the supplemental data: core sediments, core rocks, surface sediments, and surface rocks. Core rocks consist of competent material recovered in the drill core and are typically either volcanic flows or large clasts, often crystalline, within sedimentary units. (See supplemental data [SupplementA_CoreRock_table.xlsx, SupplementC_SurfaceRock_table.xlsx] for delineation between clast or in-place rock as well as a brief petrologic description.) Surface rocks span the gamut of intrusive and extrusive igneous rocks as well as consolidated sediments found throughout the region. Some samples were collected directly from outcrops, while others have likely been transported, as float, some distance from their source. The latter are believed to be representative of regionally extensive basement rock units that do not outcrop within the survey area. Although the sediment provenance may lie outside the immediate study area, surface 
and core sediment samples are assumed to be deposited in place. The sediment samples reflect a range of depositional environments but are primarily alluvial or lacustrine in origin; a single sample (GWdis) was collected from a spatially limited groundwater-discharge deposit.

Representative resistivity-frequency plots for core sediment and rock samples are shown in figures 7 and 8, respectively. Resistivity-frequency plots for all samples are provided in appendixes A, B, C, and D. In general, and as expected, lower sample resistivities were observed with water added compared to AR or dry conditions. For core sediment samples, however, this variation in resistivity is less pronounced, reflecting the wet condition of the AR samples and, as discussed later, the presence of clay. Sample resistivity tends to either decrease or remain constant as frequency increases. The strongest frequency dependence was observed in the rock samples, which tend to be quite resistive.

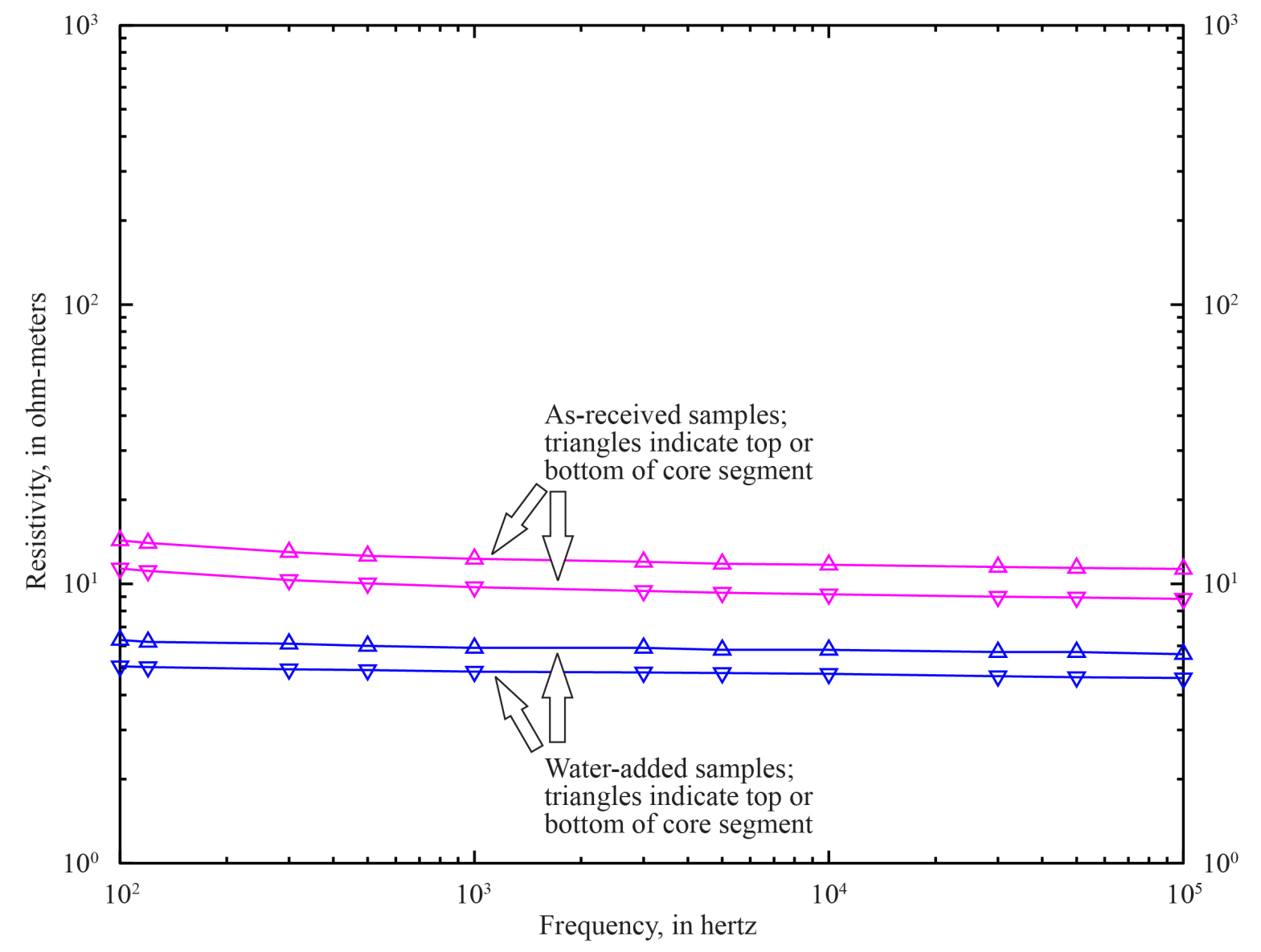

Figure 7. Graph showing resistivity versus frequency for core sediment sample CRTH1-2c-2. Triangles pointing up indicate the sample was taken from the top of the core segment, whereas triangles pointing down indicate the sample was taken from the bottom of the core segment. 


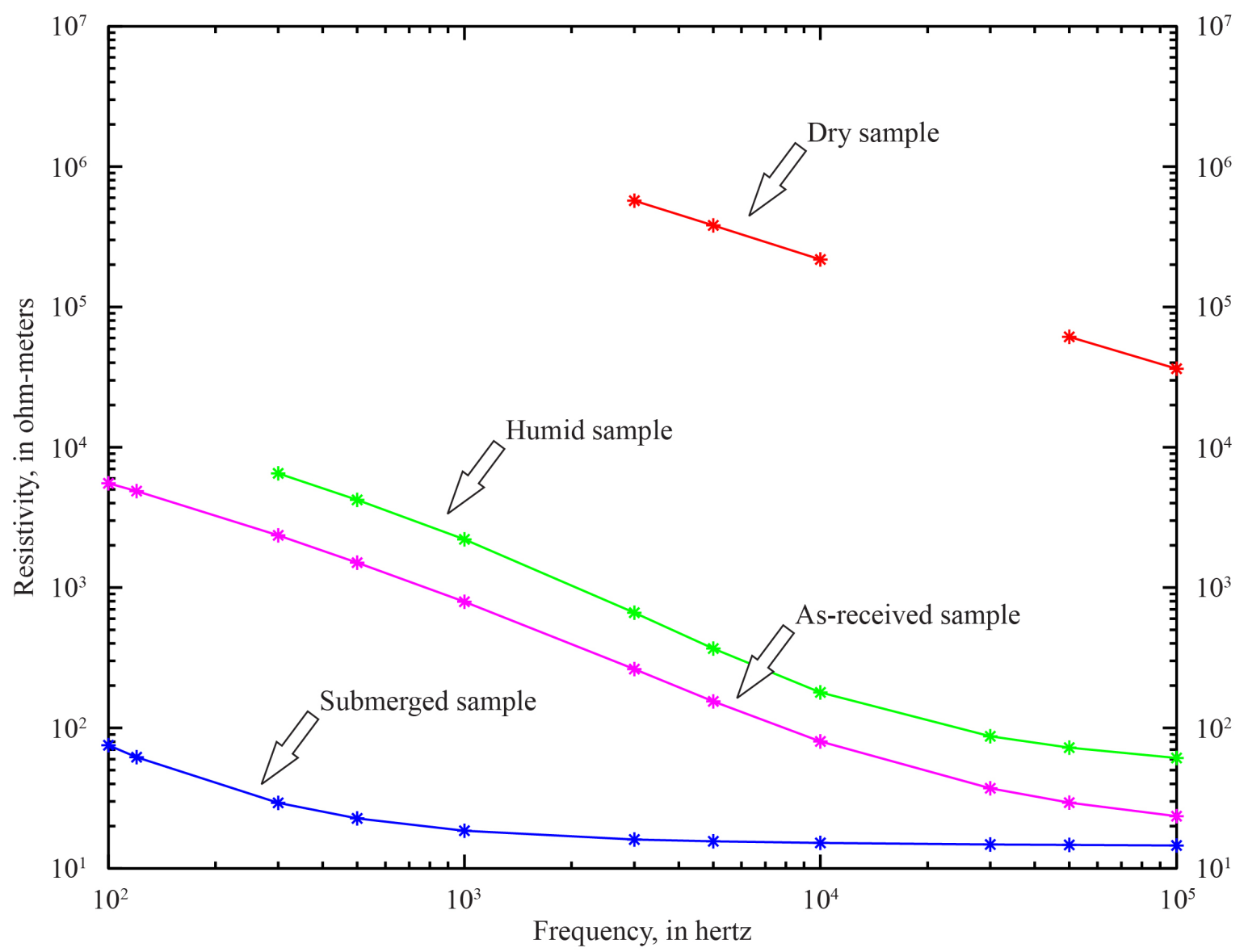

Figure 8. Graph showing resistivity versus frequency for core rock sample GOLD2-2c-1T_R.

Considering the sample set as a whole, a broad separation exists between electrically resistive rock samples (including volcanic flows encountered in the core samples) and conductive sediments (from both surface or core samples). Based on the suite of measured rock samples (disregarding data points that exhibit Warburg effects), all of the rock types that floor the basins of the NTC were observed to be electrically resistive (here considered to be resistivities greater than about $100 \Omega \cdot \mathrm{m}$ ). In actuality, all of the plutonic and metamorphic rocks and lava flows (from both surface and core samples), which includes most of the rock or clast samples, have resistivities around or above $1,000 \Omega \cdot \mathrm{m}$, the exception being altered volcanic rock encountered in boreholes in the Goldstone Basin (fig. 1). The most resistive basement rock was a diorite with measured resistivity on the order of $100,000 \Omega \cdot \mathrm{m}$. These results are consistent with an airborne electromagnetic survey in Leach Lake Basin (Bedrosian and others, this volume, chap. G), where the resistivity of all basement rock types was found to be quite high (greater than $200 \Omega \cdot \mathrm{m})$, with the exception of altered mafic volcanic rocks $(20-100 \Omega \cdot \mathrm{m})$.

By and large, the sediment samples are fairly conductive, typically with resistivities less than $100 \Omega \cdot \mathrm{m}$ and often closer to $10 \Omega \cdot \mathrm{m}$. Examining the core sediment resistivities in aggregate reveals no clear trends; however, the majority of the boreholes show core resistivities of around $10 \Omega \cdot \mathrm{m}$ at all sample depths. Several boreholes (CCT1, GOLD2, LL04, NELT2, NELT3, and NELT7) have a relatively shallow core sample and show resistivity decreasing with depth. In these boreholes, the resistivity of the near-surface samples is typically several tens of $\Omega \cdot \mathrm{m}$, transitioning at depth to 
resistivities of about $10 \Omega \cdot \mathrm{m}$. An example of core resistivity values in comparison to additional data is shown in figure 10; all core resistivity comparisons are included in appendix E.

A resistivity separation, though subtle, is evident in histograms of $\log$ resistivity for the asreceived and saturated core samples (assuming that if a WA measurement was not made, then the sample was received saturated), where two peaks are suggested (fig. 9). Groups centered around $13 \Omega \cdot \mathrm{m}$ and $23 \Omega \cdot \mathrm{m}$ are consistent between the two histograms, suggesting that ionic conduction through pore fluids may not be the dominant conductivity mechanism. Recall, however, that most of the core samples were received saturated; hence, the difference in water content between as-received and saturated samples may be quite small. A small number of samples were also observed to have resistivities between 40 and $150 \Omega \cdot \mathrm{m}$.
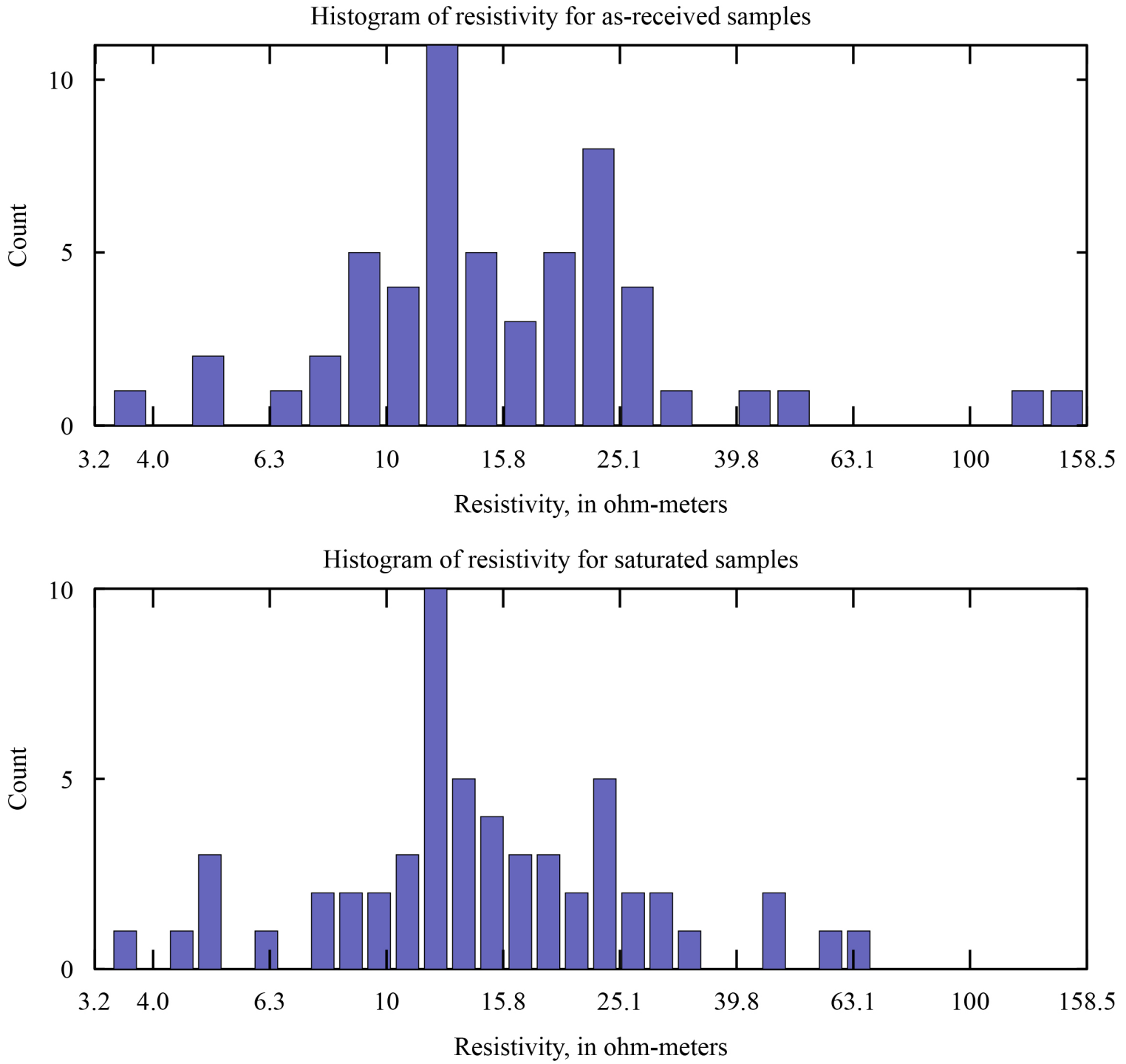

Figure 9. Histograms showing resistivity of all core sediment samples. Top panel represents the as-received state; second panel represents the saturated state (assuming that if a water-added measurement was not conducted that the sample was received fully saturated). Note: the resistivity values are binned and plotted logarithmically; values presented are in ohm-meters. 
The suite of surface sediment samples are believed to be representative of older lithostratigraphic units exposed in the eastern half of the NTC. The samples collected, however, are from isolated exposures and have not been definitively correlated with a particular lithostratigraphic unit. When saturated, the majority of these samples are characterized by resistivities below $10 \Omega \cdot \mathrm{m}$ and in several cases as low as $1 \Omega \cdot \mathrm{m}$. The low resistivity of these surface sediment samples suggest they may be correlative with the more conductive, and generally deeper, group of core sediment samples. The exposures from which these samples were collected may be part of a regional and highly conductive stratigraphic unit identified in resistivity models from both ground and airborne time-domain electromagnetic (TEM) measurements (Bedrosian and others, this volume, chap. G; Burgess and Bedrosian, this volume, chap. F).

\section{Discussion}

\section{Origin of High Conductivity}

Measurements on the core sediments show the majority of the samples to be rather conductive, regardless of the degree of saturation. This suggests that sample conductivity may be governed primarily by clay content. To evaluate this possibility, four core sediment samples from three boreholes were selected for quantitative analysis using X-ray diffraction (XRD) to identify the mineralogy and clay content of the samples. Samples analyzed include NELT1-3c-1_top, NELT2-1c-2_top, NELT2-2c1b_bottom, and NELT3-3c-1_top. Three of the samples (the exception being NELT2-1c-2, the shallowest of the samples) have measured resistivities below $20 \Omega \cdot \mathrm{m}$. These three conductive samples were found to have both a high clay fraction (14-26 weight percent) and a high, yet variable, percentage of amorphous glass (6-29 weight percent). In contrast, the less conductive sample has 9 weight percent clay content and 8 weight percent amorphous glass. Further analysis found the clay fraction in all samples to be almost entirely composed of expandable smectite, with trace amounts of kaolinite and mica. Drilling mud contains bentonite, a smectite clay, which raises the question of whether the expandable smectite is directly associated with the sediments or is simply the result of infiltration of drilling mud into the core samples. This question led to the collection and analysis of the surface sediment samples, where the concern of drilling mud contamination is absent. As discussed previously, laboratory resistivity measurements reveal that surface sediments have comparable resistivities to the drill core sediments when saturated. The comparable resistivity values between these two sample sets suggests, but does not prove, that the older surface sediments contain a significant clay fraction and that the clay in the drill core samples is not solely the product of drilling contamination.

An additional XRD analysis on a suite of surface samples was also conducted on four additional surface sediment samples and one rock sample (Crash2a [sediment], Mio3a [sediment], Mio5b [sediment], Whale-Sed [sediment], and Crash4a-weld-R [rock]) as well as a sample of the drilling mud from borehole NELT6 to evaluate clay and amorphous glass content. These five surface samples came from three distinct areas (fig. 1): Nelson Lake (Crash samples), Central Corridor (Mio samples), and just north of Cronise Basin (Whale sample). The results from these four sediment samples show high clay content, varying from 10 to 45 weight percent, and amorphous glass content ranging from 8 to 27 weight percent. The amorphous glass and clay contents are in the same range as the three core sediment samples from the Nelson Lake area. Although this indicates that the high clay content in the core samples is inherent to the basin sediments, three of the four core sediment samples (NELT1-3c-1, NELT2-1c-2, and NELT3-3c-1) have an XRD signature that is similar to the drilling mud's XRD signature. Because of this, we cannot rule out the possibility of drilling mud contamination. However, 
the content of clay and amorphous glass is consistent between the core and surface samples, and we believe that the core resistivity values are representative of the host lithologies.

We speculate that the three conductive, clay-rich core samples (NELT1-3c-1, NELT2-2c-1b, and NELT3-3c-1) are Tertiary. Local and regional volcanism during the Miocene is the most likely source of amorphous glass in the sediments, and we hypothesize that some of this glass, in the presence of water, has been chemically weathered to smectite. The reaction of glass with water of moderate $\mathrm{pH}$ and low ionic strength is known to produce clay, predominantly smectite, as a secondary alteration product (Vaniman, 2006). Studies by Giorgetti and others $(2006,2009)$ find volcanic glass within felsic and mafic volcanic rocks to be more susceptible to low-temperature hydrothermal alteration than the crystalline phases. The less conductive core sediment sample, which is also the shallowest of the four samples, is interpreted to be Quaternary. The lower deeper samples' clay and amorphous glass fractions reflect a regional decrease in volcanism, hence a decrease in volcanic source material, following the Miocene.

\section{Correlation with Ground TEM Models}

Twelve of the fourteen boreholes where core samples were collected are close to TEM resistivity sounding locations. Names and locations for boreholes, nearest TEM sounding, and the distance from each borehole to the nearest TEM sounding are shown in table 1 (NELT3 and NELT6 both had two TEM soundings nearby). This provides an opportunity to compare laboratory measurements to geophysical resistivity models and borehole resistivity logs (Kjos and others, 2014; Burgess and Bedrosian, this volume, chap. F). A sample figure showing the resistivity correlation between these three datasets for borehole LL04 is shown in figure 10; comparison plots for the remaining boreholes are presented in appendix E. For all comparisons, both AR and WA values are shown; if multiple samples were measured within a cored interval (typically one sample from the top and one sample from the bottom of core, a distance of $\sim 0.3 \mathrm{~m}$ ), top and bottom resistivity values are shown separately. Overall, the laboratory resistivity data match the TEM models quite well.

Table 1. Borehole locations (Kjos and others, 2014), nearest time-domain electromagnetic (TEM) sounding locations (Burgess and Bedrosian, this volume, chap. $F$ ), and distance in meters $(\mathrm{m})$ between boreholes $(\mathrm{BH})$ and nearest TEM soundings.

[UTM, Universal Transverse Mercator projection, zone 11; BH, borehole; TEM, time-domain electromagnetics; $\mathrm{m}$, meter]

\begin{tabular}{ccccccc}
\hline $\begin{array}{c}\text { Borehole } \\
\text { (BH) }\end{array}$ & BH UTM Easting & BH UTM Northing & TEM sounding & TEM UTM Easting TEM UTM Northing & $\begin{array}{c}\text { Distance, in } \\
\text { meters }\end{array}$ \\
\hline BLA5 & 533775 & 3903859 & BL6 & 534151 & 3904739 & 957 \\
CCT1 & 534643 & 3913459 & CC1 & 534773 & 3913921 & 480 \\
CRTH1 & 549819 & 3893511 & CR6 & 548720 & 3893207 & 1140 \\
CRTH2 & 548135 & 3899568 & CR2 & 547852 & 3899664 & 299 \\
GOLD1 & 511457 & 3913224 & AU3 & 510965 & 3913383 & 518 \\
GOLD2 & 511489 & 3913255 & -- & -- & -- & -- \\
LL04 & 534331 & 3890648 & LN2 & 534206 & 3890727 & 147 \\
NELT1 & 522429 & 3920367 & NL03 & 521700 & 3920438 & 733 \\
NELT2 & 526952 & 3919008 & NL14 & 526969 & 3919264 & 257 \\
NELT3 & 518265 & 3921007 & NL11 & 518237 & 3921137 & 133 \\
NELT3 & 518265 & 3921007 & NL20 & 518236 & 3920854 & 156 \\
NELT4 & 528440 & 3917291 & NL13 & 528649 & 3916821 & 514
\end{tabular}




\begin{tabular}{ccccccc}
\hline $\begin{array}{c}\text { Borehole } \\
\text { (BH) }\end{array}$ & BH UTM Easting & BH UTM Northing & TEM sounding & TEM UTM Easting TEM UTM Northing $\begin{array}{c}\text { Distance, in } \\
\text { meters }\end{array}$ \\
\hline NELT5 & 514184 & 3920199 & -- & -- & -- & -- \\
NELT6 & 518661 & 3918538 & NL04 & 518576 & 3918340 & 215 \\
NELT6 & 518661 & 3918538 & NL30 & 518499 & 3918431 & 194 \\
NELT7 & 520618 & 3925021 & NL18 & 521343 & 3925173 & 741 \\
\hline
\end{tabular}

*Boreholes GOLD2 and NELT5 did not have nearby TEM soundings.

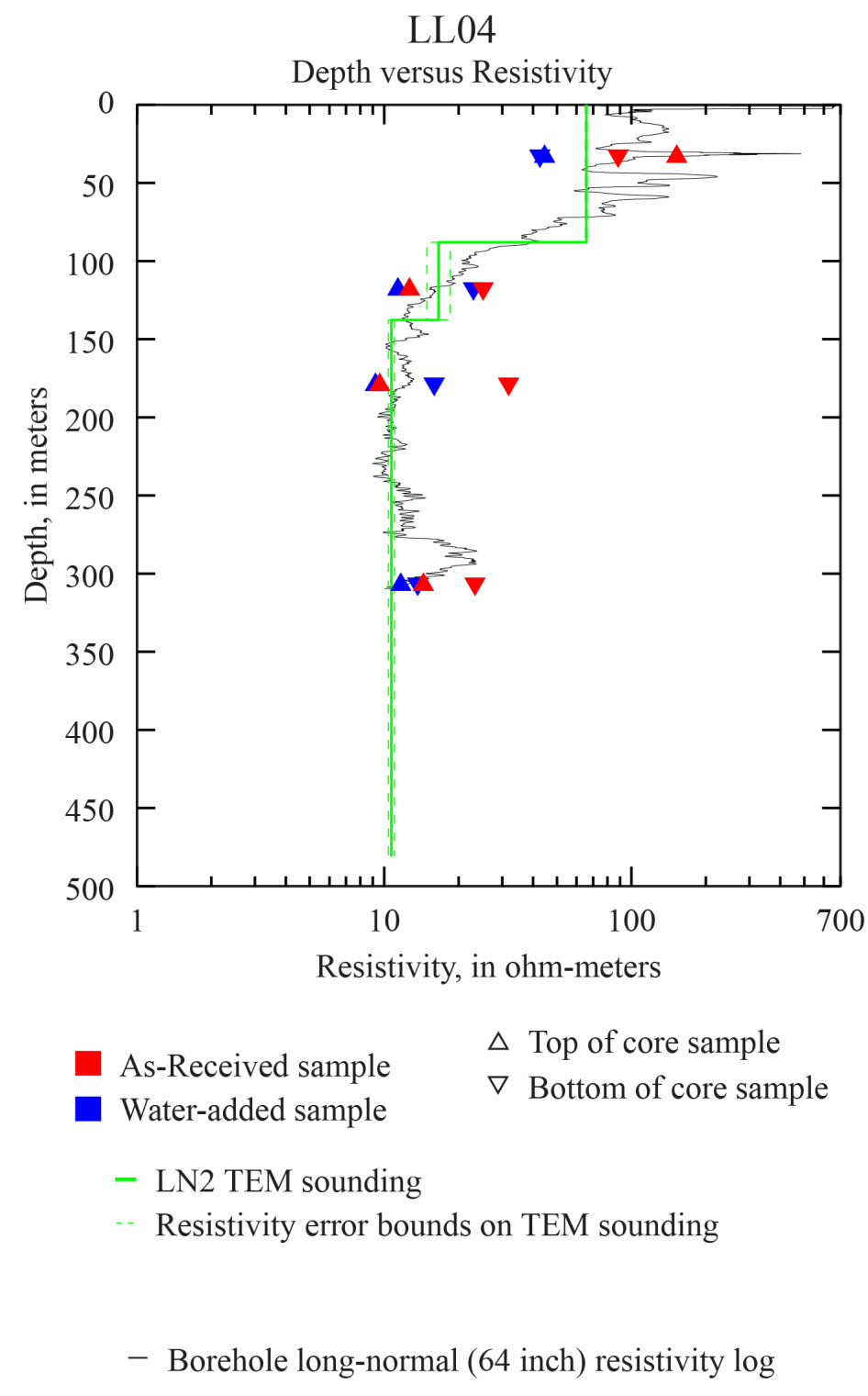

Figure 10. Graph showing resistivity comparison for samples from borehole LLO4, time-domain electromagnetic (TEM) sounding LN2, and long-normal borehole resistivity log. 
Several boreholes encountered lava flows within the sedimentary section. Typically, the lava flows are a few meters to tens of meters thick, and core samples from these flows were of moderate to high electrical resistivity, the exception being altered volcanic rocks within the Goldstone Basin cores. The generally resistive volcanic flows are not reflected in the low to moderate resistivities of the TEM models (for example, CRTH2). This discrepancy reflects the sensitivity and resolution of the TEM method, which is insensitive to thin, horizontal resistors. As a rule of thumb, a resistive layer must have a thickness comparable to its depth in order to be resolved by a surface TEM sounding (Orange, 1989). For example, the electrically resistive volcanic flow encountered at 293-m depth in CRTH2 would need to have a thickness of $293 \mathrm{~m}$ or more in order to be resolved by a TEM sounding. Forward modeling has verified that surface TEM data are consistent with, yet insensitive to, the volcanic flows or dacite encountered in boreholes CRTH2 (Burgess and Bedrosian, chapter F, this volume), GOLD1, and NELT2 (see appendix E; Kjos and others, 2014).

In addition to volcanic flows encountered in higher cored intervals, the deepest cored interval in five boreholes (NELT4, GOLD2, GOLD1, CRTH2, NELT7) contained igneous rock or, at the very least, clasts of igneous parent material. According to Kjos and others (2014), borehole NELT4 encountered crystalline gneissic bedrock, and the borehole interval containing GOLD2-3c and GOLD2$4 \mathrm{c}$ is interpreted as weathered and fractured bedrock. Boreholes GOLD1 and CRTH2 both terminate in extrusive igneous material (possible interbasin flows as opposed to bedrock), while borehole NELT7 encountered only igneous clasts within the deepest cored interval.

Based on the core, NELT4 encountered basement at a minimum of $265 \mathrm{~m}$. Gravity-based estimates of depth to basement (Jachens and Langenheim, this volume, chap. H) are in close agreement and suggest a depth to basement of $250 \mathrm{~m}$. The deep cores from GOLD2 are more variable: Rock samples in the top and bottom of GOLD2-3c-1 (GOLD2-3c-1T, GOLD2-3c-1B; 122-m depth) are coarse-grained clasts sourced from an intrusive body, and the segment at the bottom of the borehole (GOLD2-4c-1; 137-m depth) is a clast of very fine grained metamorphic rock. (Kjos and others, 2014, list this clast as aphanitic basalt; however, our evaluation suggests metamorphic. See

SupplementA_CoreRock_table.xlsx for a complete description.) The corresponding gravity-based basement estimate of $375 \mathrm{~m}$ is significantly greater at this location.

\section{Conclusions}

Laboratory resistivity measurements provide a means to link geophysical resistivity models to geology and lithology. Measurements were carried out on 54 core samples from 14 boreholes in addition to 57 surface samples within the Fort Irwin NTC. The samples span a range of sediment lithologies and rock samples which represent the major basement rock types flooring the basins of the NTC. All of the basement rock types were found to be resistive, typically greater than $1,000 \Omega \cdot \mathrm{m}$, whereas sediment samples were typically less than $50 \Omega \cdot \mathrm{m}$. Surface and borehole samples are subdivided into two broad groups: moderately conductive Quaternary sediments with low clay content and minimal volcanic input and highly conductive, older (Tertiary?) sediments with higher clay content and significant volcanic input. Excellent correlation is found between TEM resistivity models and core resistivity samples, further supporting a prominent geophysical distinction in resistivity between Quaternary and Tertiary sediments. 


\section{References Cited}

Bedrosian, P.A., Ball, L.B., and Bloss, B.R., 2014, Airborne electromagnetic data and processing within Leach Lake Basin, Fort Irwin, California, chap. G of Buesch, D.C., ed., Geology and geophysics applied to groundwater hydrology at Fort Irwin, California: U.S. Geological Survey Open-File Report 2013-1024 (this volume).

Burgess, M.K., and Bedrosian, P.A., 2014, Time-domain electromagnetic surveys at Fort Irwin, San Bernardino County, California, 2010-2012, chap. F of Buesch, D.C., ed., Geology and geophysics applied to groundwater hydrology at Fort Irwin, California: U.S. Geological Survey Open-File Report 2013-1024 (this volume).

Flekkøy, E.G., 2013, A physical basis for the Cole-Cole description of electrical conductivity of mineralized porous media: Geophysics, v. 78, no. 5, p. D355-D368.

Giorgetti, G., Monecke, T., Kleeberg, R., and Hannington, M.D., 2006, Low-temperature hydrothermal alteration of silicic glass at the PACMANUS hydrothermal vent field, Manus Basin - an XRD, SEM, and AEM-TEM study: Clays and Clay Minerals, v. 54, no. 2, p. 240-251.

Giorgetti, G., Monecke, T., Kleeberg, R., and Hannington, M.D., 2009, Low-temperature hydrothermal alteration of trachybasalt at Conical Seamount, Papua New Guinea-formation of smectite and metastable precursor phases: Clays and Clay Minerals, v. 57, no. 6, p. 725-741.

Jachens, R.C., and Langenheim, V.E., 2014, Gravity survey and interpretation of Fort Irwin and vicinity, Mojave Desert, California, chap. H of Buesch, D.C., ed., Geology and geophysics applied to groundwater hydrology at Fort Irwin, California: U.S. Geological Survey Open-File Report 20131024 (this volume).

Kjos, A.R., Densmore, J.N., Nawikas, J.M., and Brown, A.A., 2014, Construction, water-level, and water-quality data for multiple-well monitoring sites and test wells, Fort Irwin National Training Center, San Bernardino County, California, 2009-12: U.S. Geological Survey Data Series 788, 139 p., https://dx.doi.org/10.3133/ds788.

Miller, D.M., Menges, C.M., and Lidke, D.J., 2014, Generalized surficial geologic map of the Fort Irwin area, San Bernardino County, California, chap. B of Buesch, D.C., ed., Geology and geophysics applied to groundwater hydrology at Fort Irwin, California: U.S. Geological Survey Open-File Report 2013-1024 (this volume).

Miller, D.M., and Yount, J.L., 2002, Late Cenozoic tectonic evolution of the north-central Mojave Desert inferred from fault history and physiographic evolution of the Fort Irwin area, California: Geological Society of America Memoir, v. 195, p. 173-197.

Orange, A.S., 1989, Magnetotelluric exploration for hydrocarbons: Proceedings of the Institute of Electrical and Electronics Engineers, v. 77, no. 2, p. 287-317, doi: 10.1109/5.18627.

Vaniman, David, 2006, Tuff mineralogy, chap. 2.2 of Heiken, G., ed., Tuffs - their properties, uses, hydrology, and resources: Geological Society of America Special Papers, v. 408, p. 11-15, doi: $10.1130 / 2006.2408(2.2)$. 


\section{Appendix A. Core Rock Resistivity Versus Frequency}

Figures, one per sample, showing sample resistivity, in ohm-meters, versus frequency, in hertz. Each curve represents a different degree of saturation. 
CRTH2-3c-2B_R

Resistivity versus Frequency

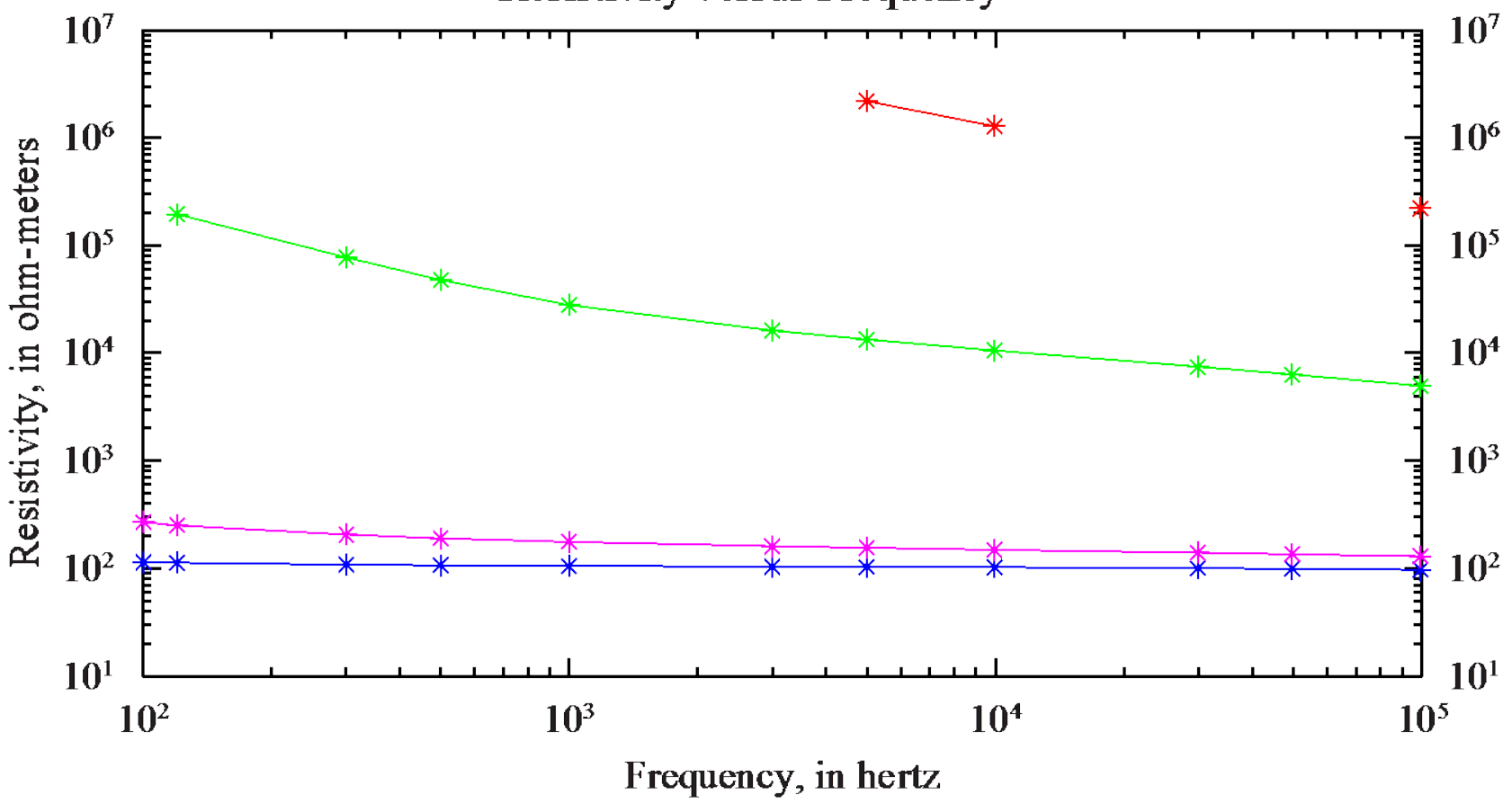

CRTH2-3c-2T_R

Resistivity versus Frequency

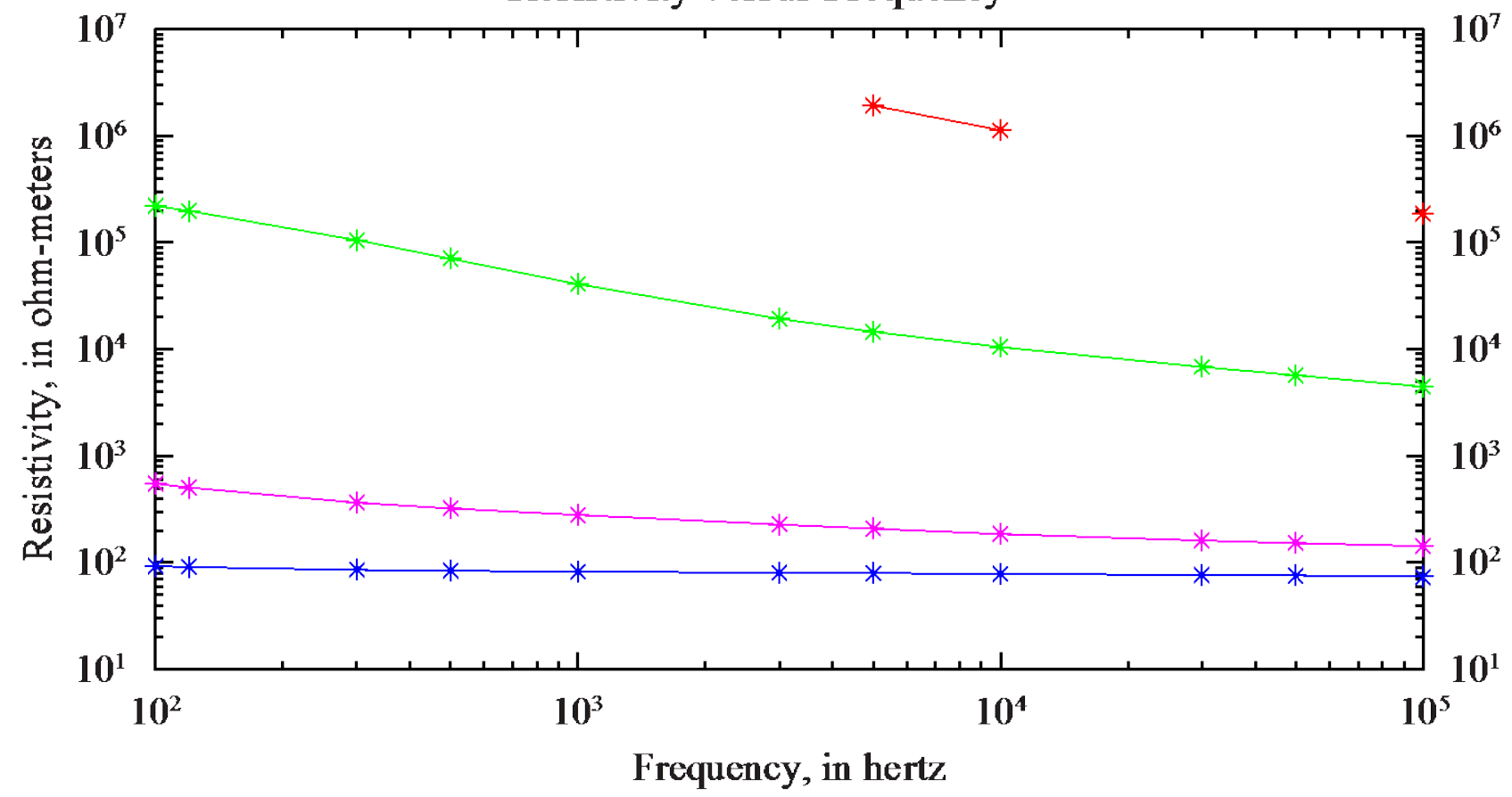

As-received measurement

- Dry measurement

Humid measurement

- Submerged measurement
* Datum point 
GOLD1-3c-1B_R

Resistivity versus Frequency

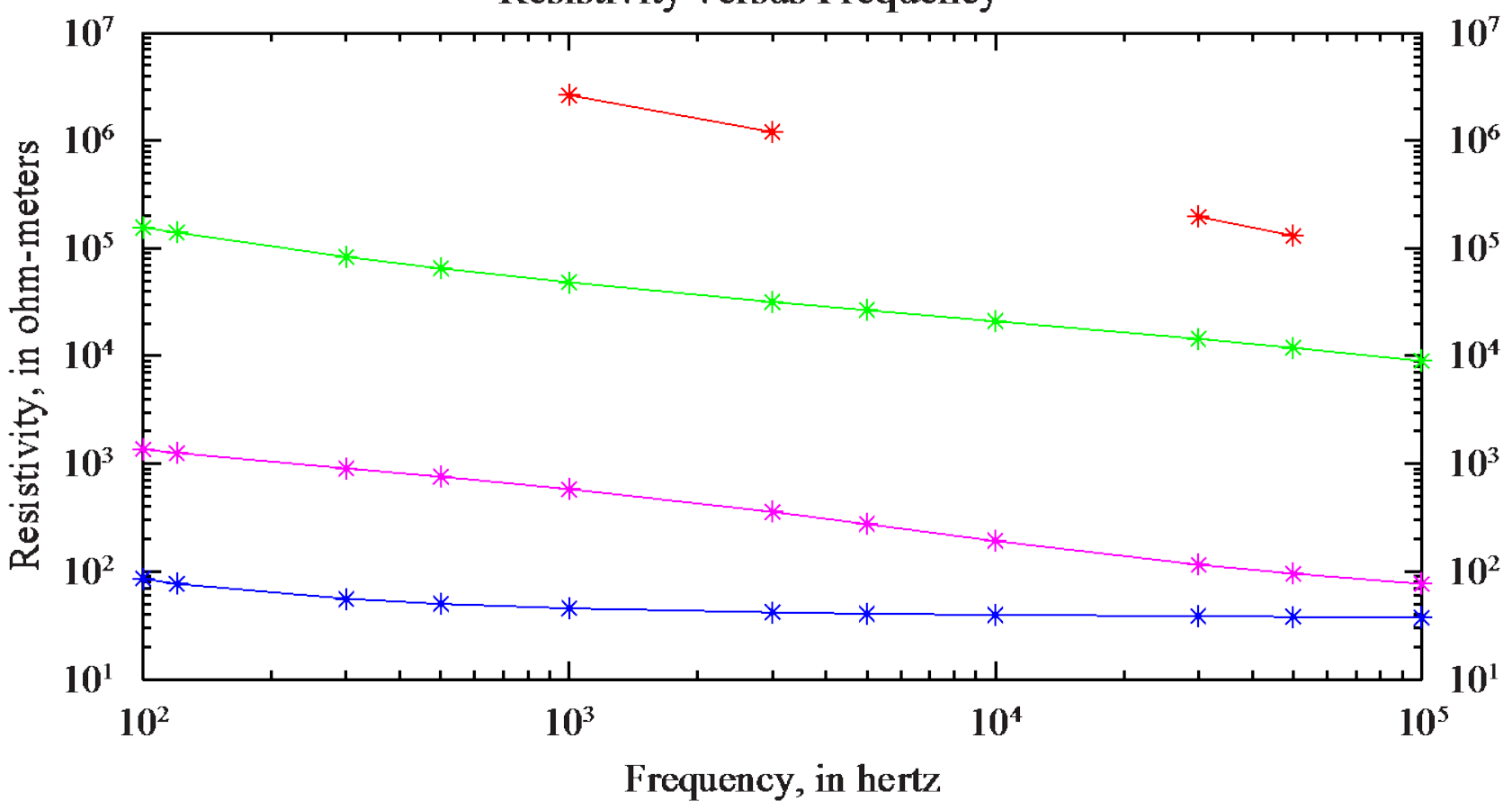

GOLD1-3c-1T_R

Resistivity versus Frequency

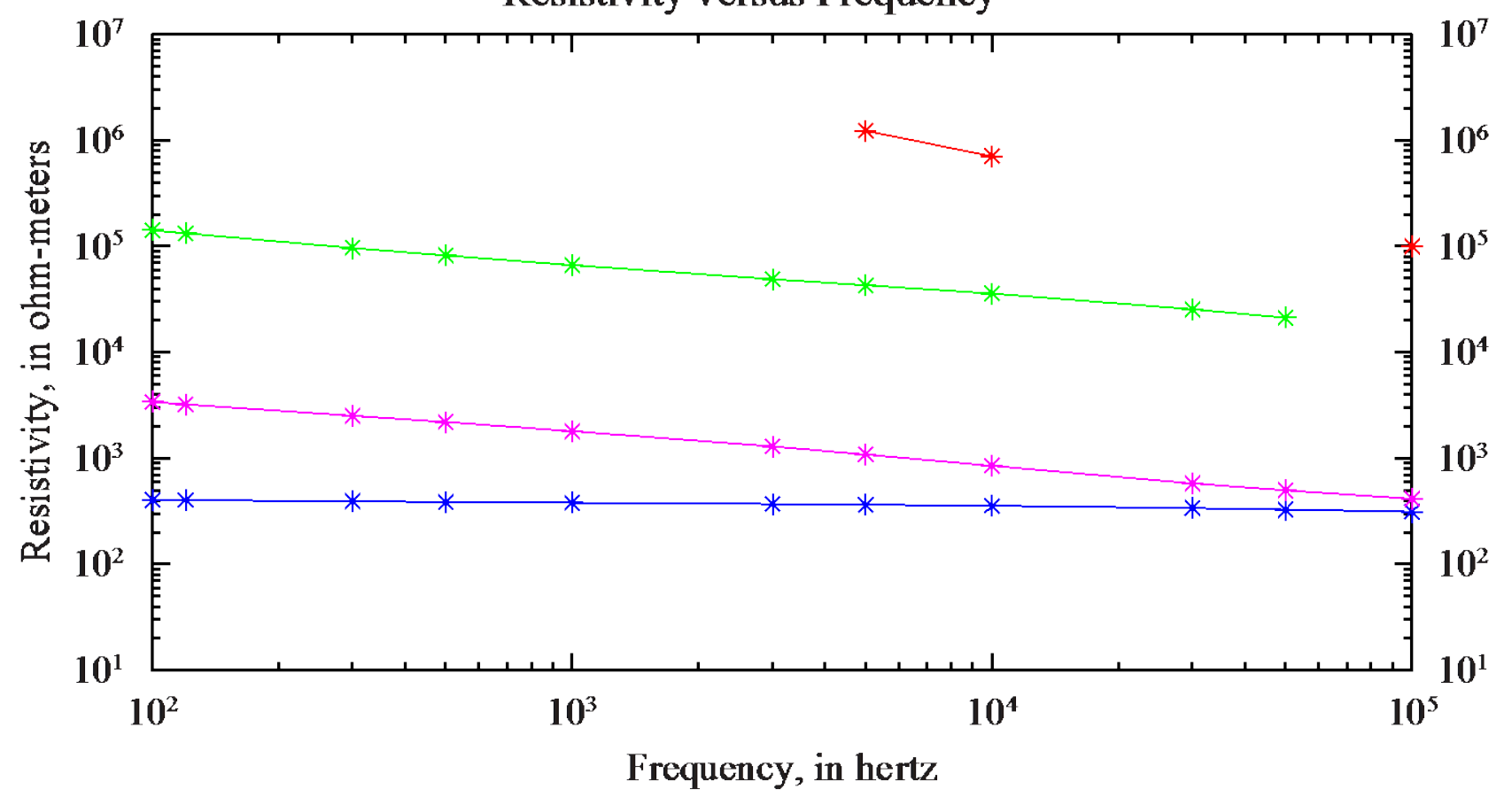

As-received measurement

- Dry measurement

Humid measurement

* Datum point

- Submerged measurement 
GOLD2-2c-1T_R

Resistivity versus Frequency

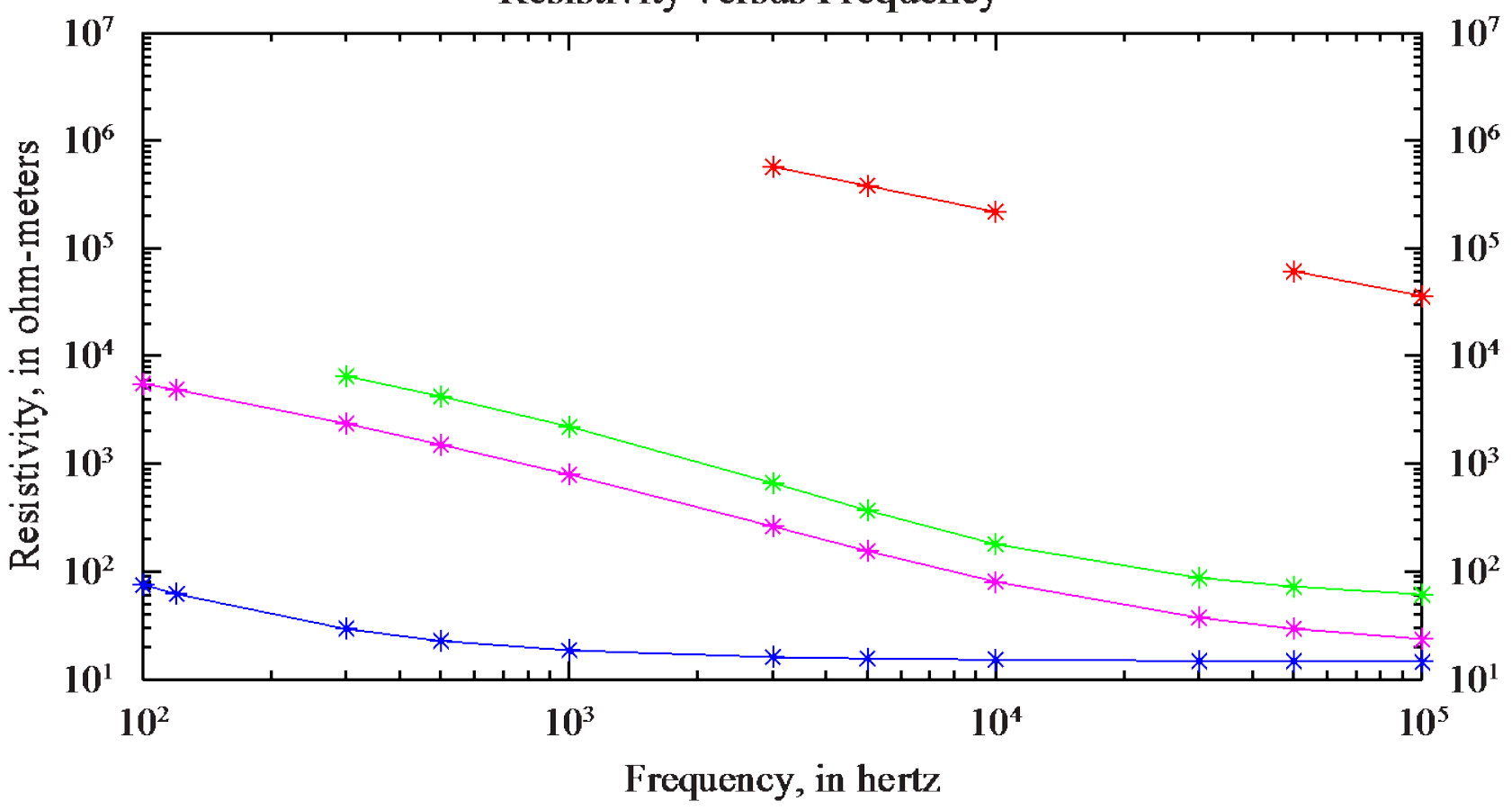

GOLD2-3c-1B_R

Resistivity versus Frequency

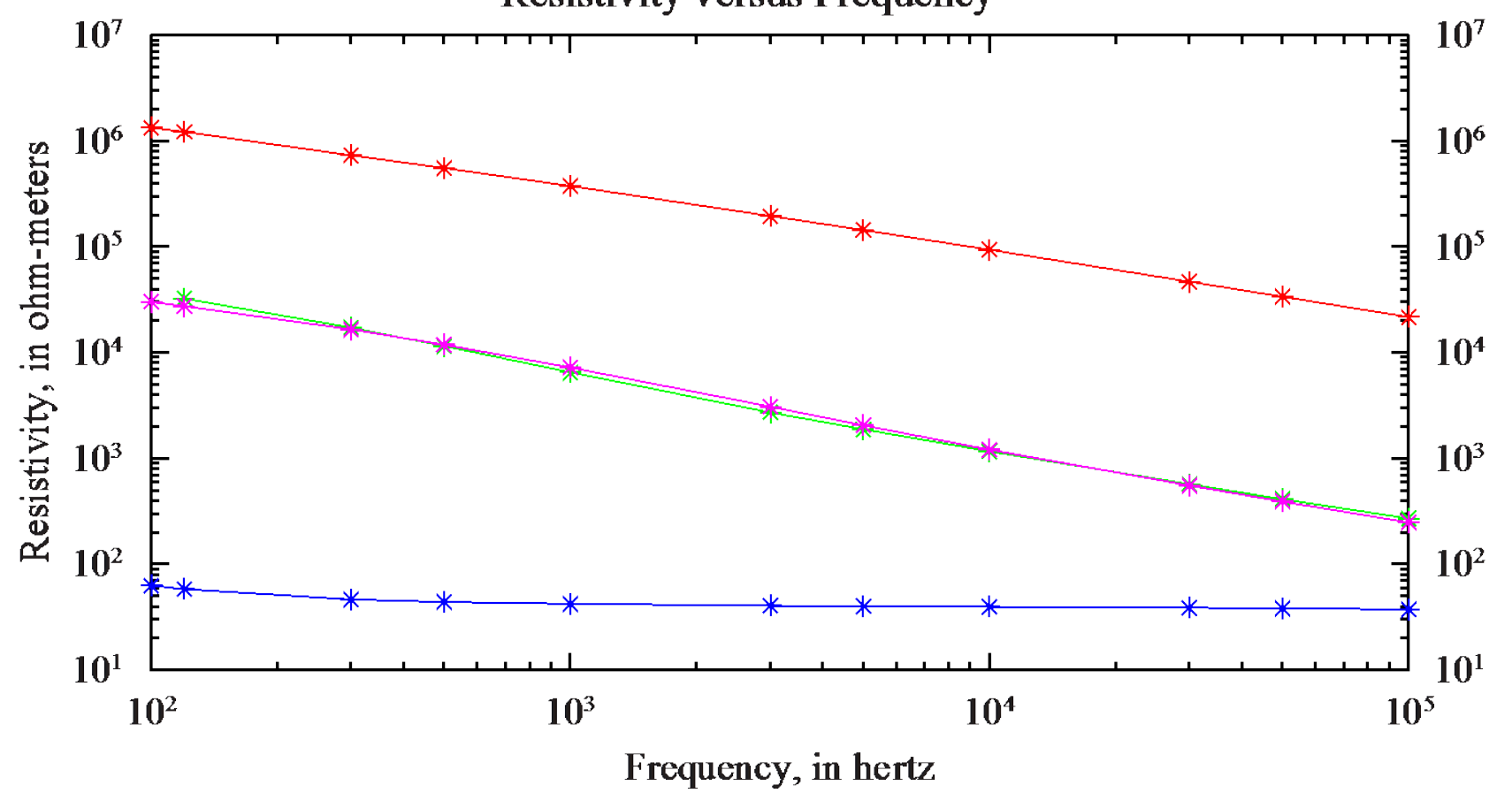

As-received measurement

- Dry measurement

Humid measurement

* Datum point

- Submerged measurement 
GOLD2-3c-1T_R

Resistivity versus Frequency

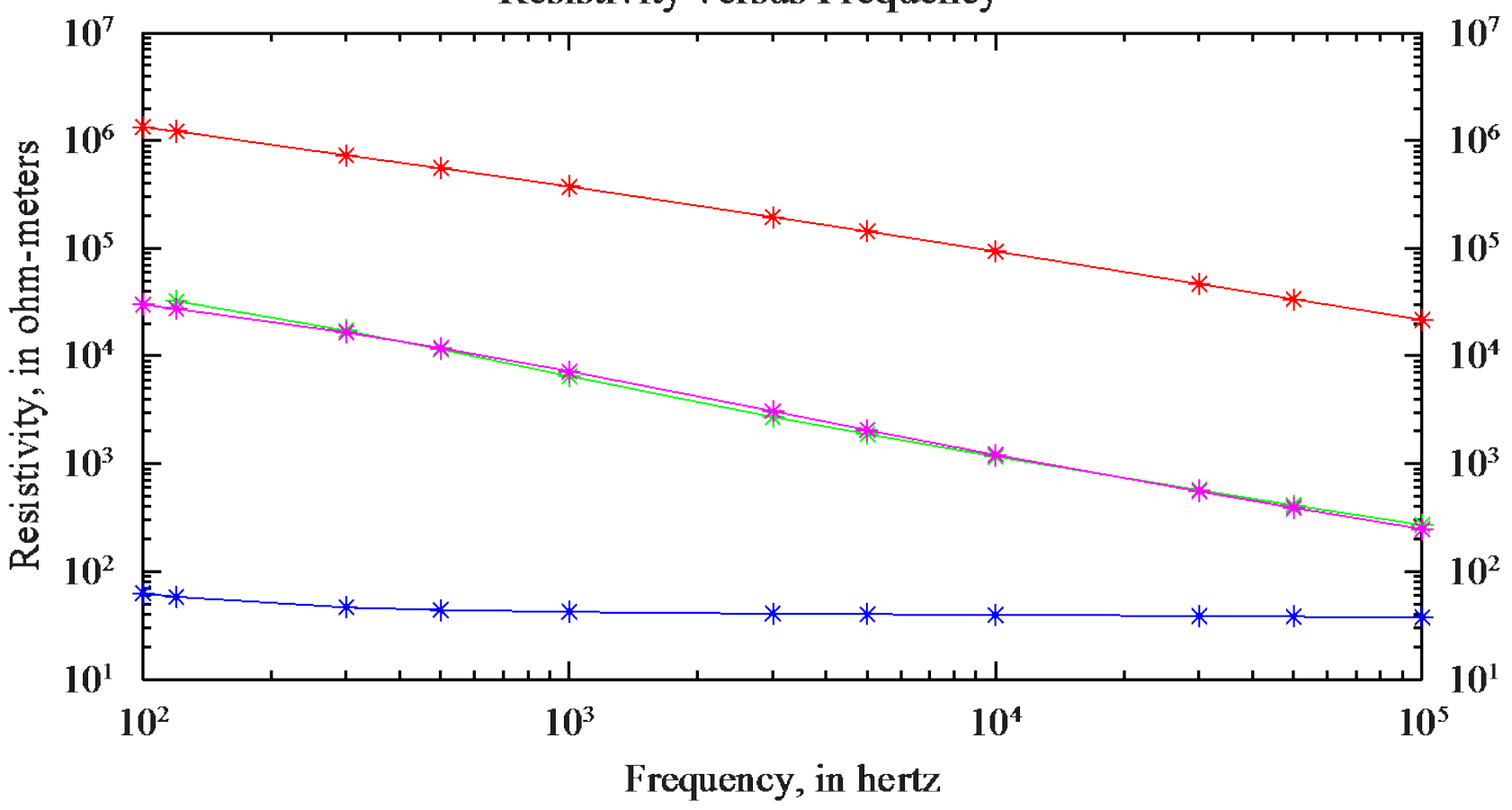

GOLD2-4c-1_R

Resistivity versus Frequency

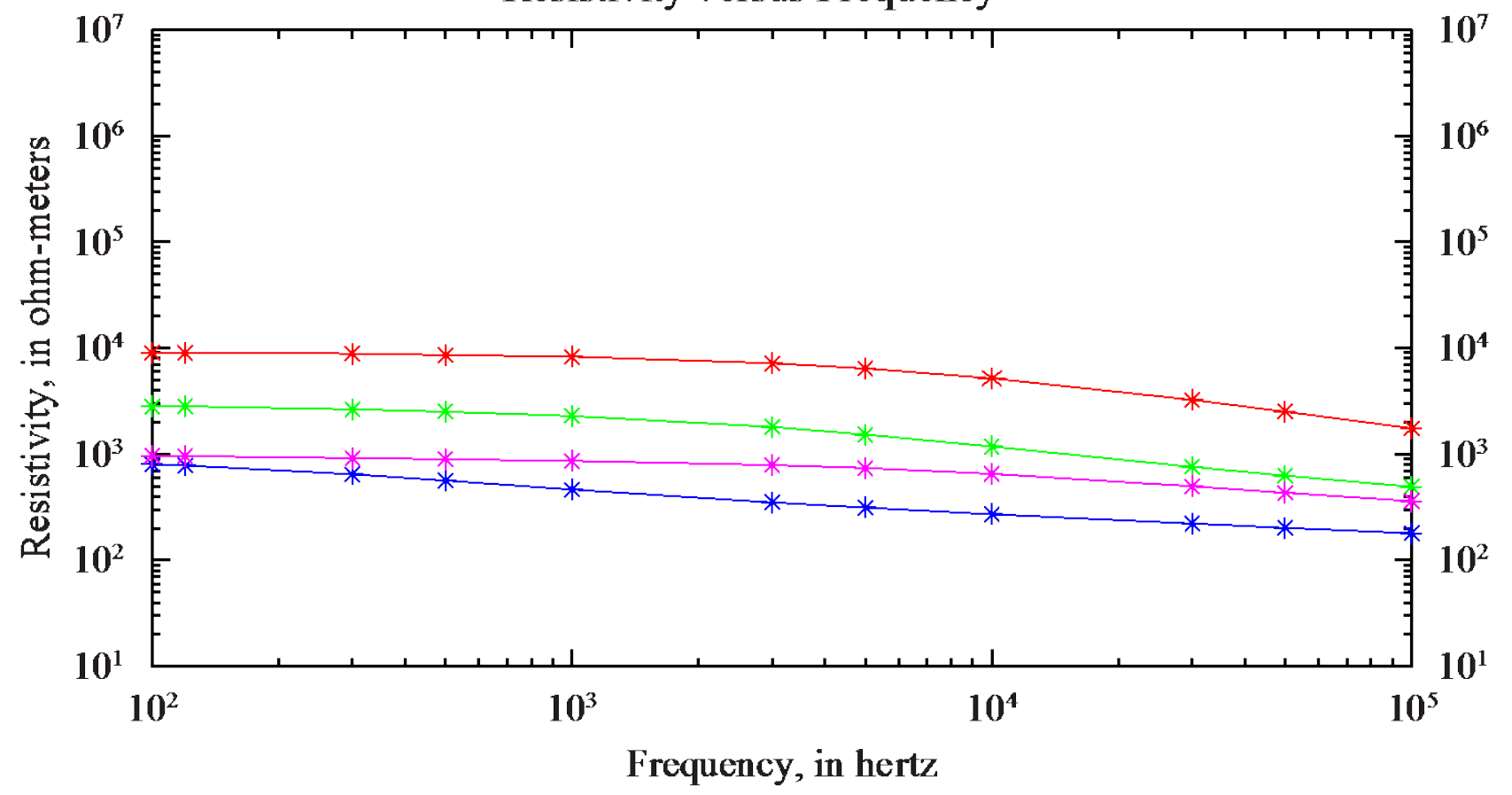

As-received measurement

- Dry measurement

Humid measurement

* Datum point

- Submerged measurement 

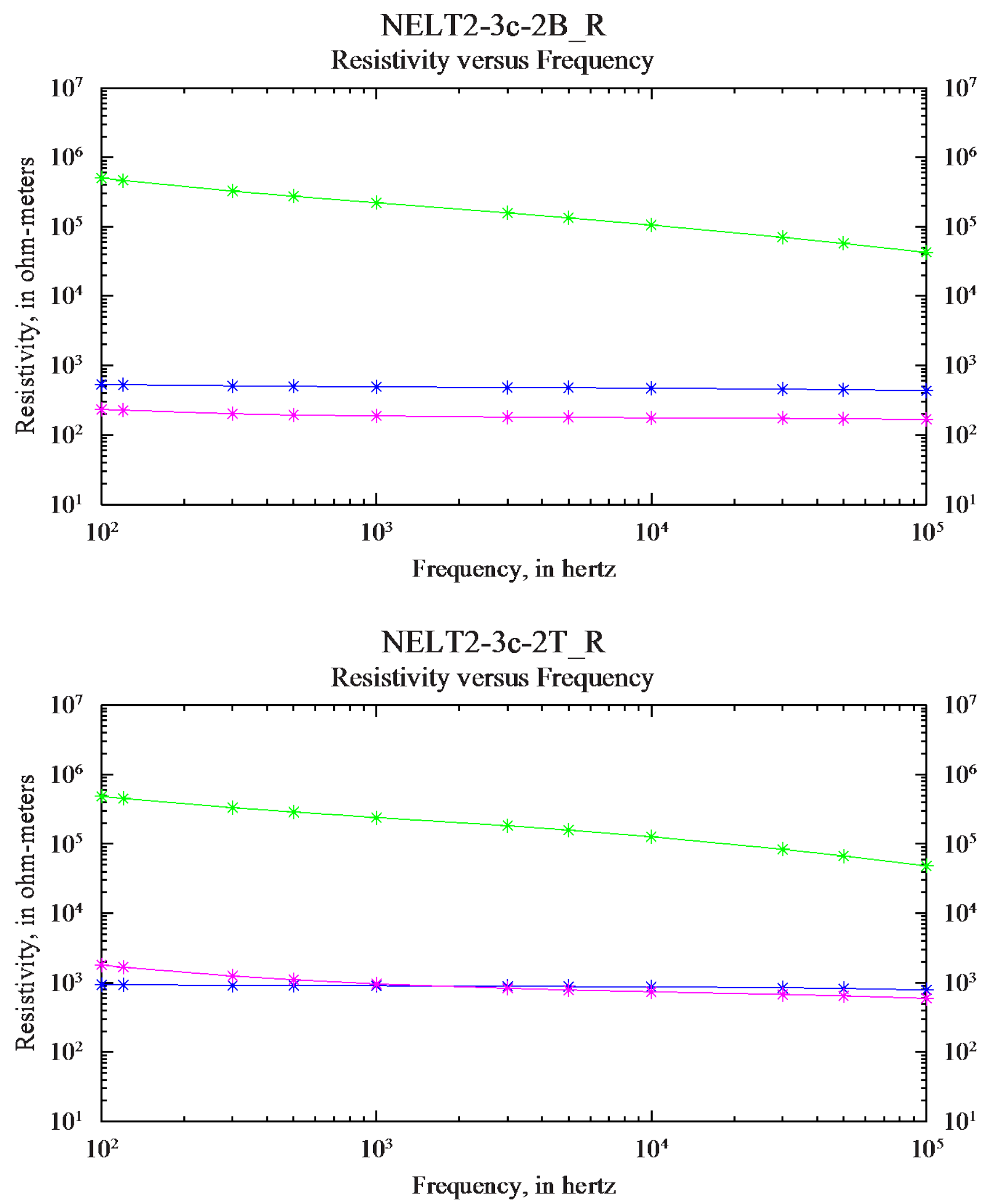

As-received measurement

Humid measurement

* Datum point

- Submerged measurement 

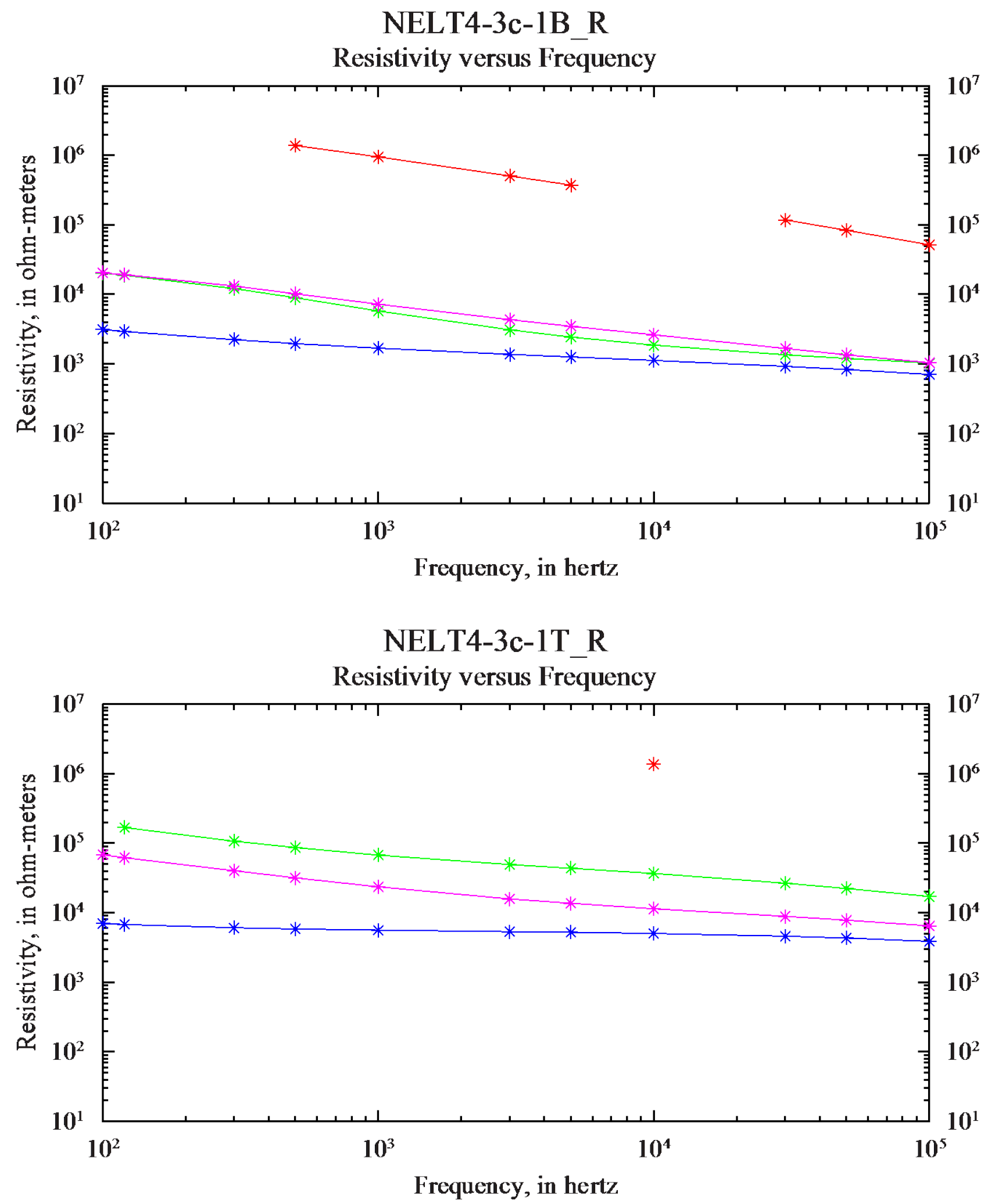

As-received measurement

Dry measurement

Humid measurement

- Submerged measurement
* Datum point 

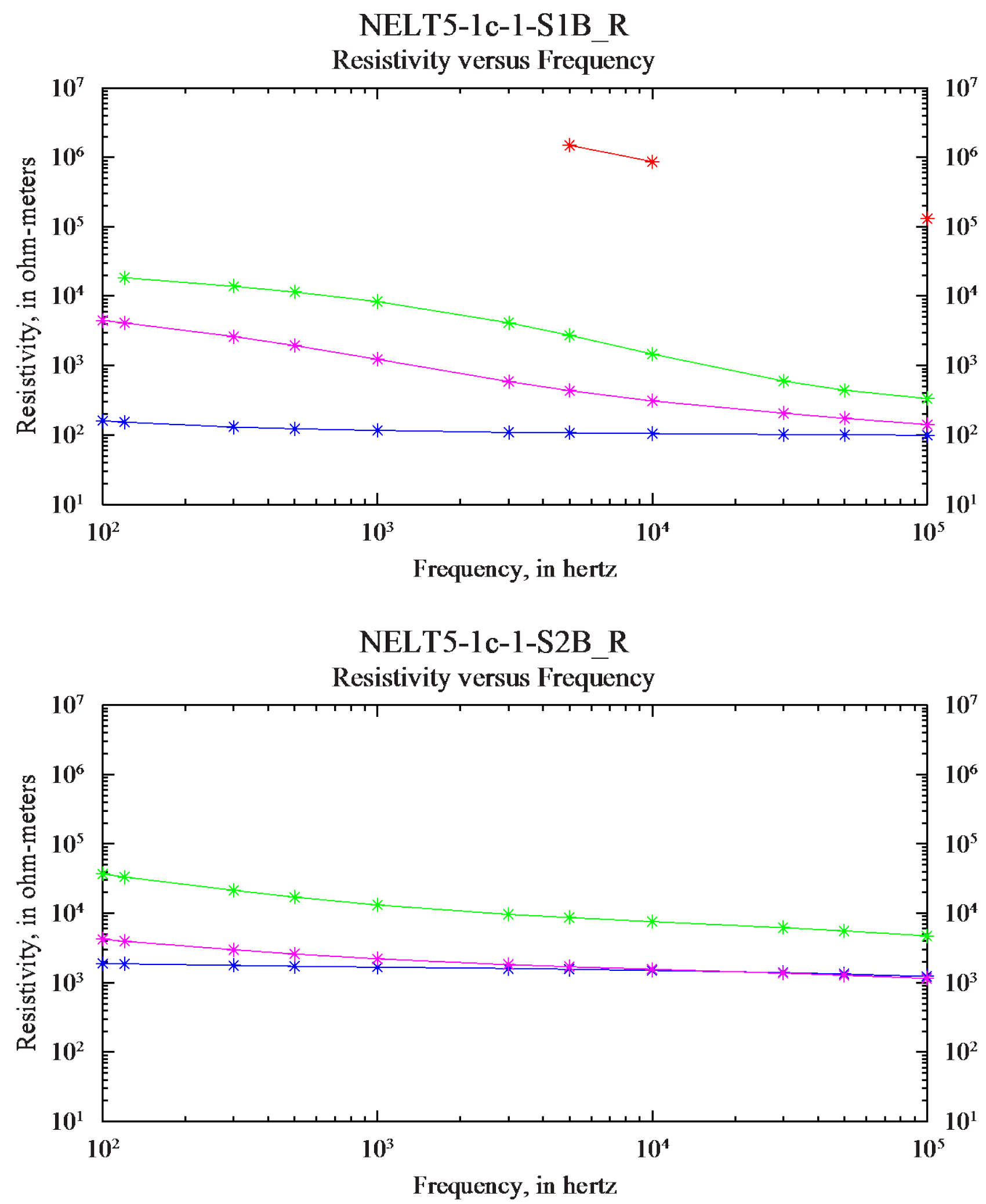

As-received measurement

- Dry measurement

Humid measurement

- Submerged measurement
* Datum point 

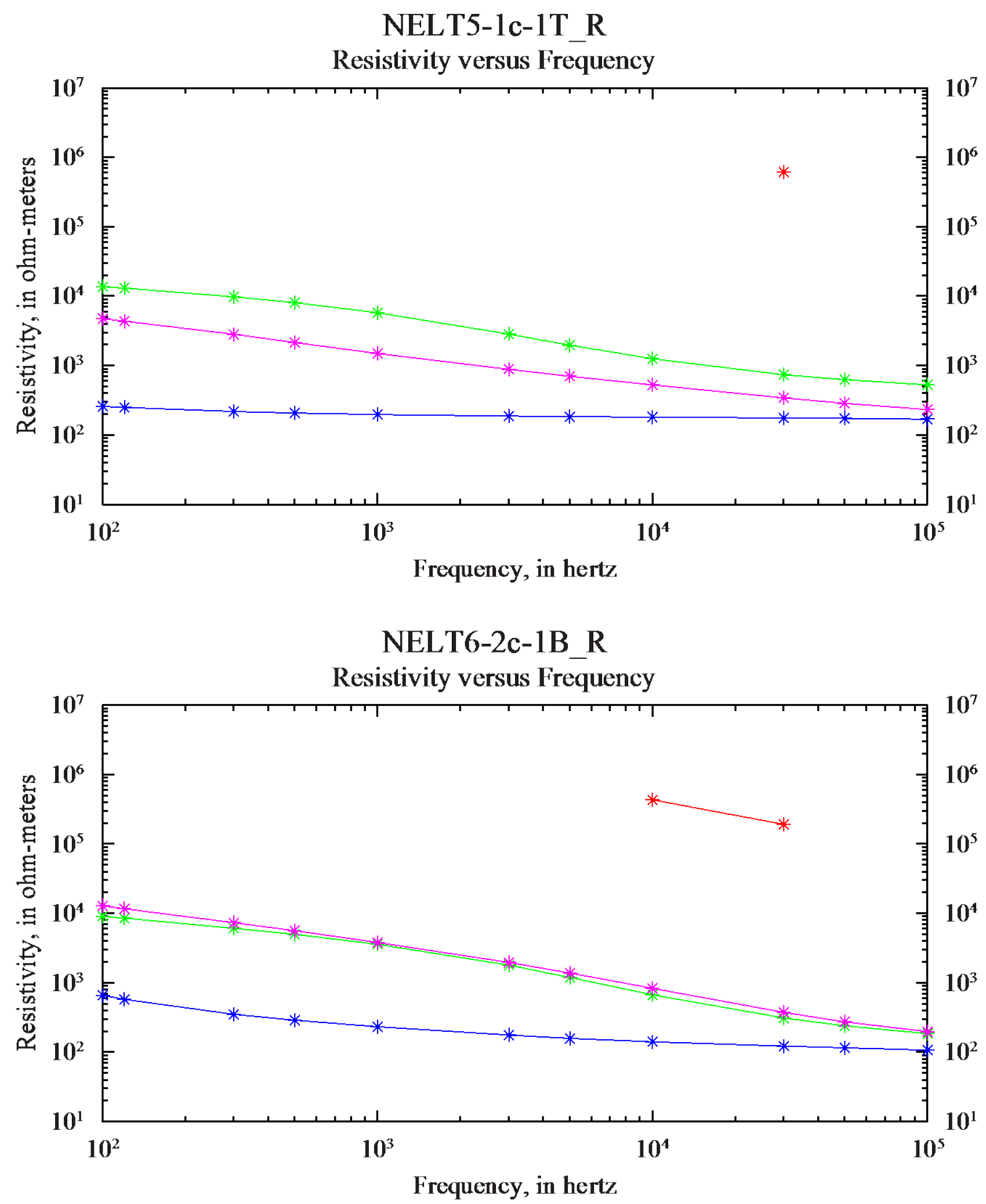

As-received measurement

- Dry measurement

Humid measurement

* Datum point

- Submerged measurement 

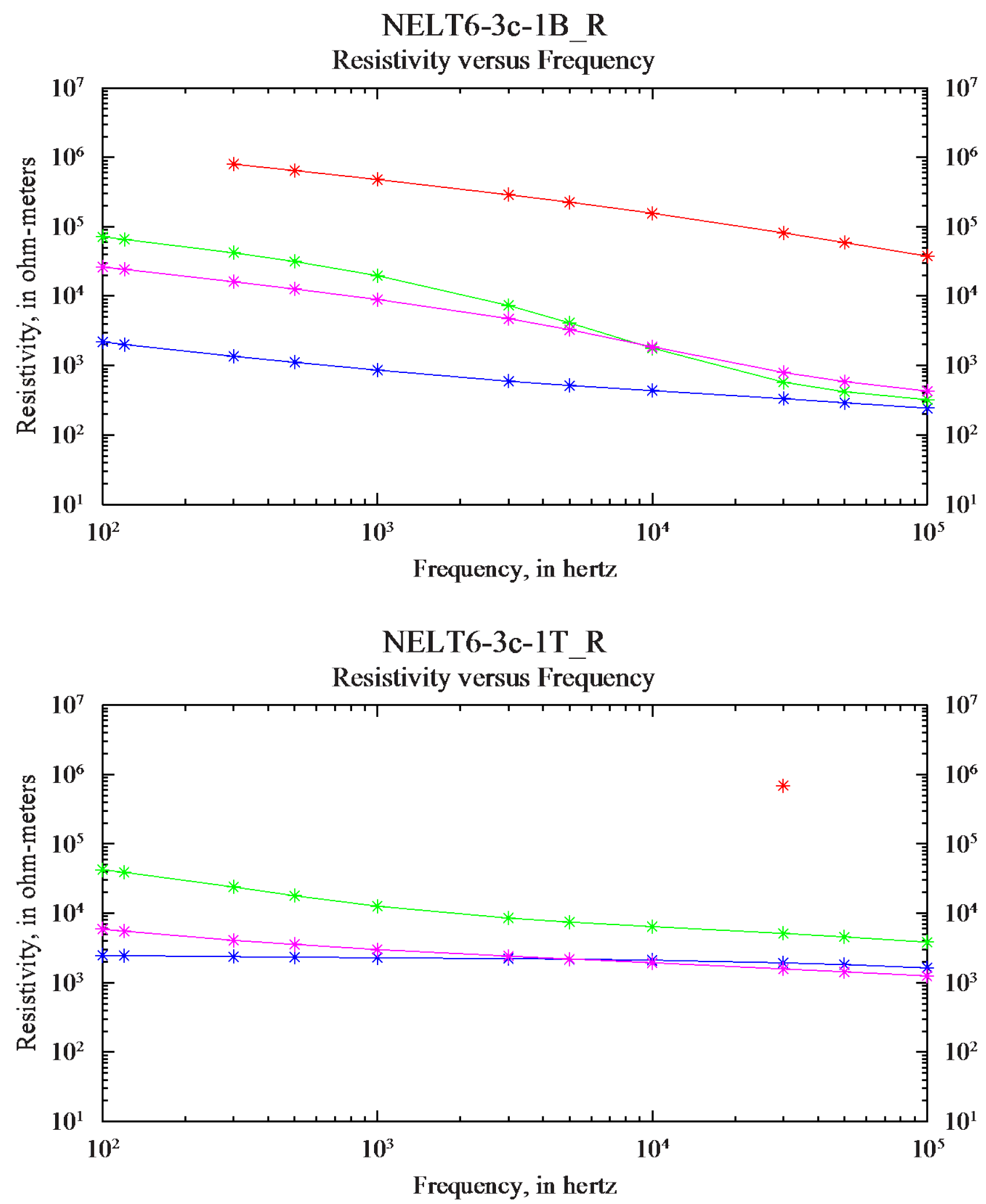

As-received measurement

- Dry measurement

Humid measurement

* Datum point

- Submerged measurement 

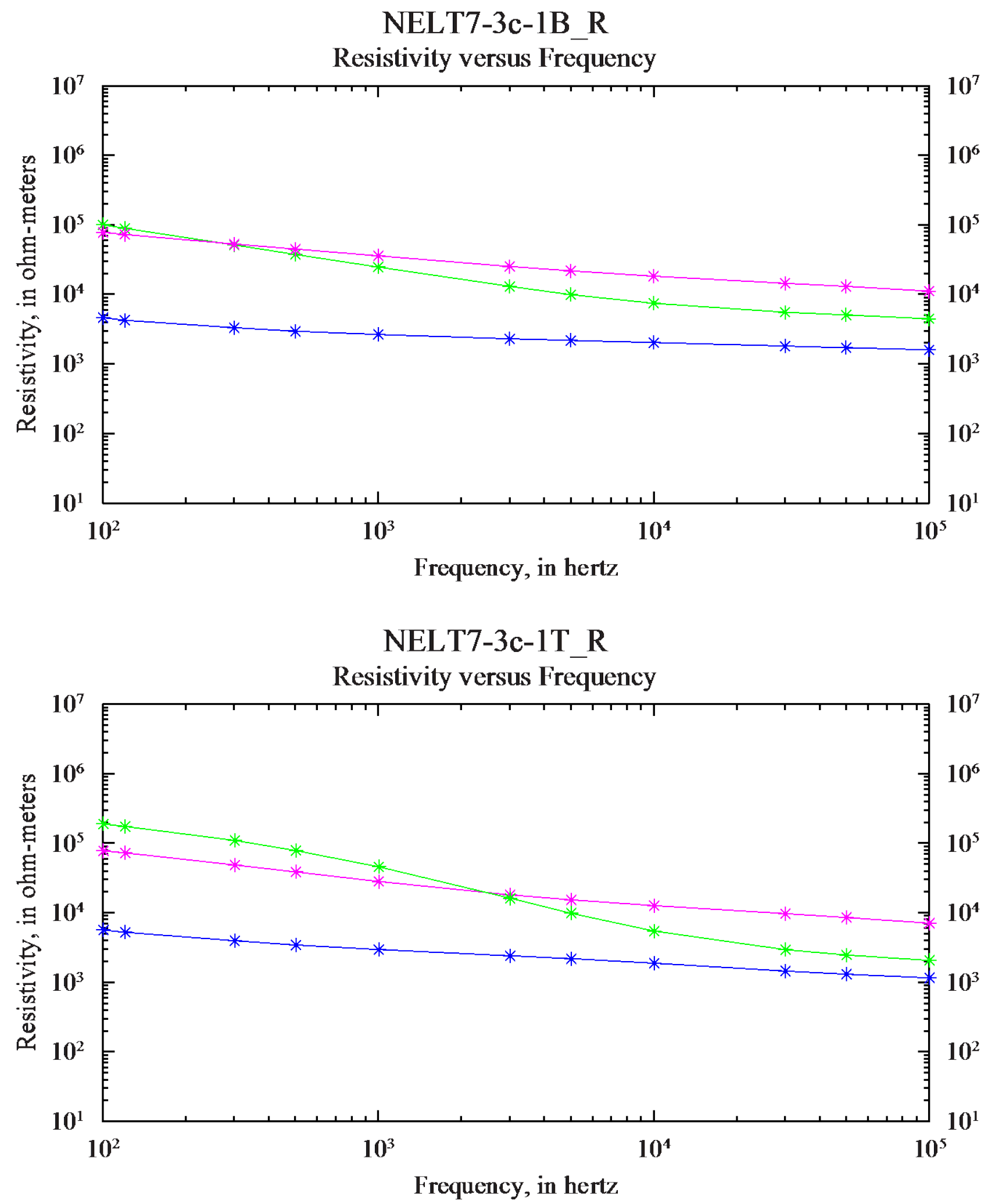

As-received measurement

Humid measurement

* Datum point

- Submerged measurement 


\section{Appendix B. Core Sediment Resistivity Versus Frequency}

Figures, one per sample, showing sample resistivity, in ohm-meters, versus frequency, in hertz. Each curve represents a different degree of saturation. 

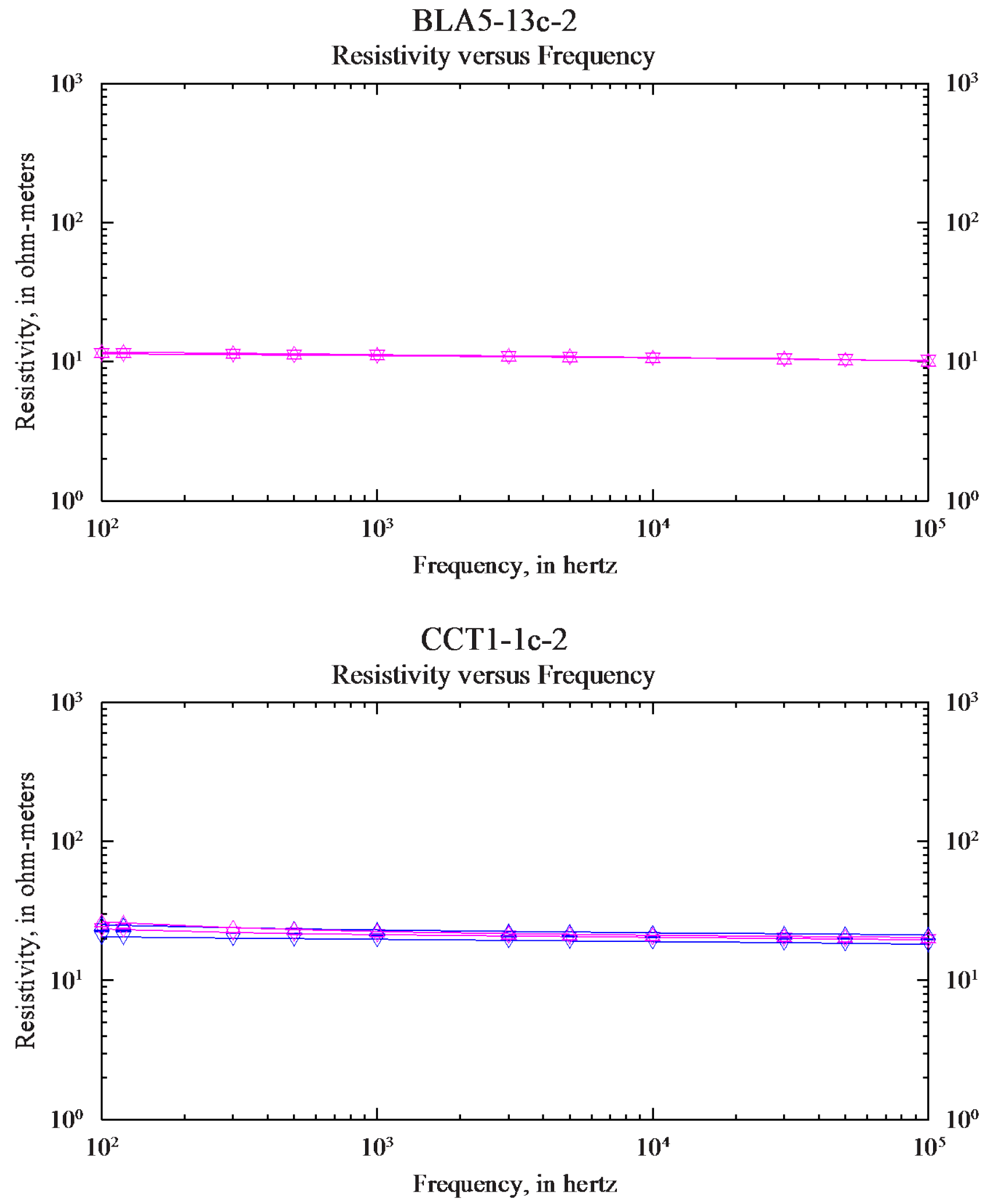

As-received measurement

Water-added measurement $\triangle$ Datum point indicating top of core sample

$\nabla$ Datum point indicating bottom of core sample 
CCT1-2c-1

Resistivity versus Frequency

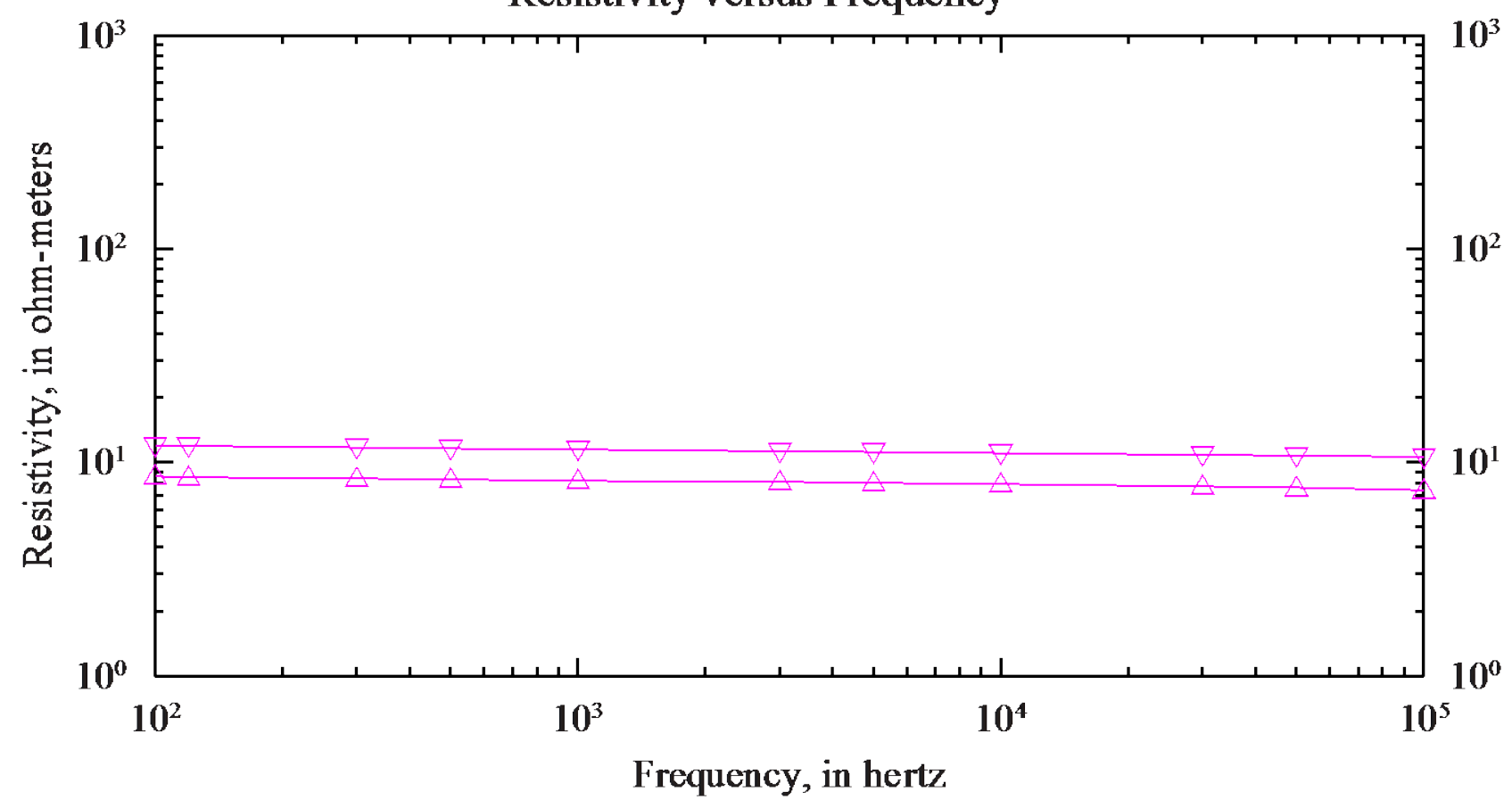

CCT $1-3 c-2$

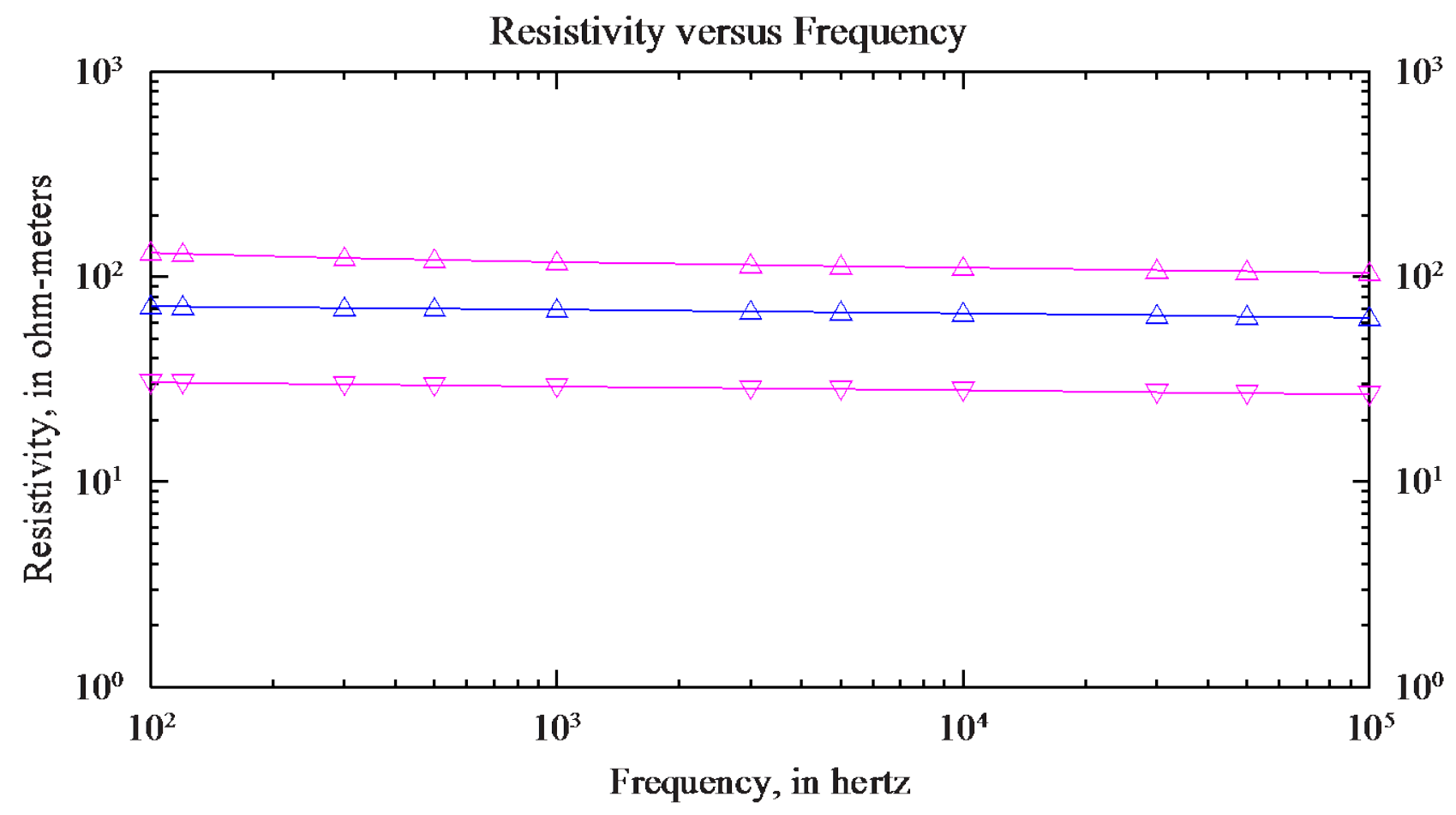

As-received measurement

Water-added measurement $\triangle$ Datum point indicating top of core sample

$\nabla$ Datum point indicating bottom of core sample 

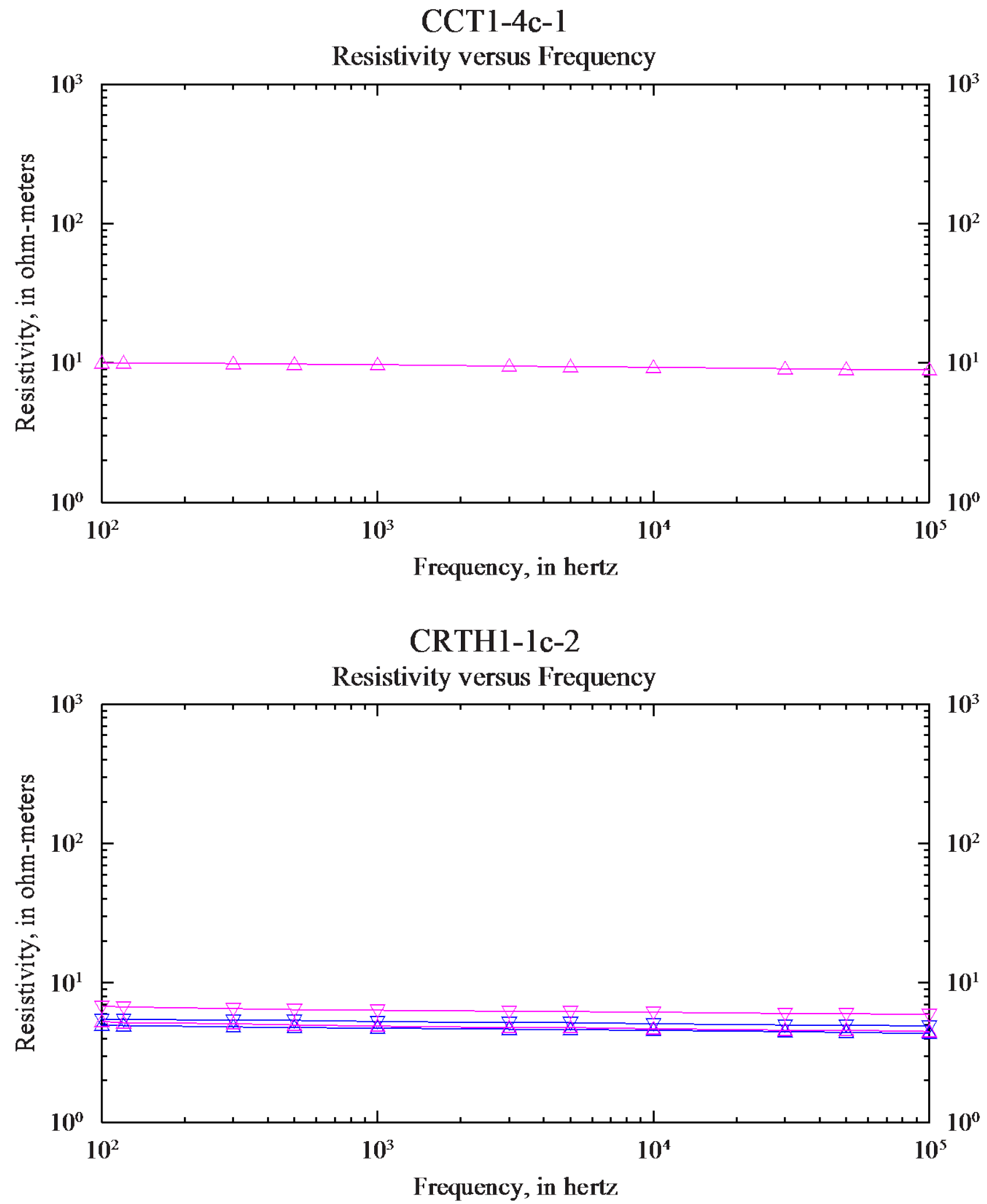

As-received measurement

Water-added measurement $\triangle$ Datum point indicating top of core sample

$\nabla$ Datum point indicating bottom of core sample 

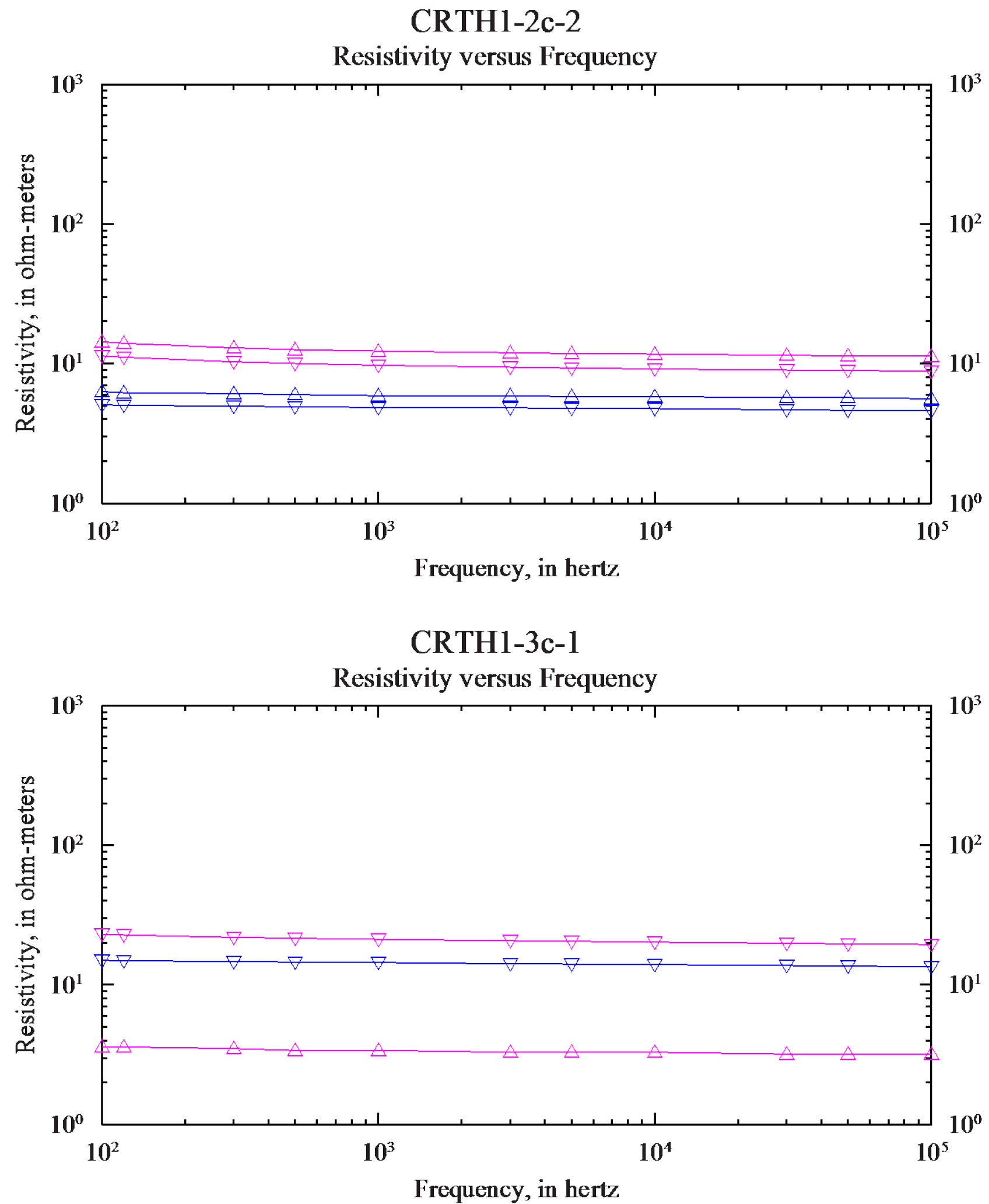

As-received measurement

Water-added measurement $\triangle$ Datum point indicating top of core sample

$\nabla$ Datum point indicating bottom of core sample 

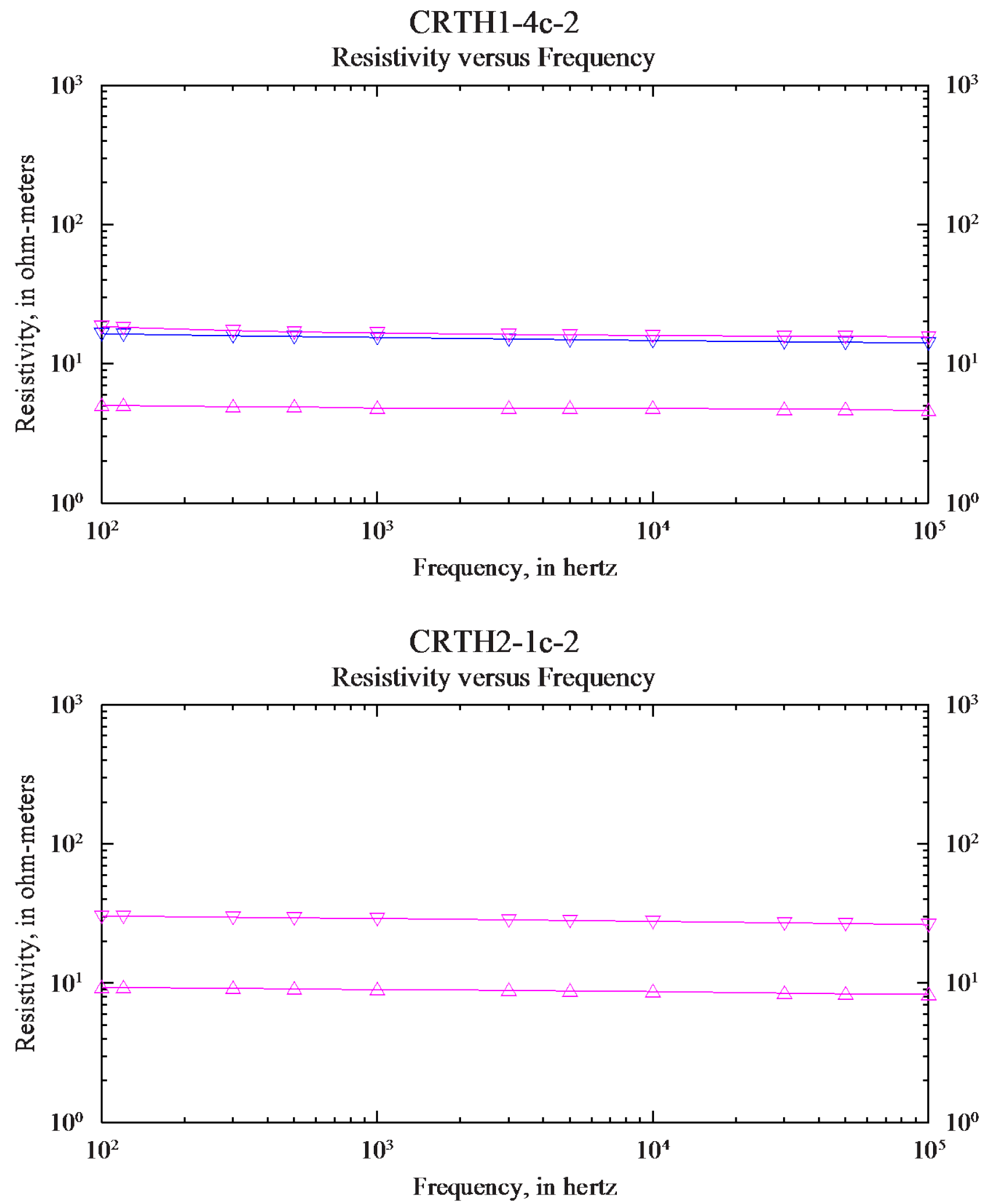

As-received measurement

Water-added measurement $\triangle$ Datum point indicating top of core sample

$\nabla$ Datum point indicating bottom of core sample 
GOLD1-1c-1

Resistivity versus Frequency

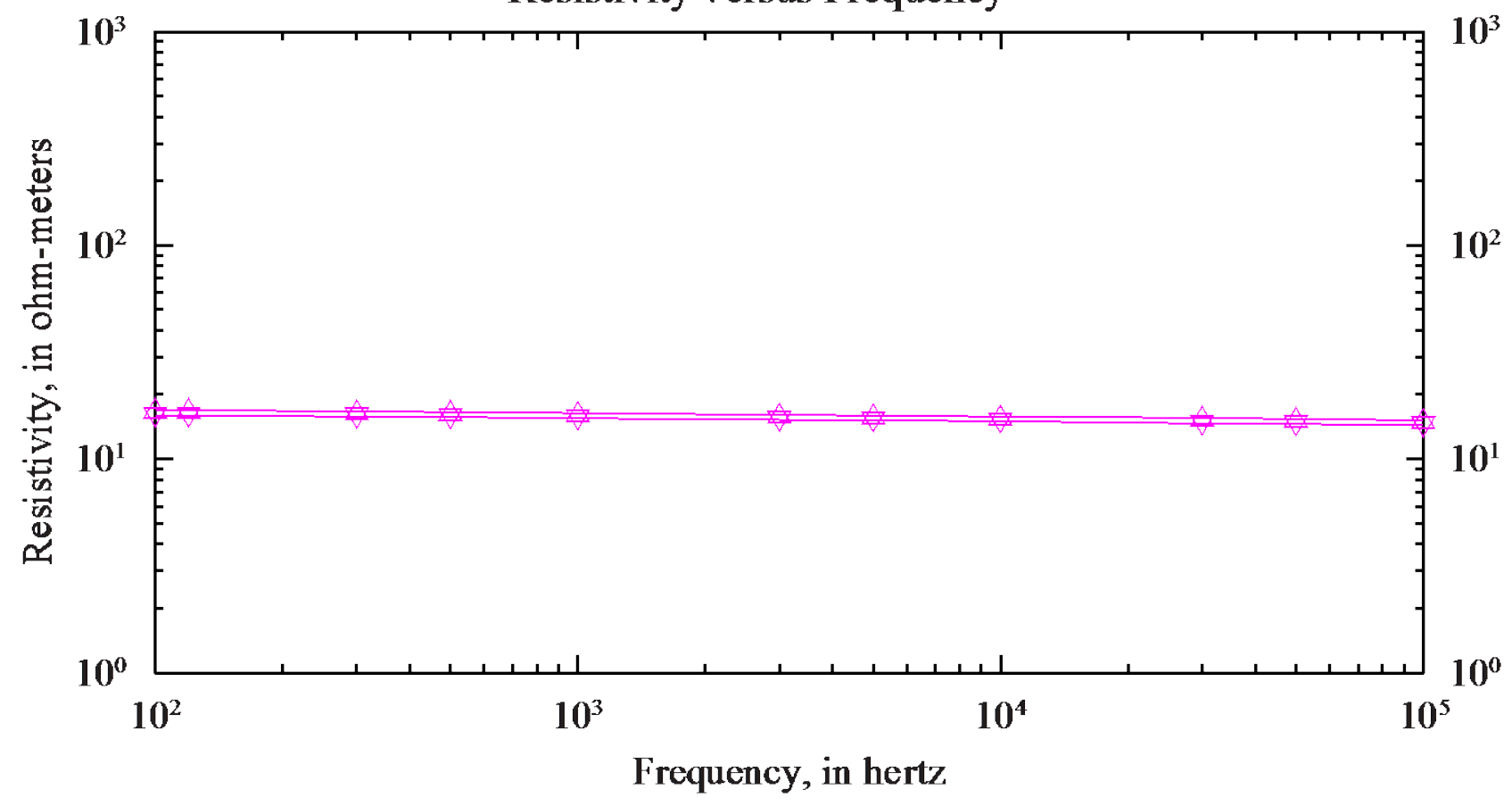

GOLD1-2c-1

Resistivity versus Frequency

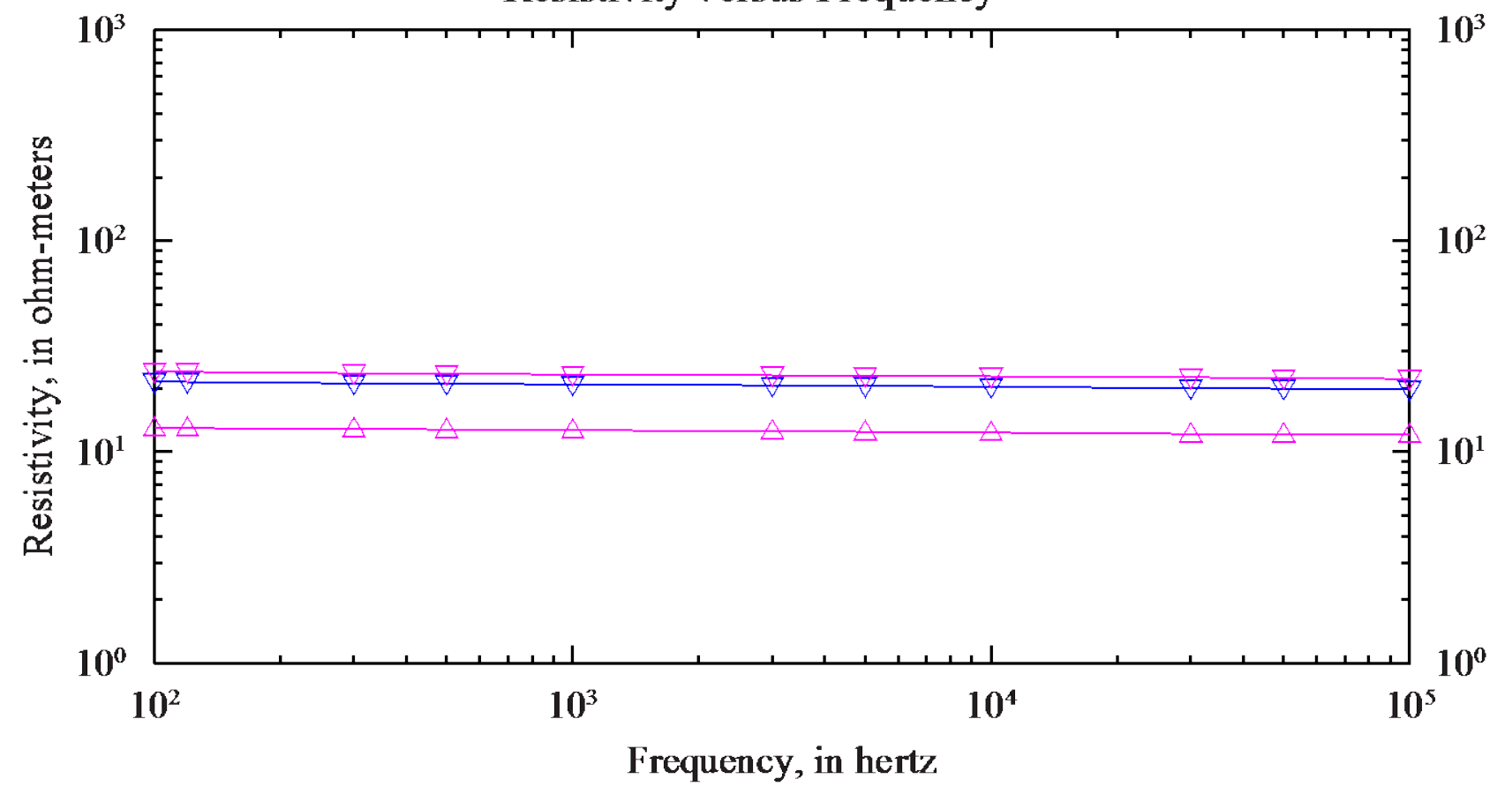

As-received measurement

Water-added measurement $\triangle$ Datum point indicating top of core sample

$\nabla$ Datum point indicating bottom of core sample 
GOLD1-3c-1

Resistivity versus Frequency

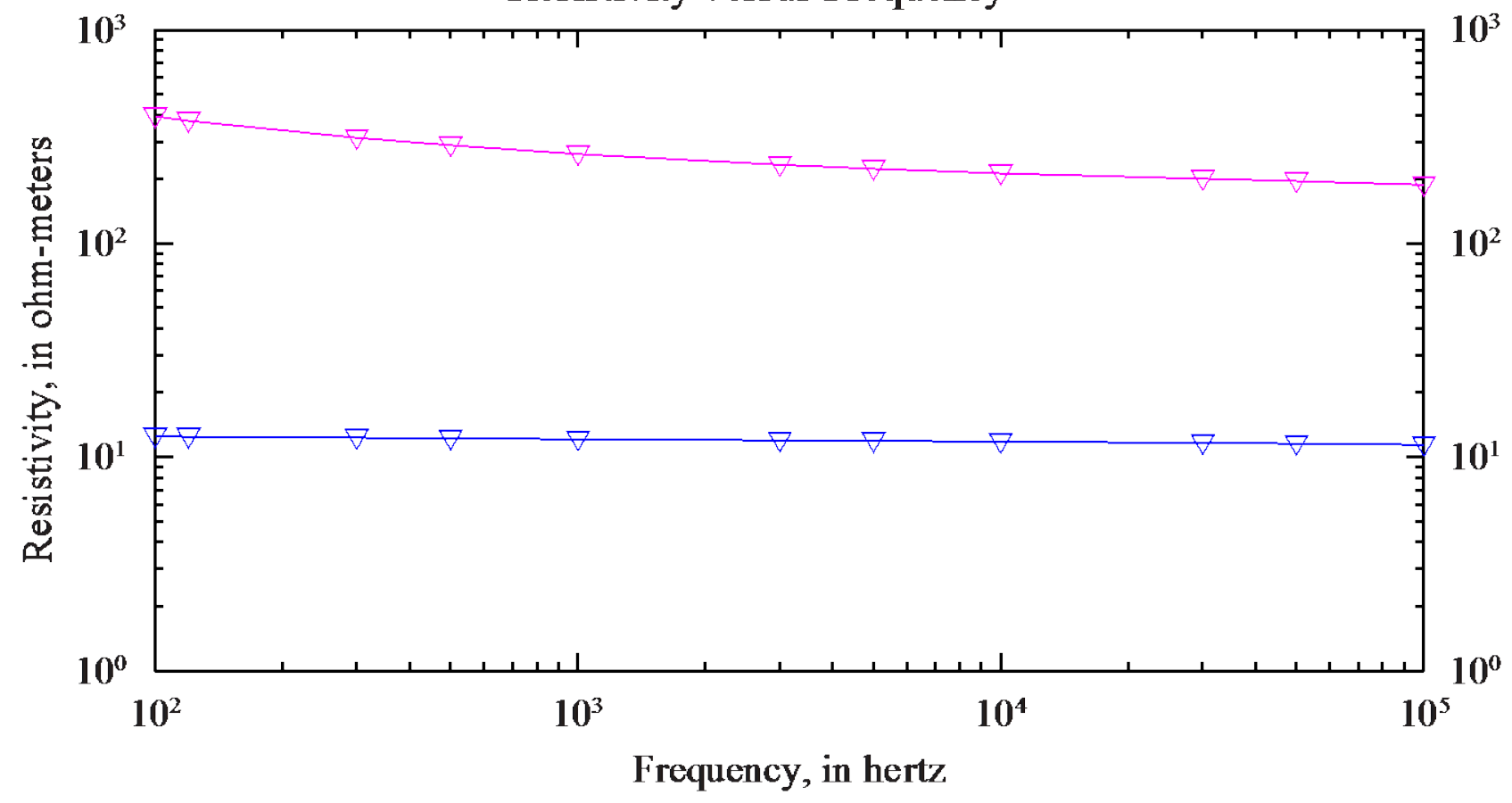

GOLD2-1c-1

Resistivity versus Frequency

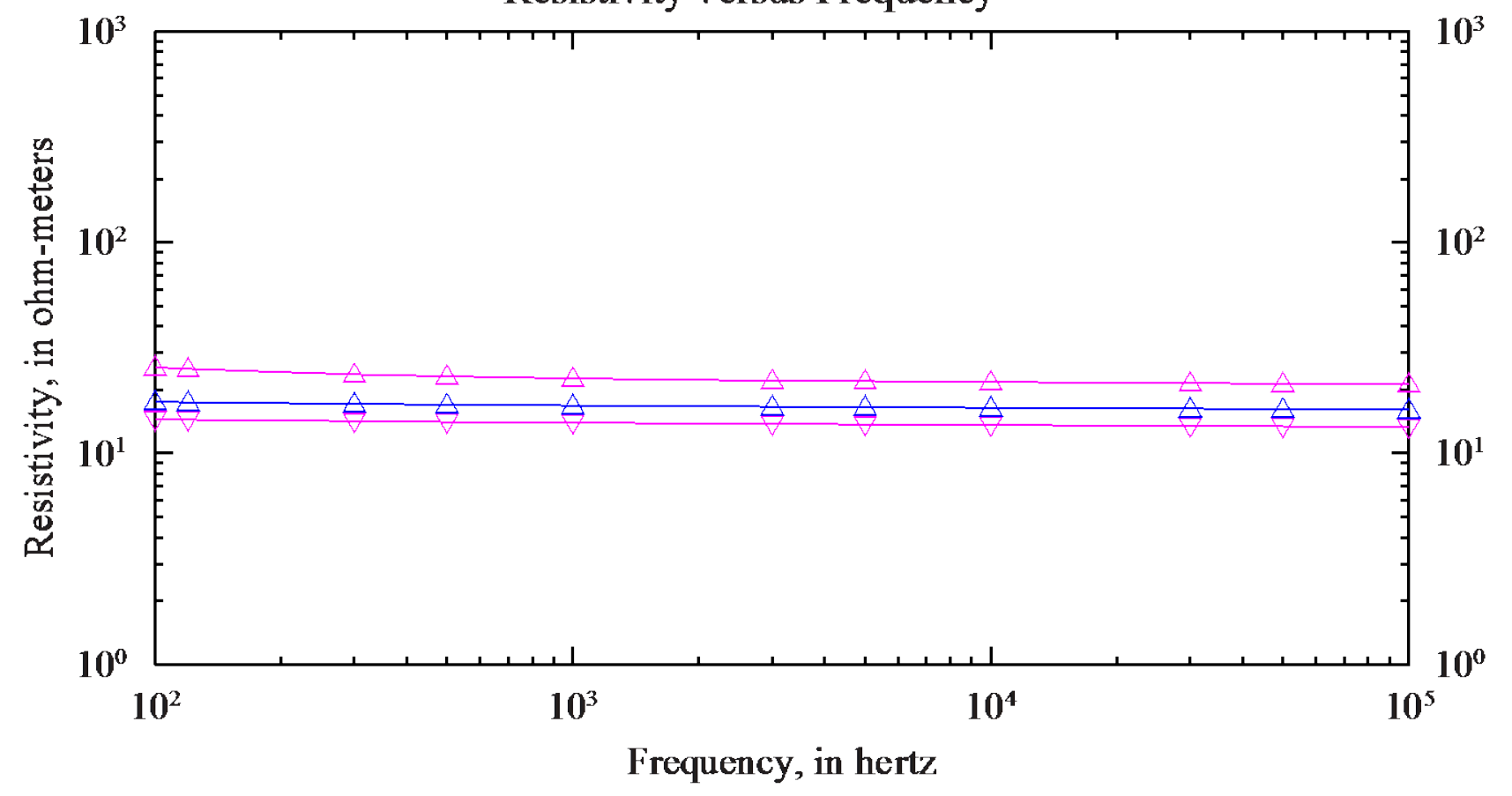

As-received measurement

Water-added measurement $\triangle$ Datum point indicating top of core sample

$\nabla$ Datum point indicating bottom of core sample 
GOLD2-2c-1

Resistivity versus Frequency

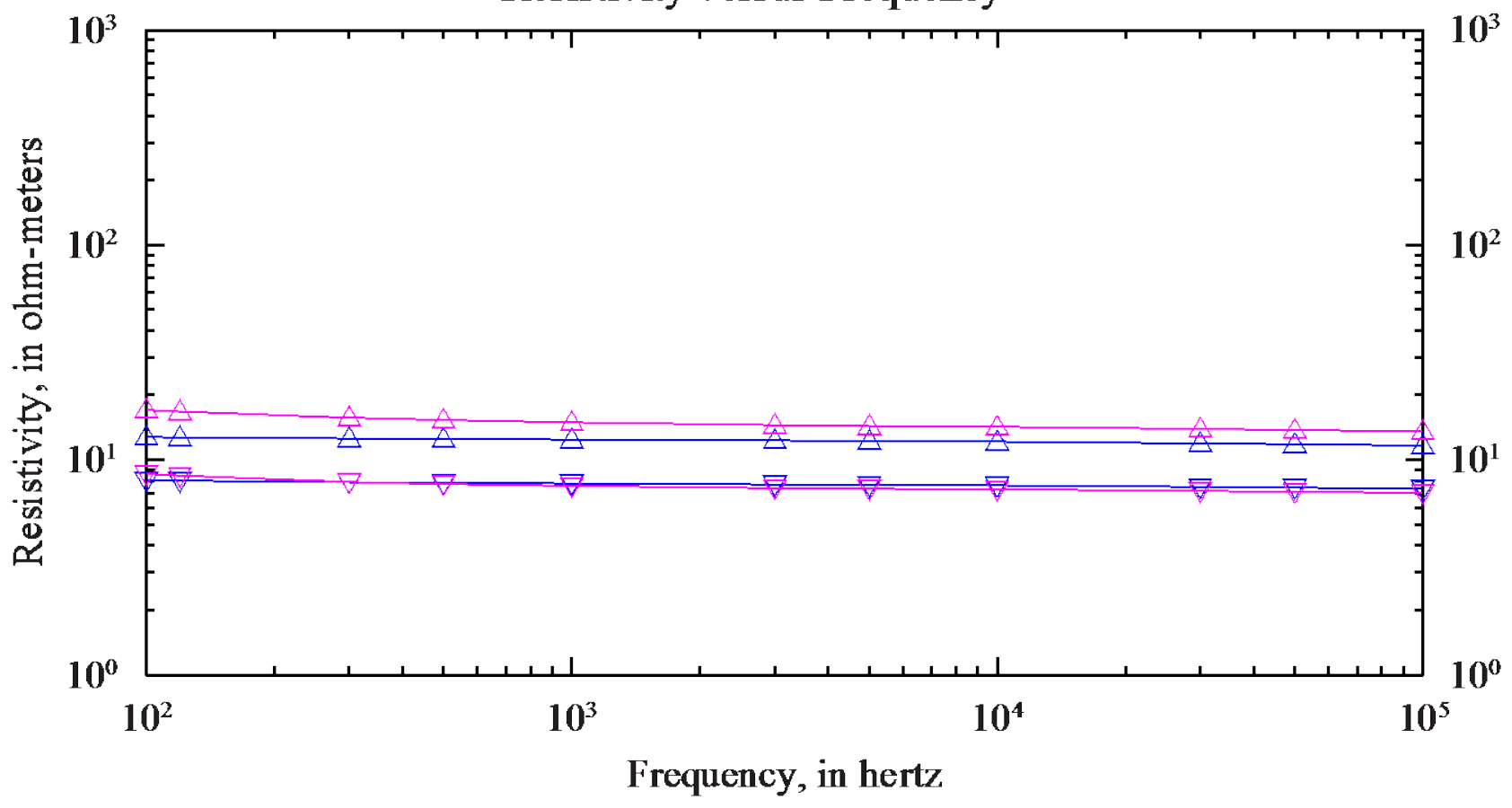

LL04-1c-1

Resistivity versus Frequency

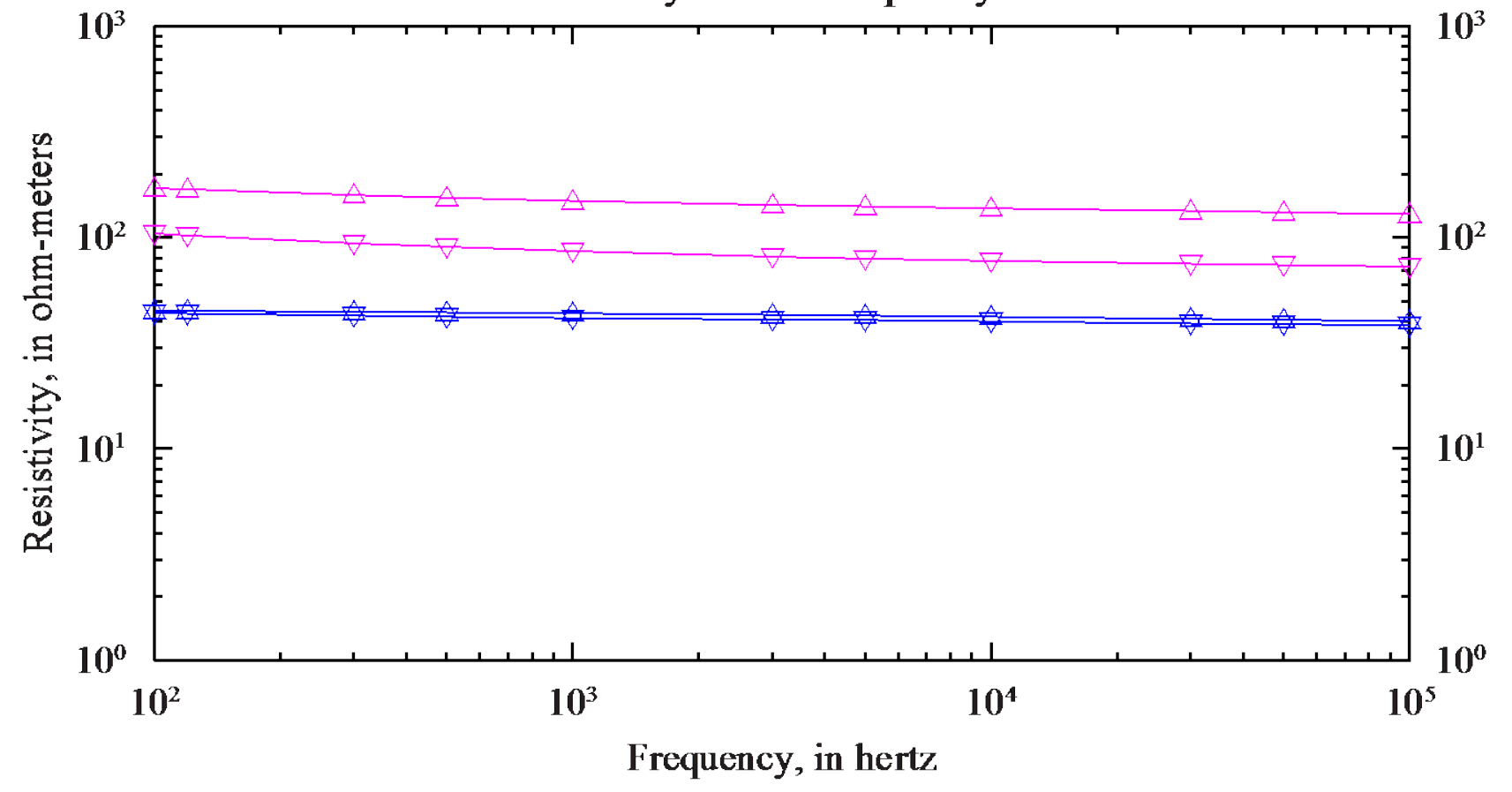

As-received measurement

Water-added measurement $\triangle$ Datum point indicating top of core sample

$\nabla$ Datum point indicating bottom of core sample 

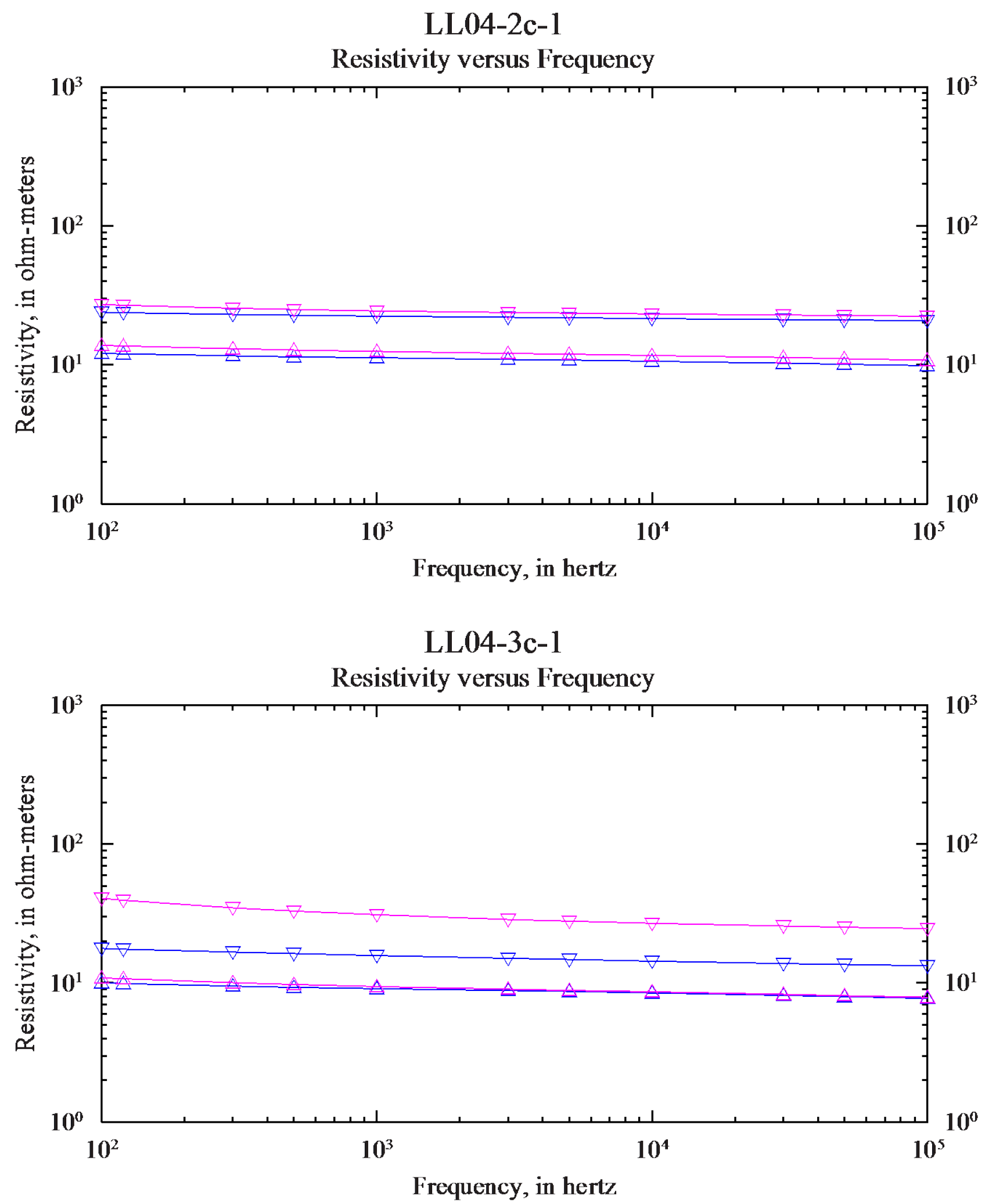

As-received measurement

Water-added measurement $\triangle$ Datum point indicating top of core sample

$\nabla$ Datum point indicating bottom of core sample 

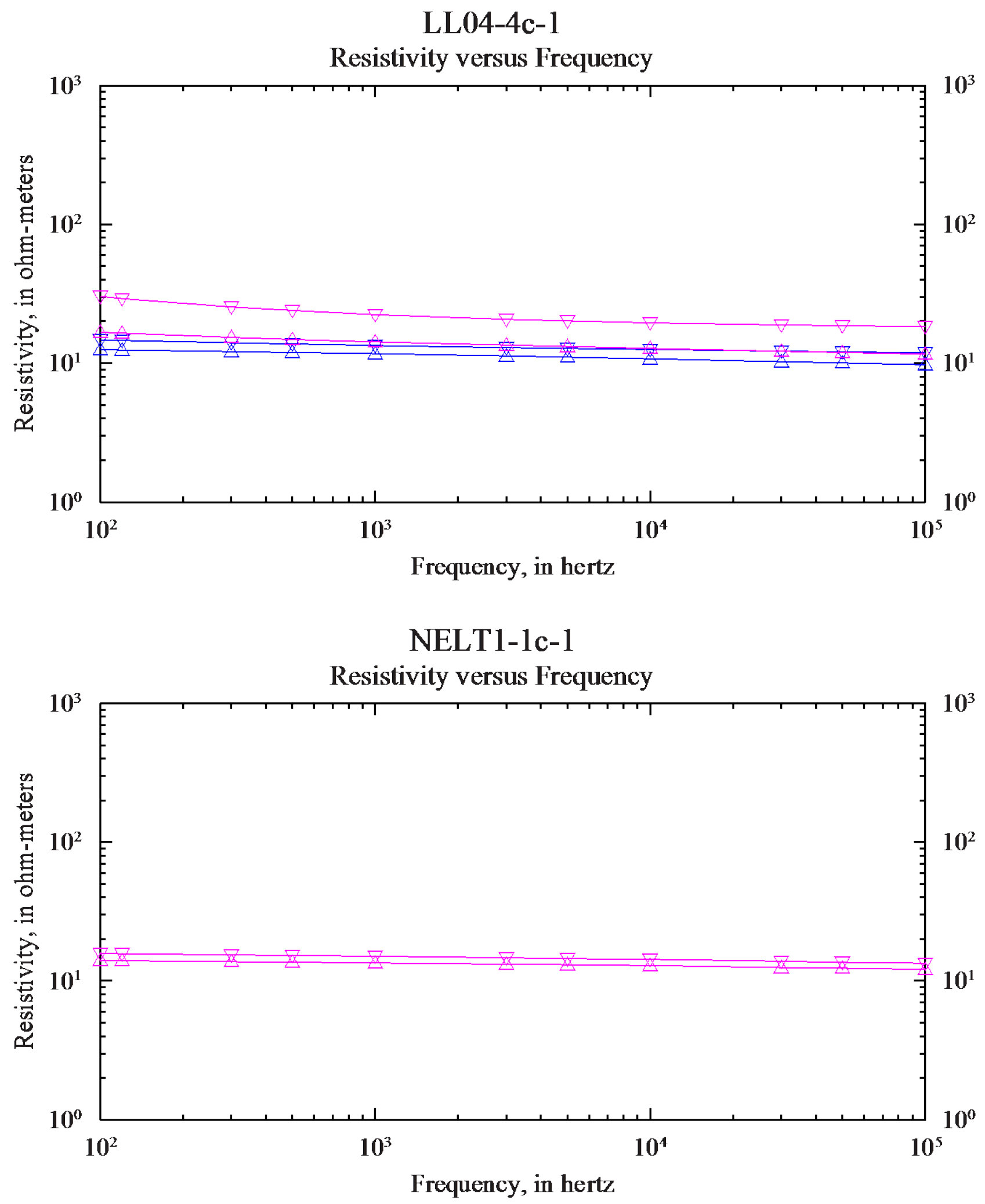

As-received measurement

Water-added measurement $\triangle$ Datum point indicating top of core sample

$\nabla$ Datum point indicating bottom of core sample 

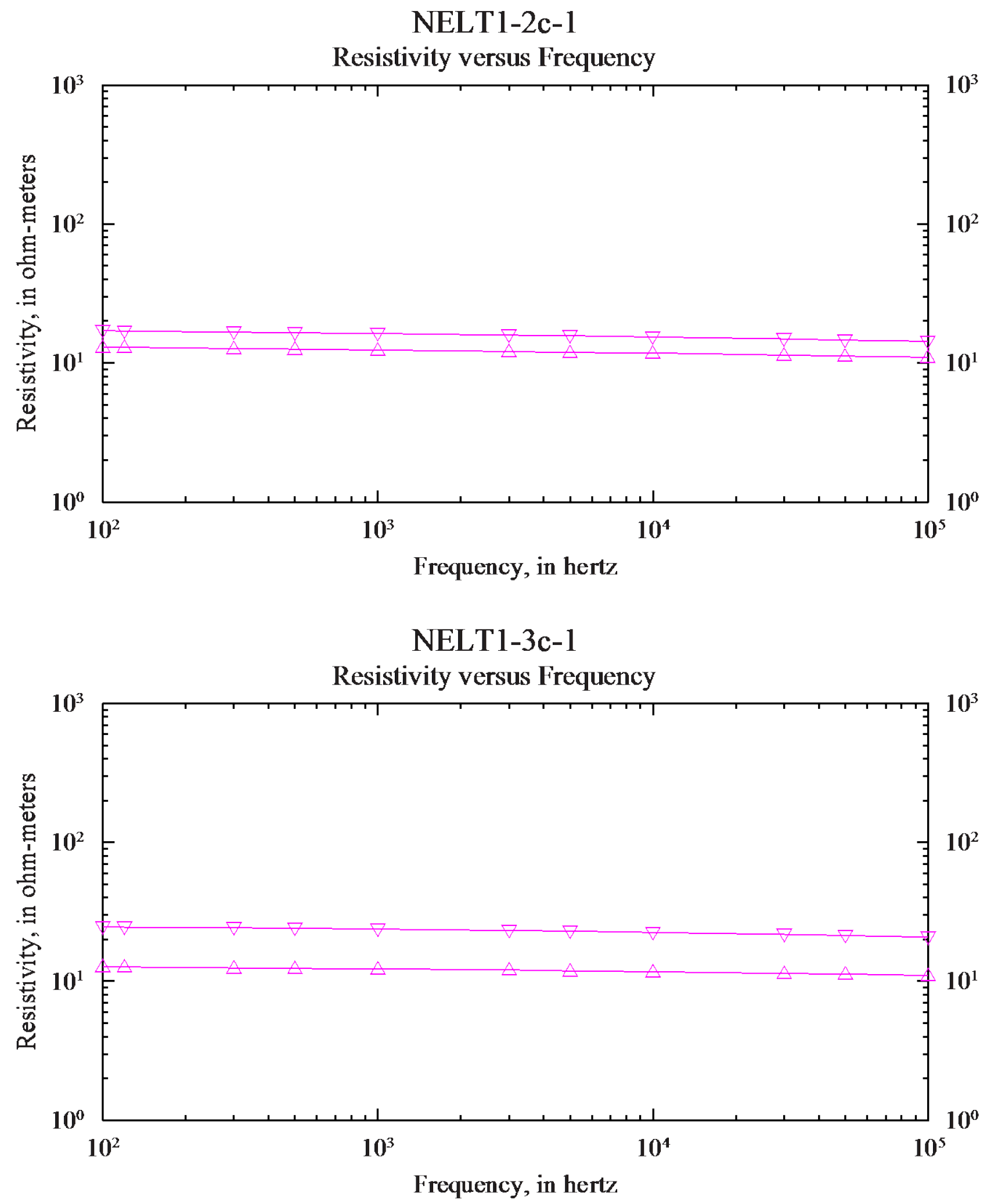

As-received measurement

$\triangle$ Datum point indicating top of core sample

$\nabla$ Datum point indicating bottom of core sample 
NELT2-1c-2

Resistivity versus Frequency

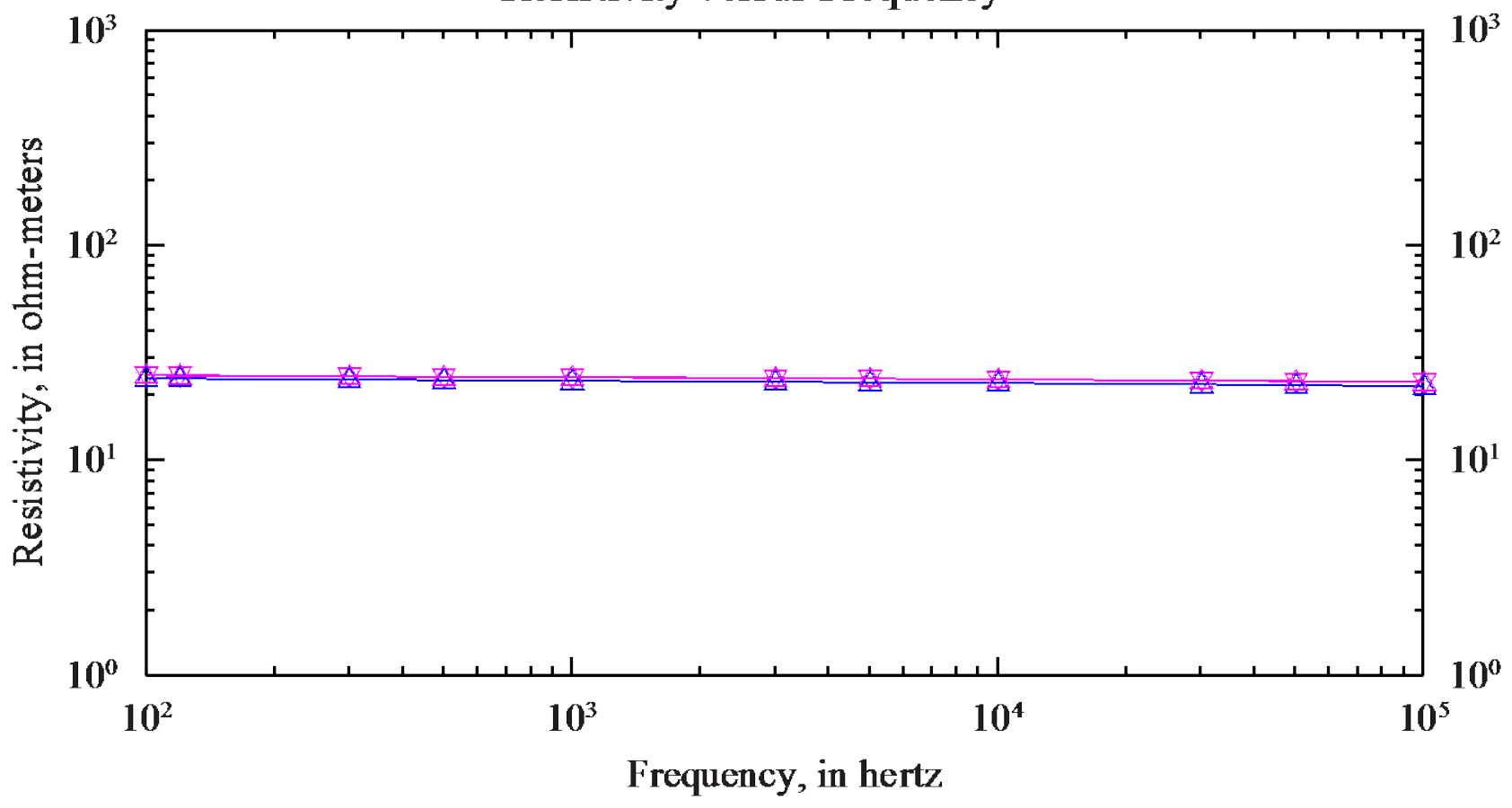

NELT2-2c-1b

Resistivity versus Frequency

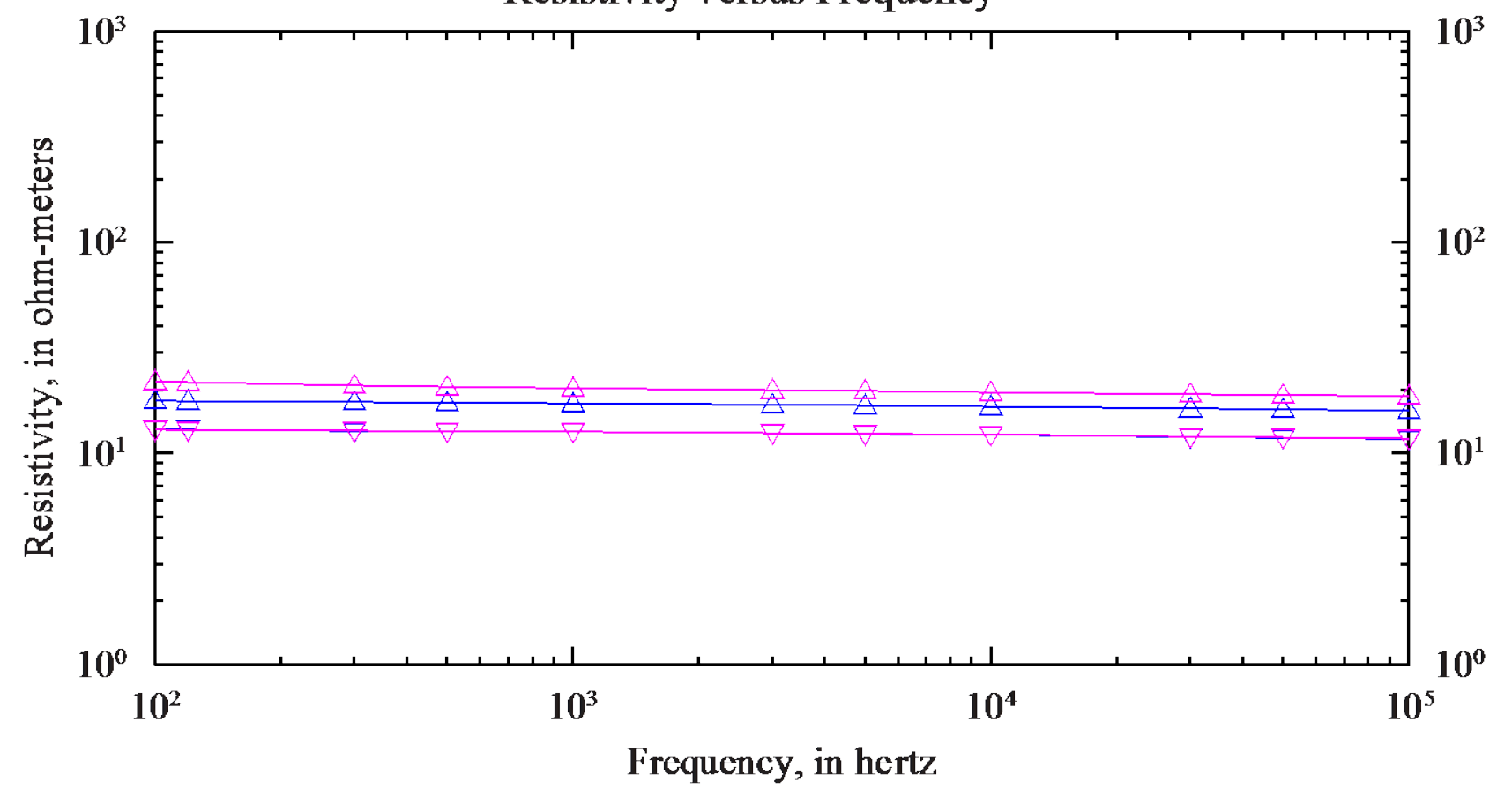

As-received measurement

Water-added measurement $\triangle$ Datum point indicating top of core sample

$\nabla$ Datum point indicating bottom of core sample 

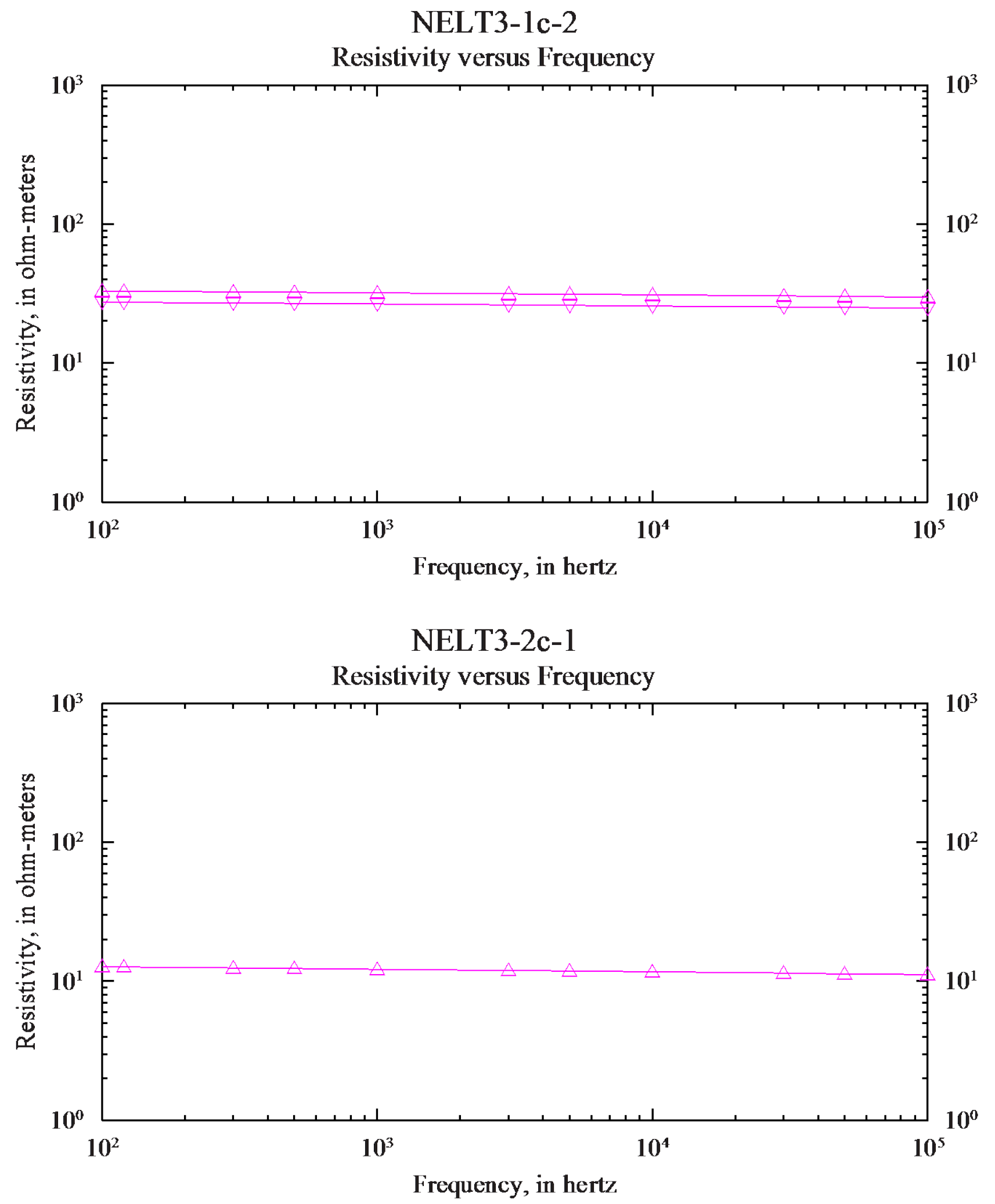

As-received measurement

$\triangle$ Datum point indicating top of core sample

$\nabla$ Datum point indicating bottom of core sample 

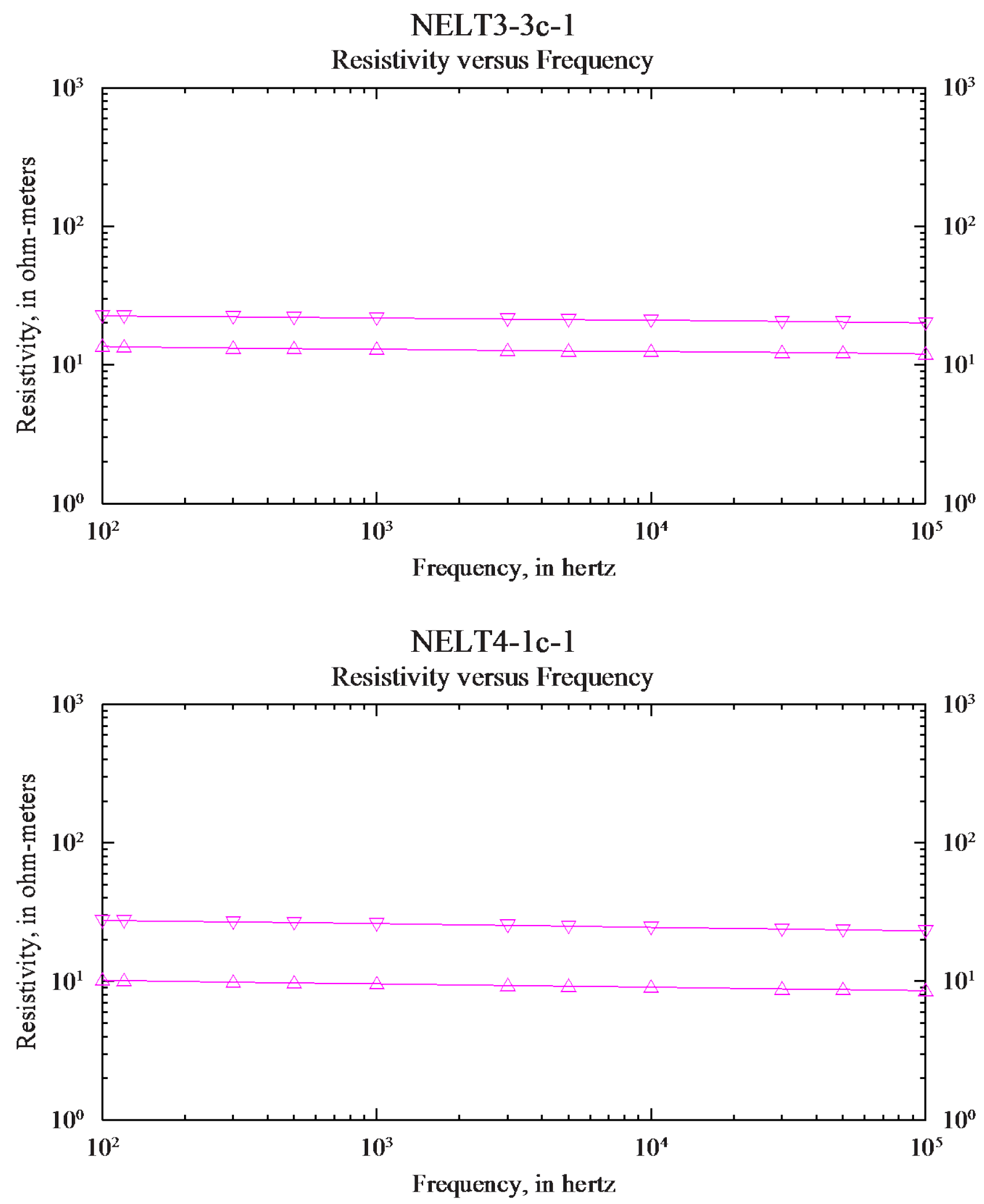

As-received measurement

$\triangle$ Datum point indicating top of core sample

$\nabla$ Datum point indicating bottom of core sample 

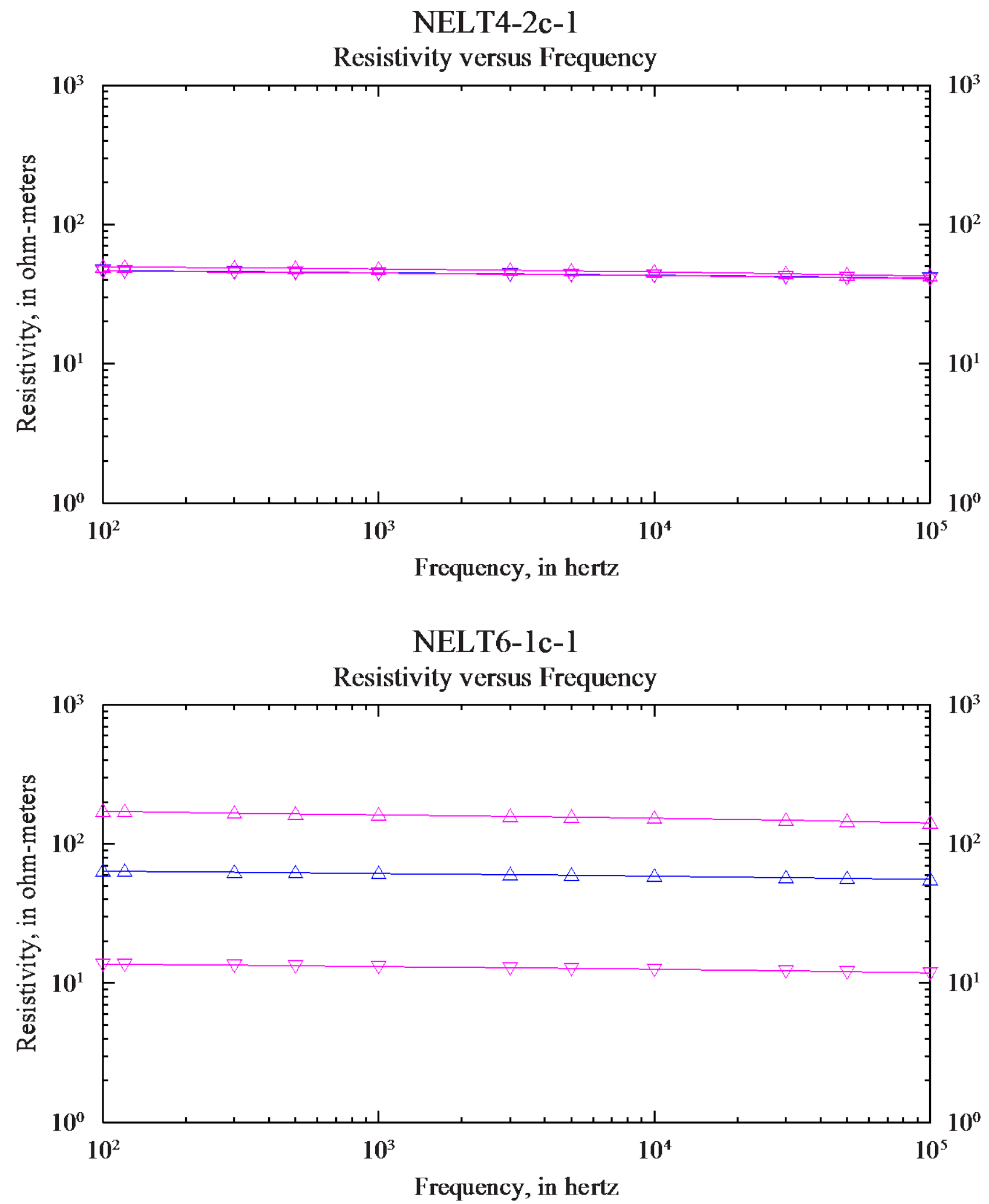

As-received measurement

Water-added measurement $\triangle$ Datum point indicating top of core sample

$\nabla$ Datum point indicating bottom of core sample 

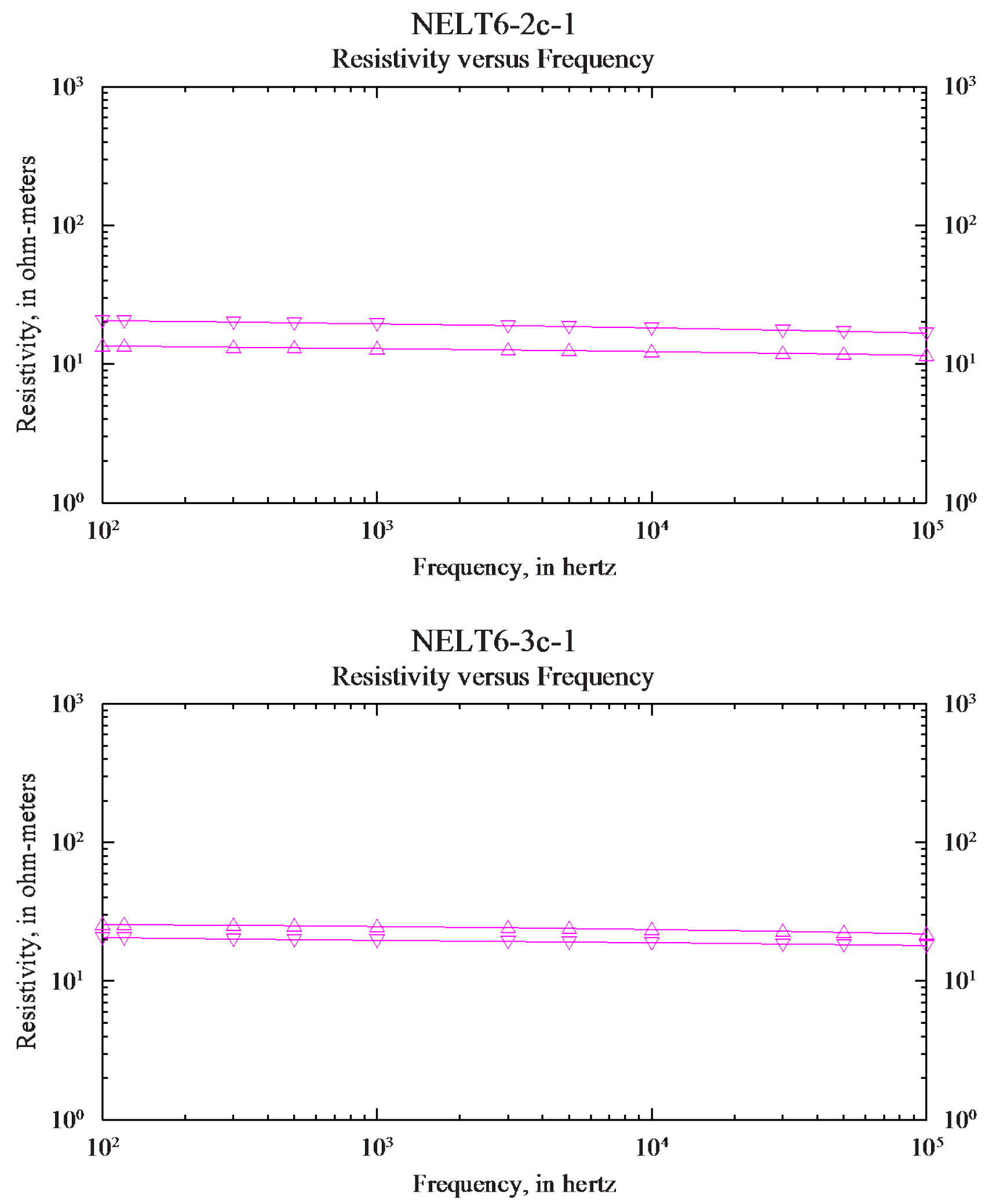

As-received measurement

$\triangle$ Datum point indicating top of core sample

$\nabla$ Datum point indicating bottom of core sample 

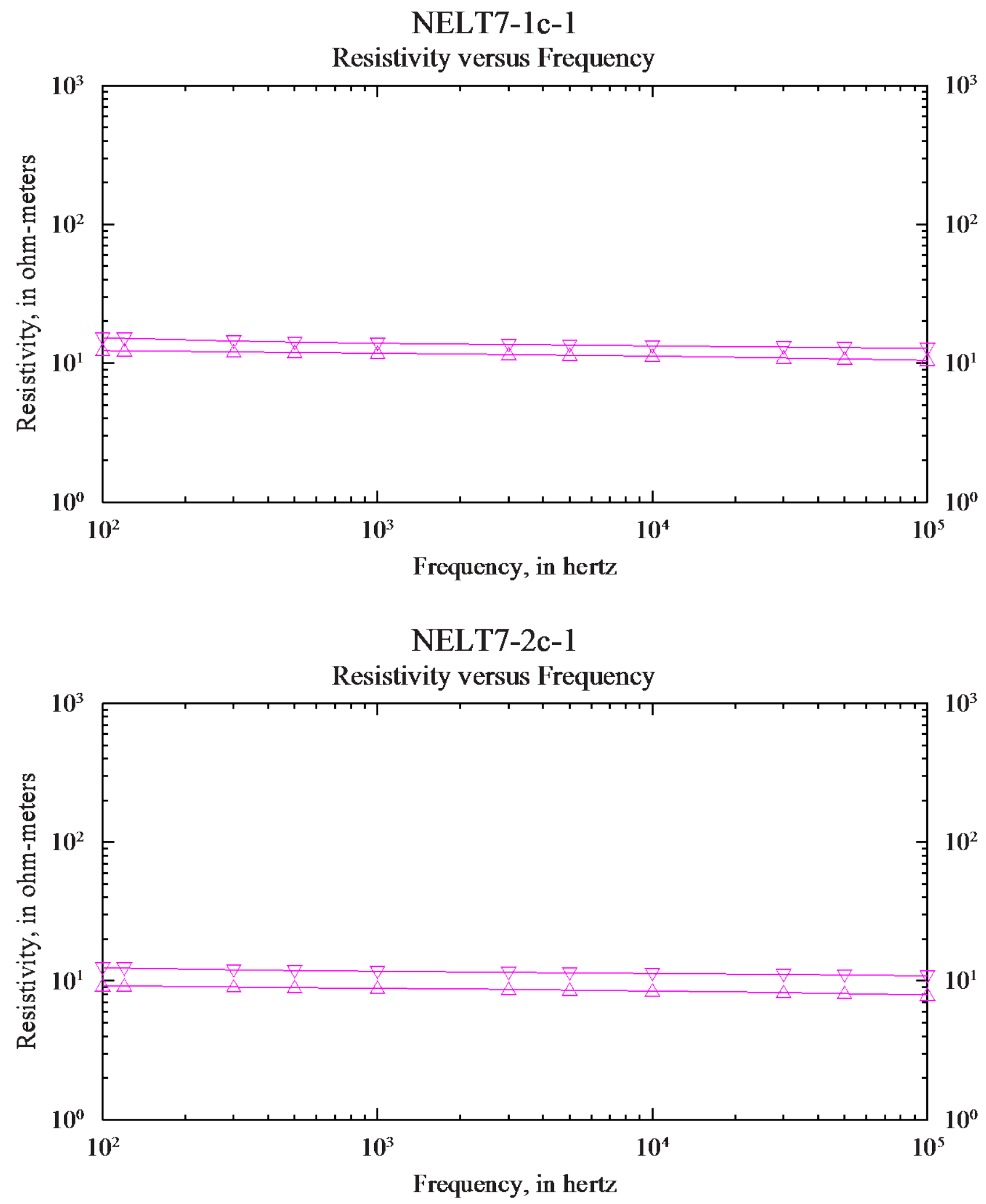

As-received measurement

$\triangle$ Datum point indicating top of core sample

$\nabla$ Datum point indicating bottom of core sample 


\section{Appendix C. Surface Rock Resistivity Versus Frequency}

Figures, one per sample, showing sample resistivity, in ohm-meters, versus frequency, in hertz. Each curve represents a different degree of saturation. 

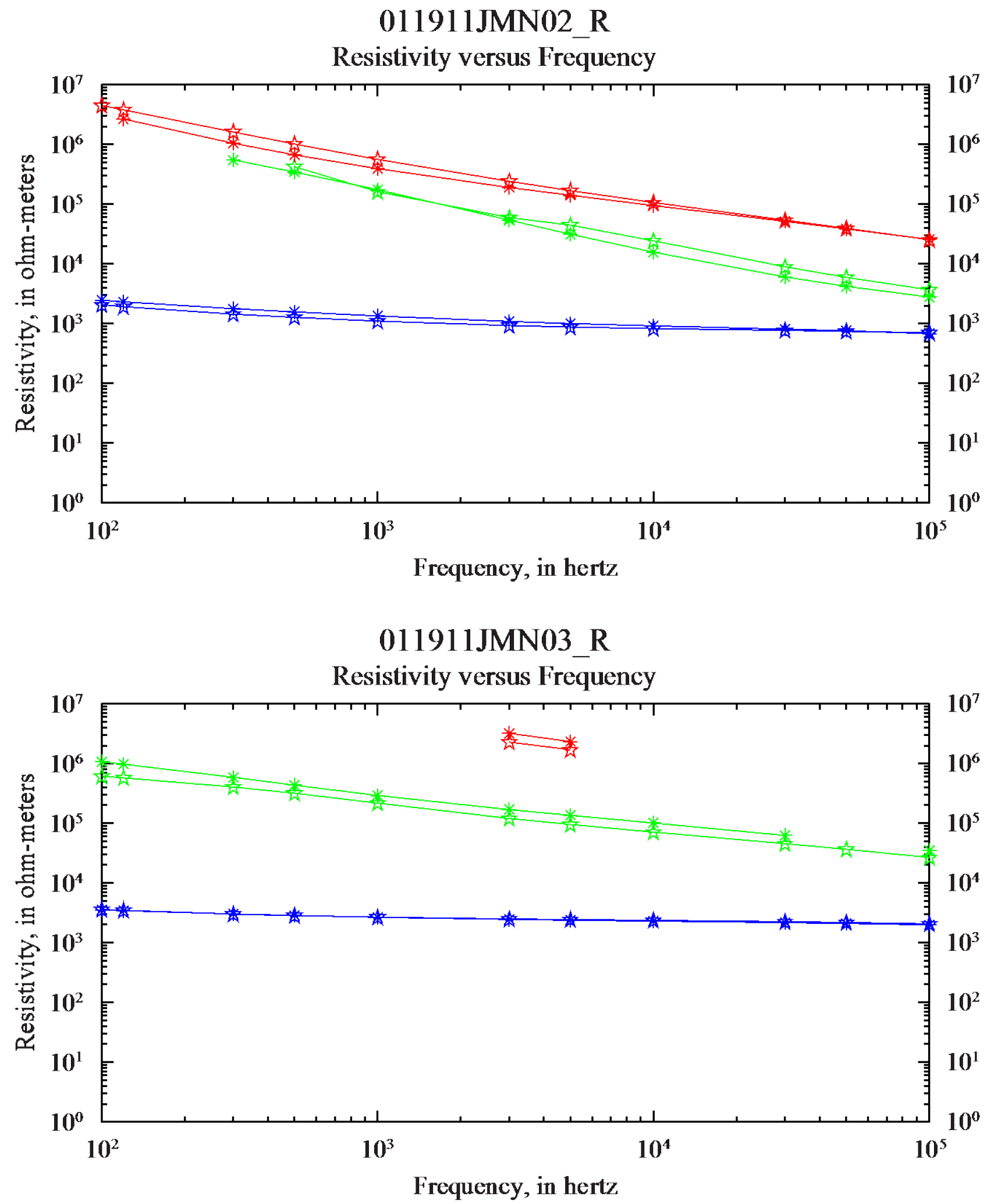

Dry measurement

Humid measurement

* Datum point indicating first sample

is Datum point indicating second sample

- Submerged measurement 

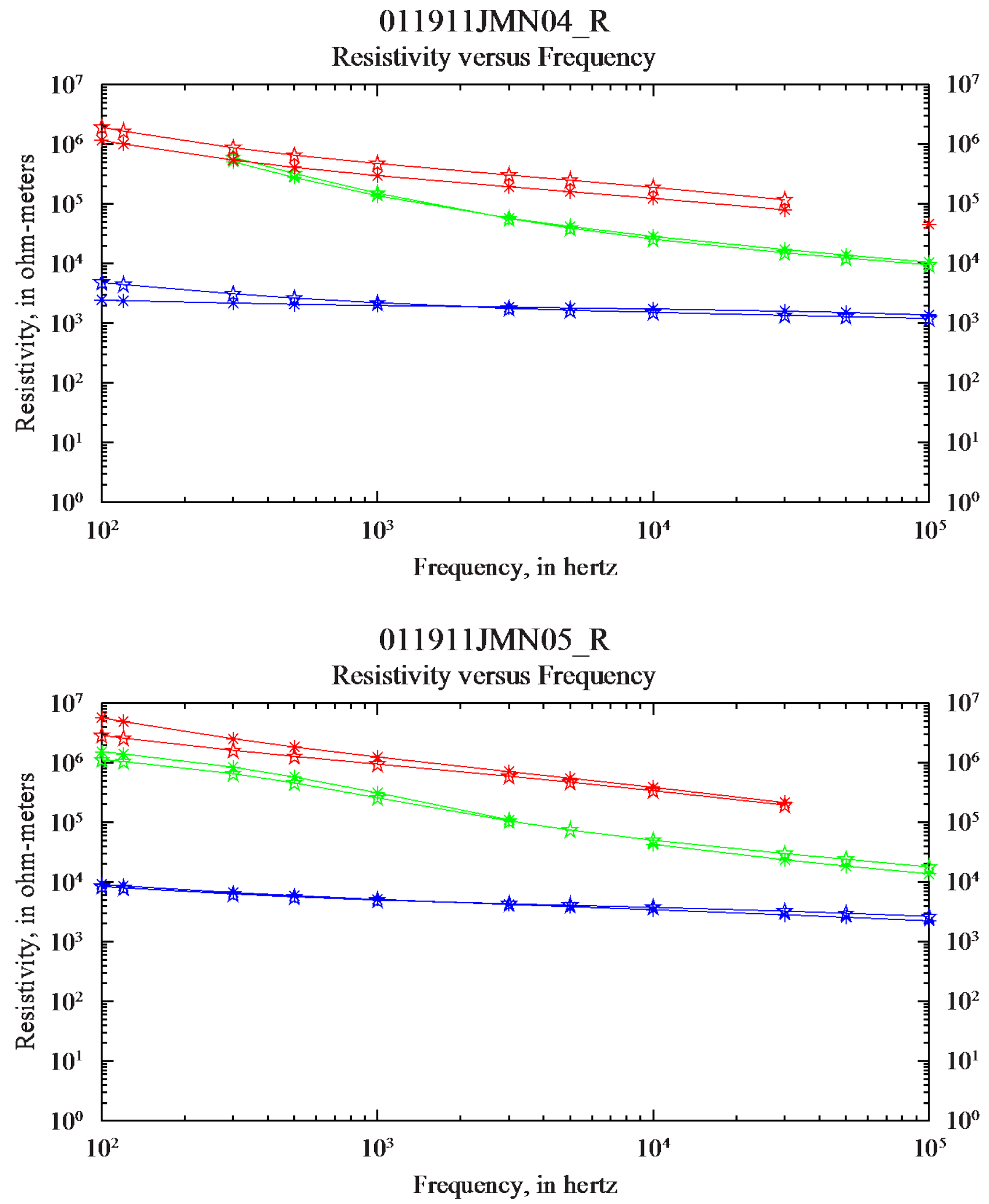

Dry measurement

Humid measurement

* Datum point indicating first sample

is Datum point indicating second sample

- Submerged measurement 

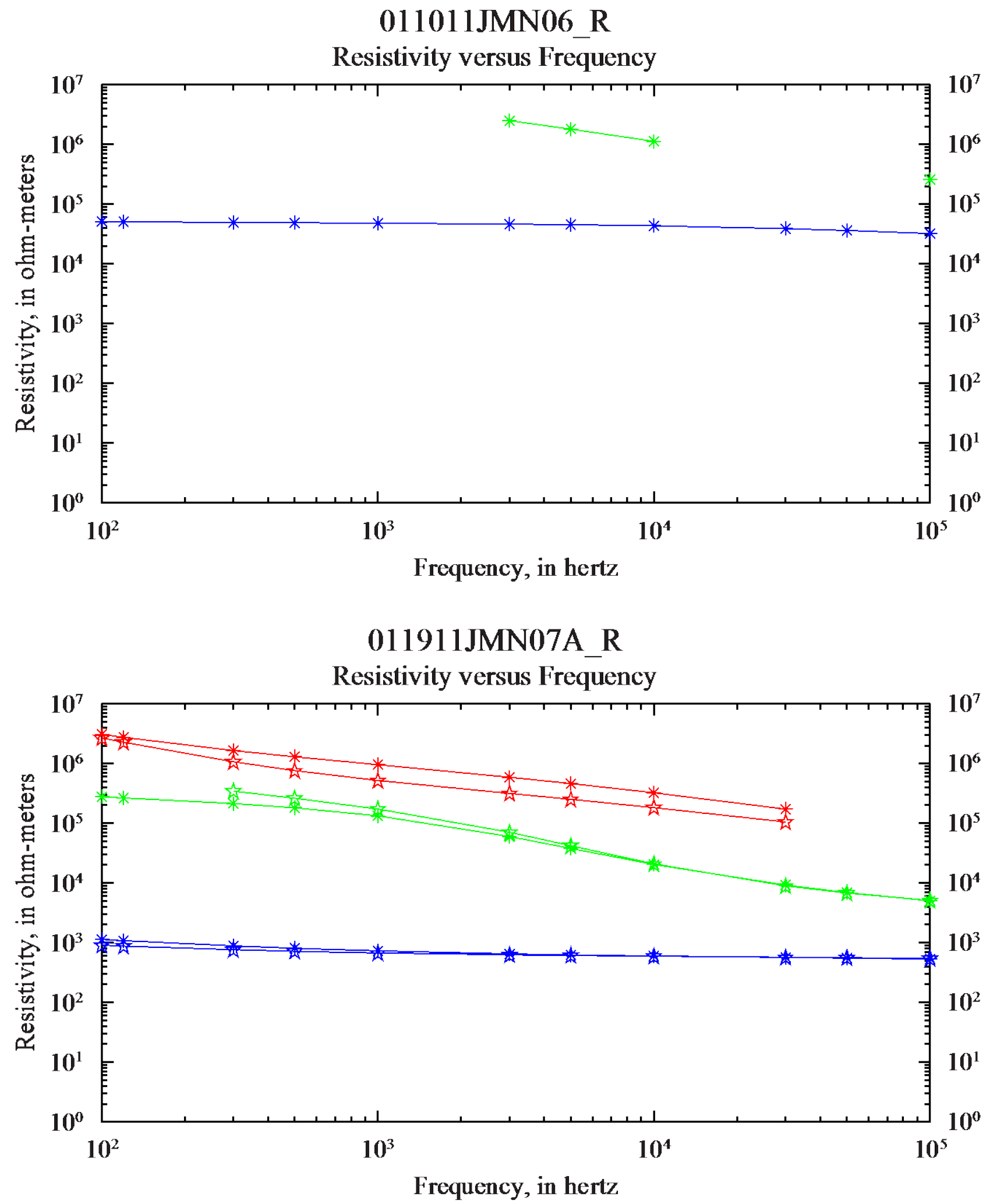

Dry measurement

Humid measurement

* Datum point indicating first sample

is Datum point indicating second sample

- Submerged measurement 

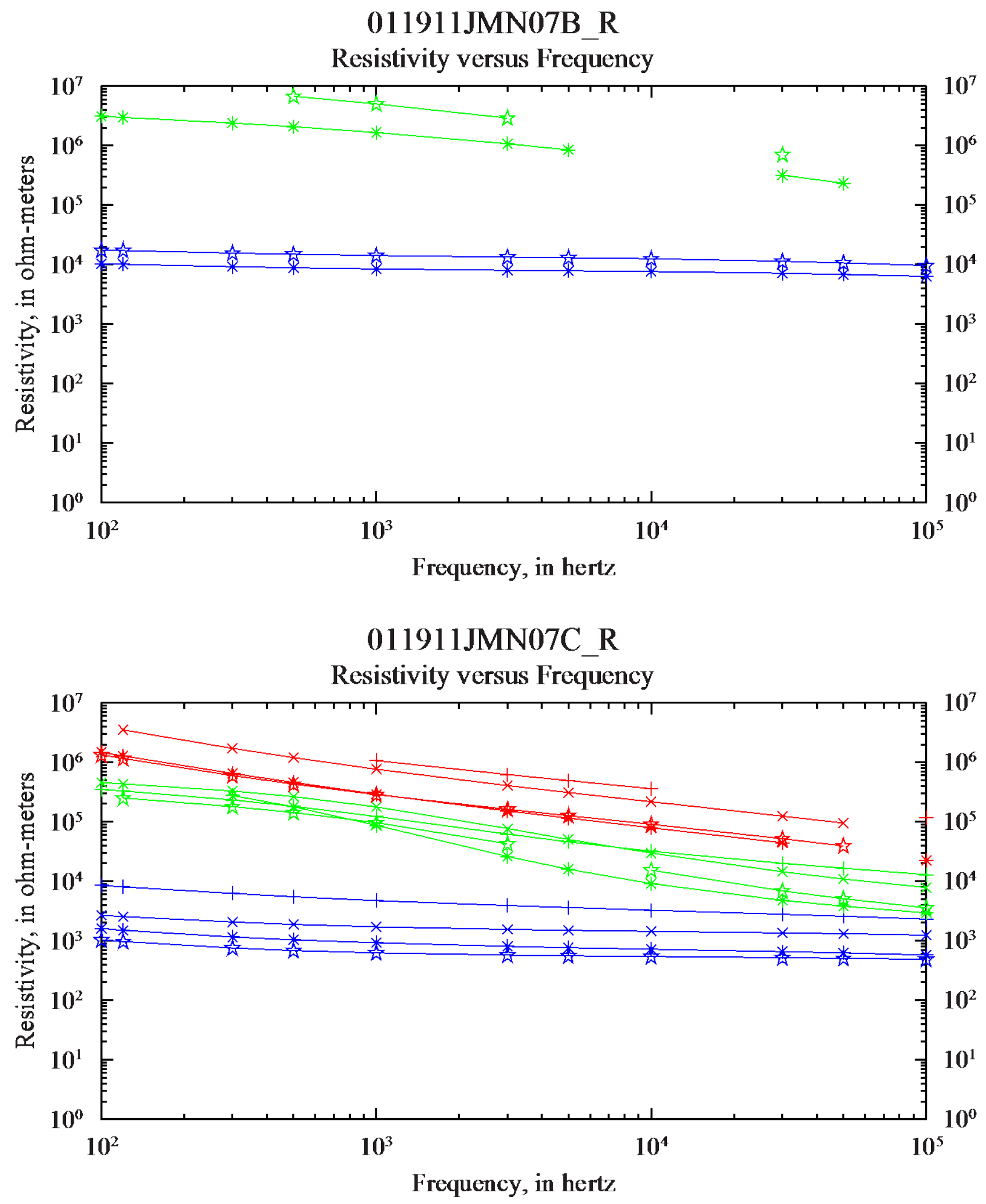

Dry measurement

Humid measurement

Submerged measurement
* Datum point indicating first sample

is Datum point indicating second sample

$\times$ Datum point indicating third sample

+ Datum point indicating fourth sample 

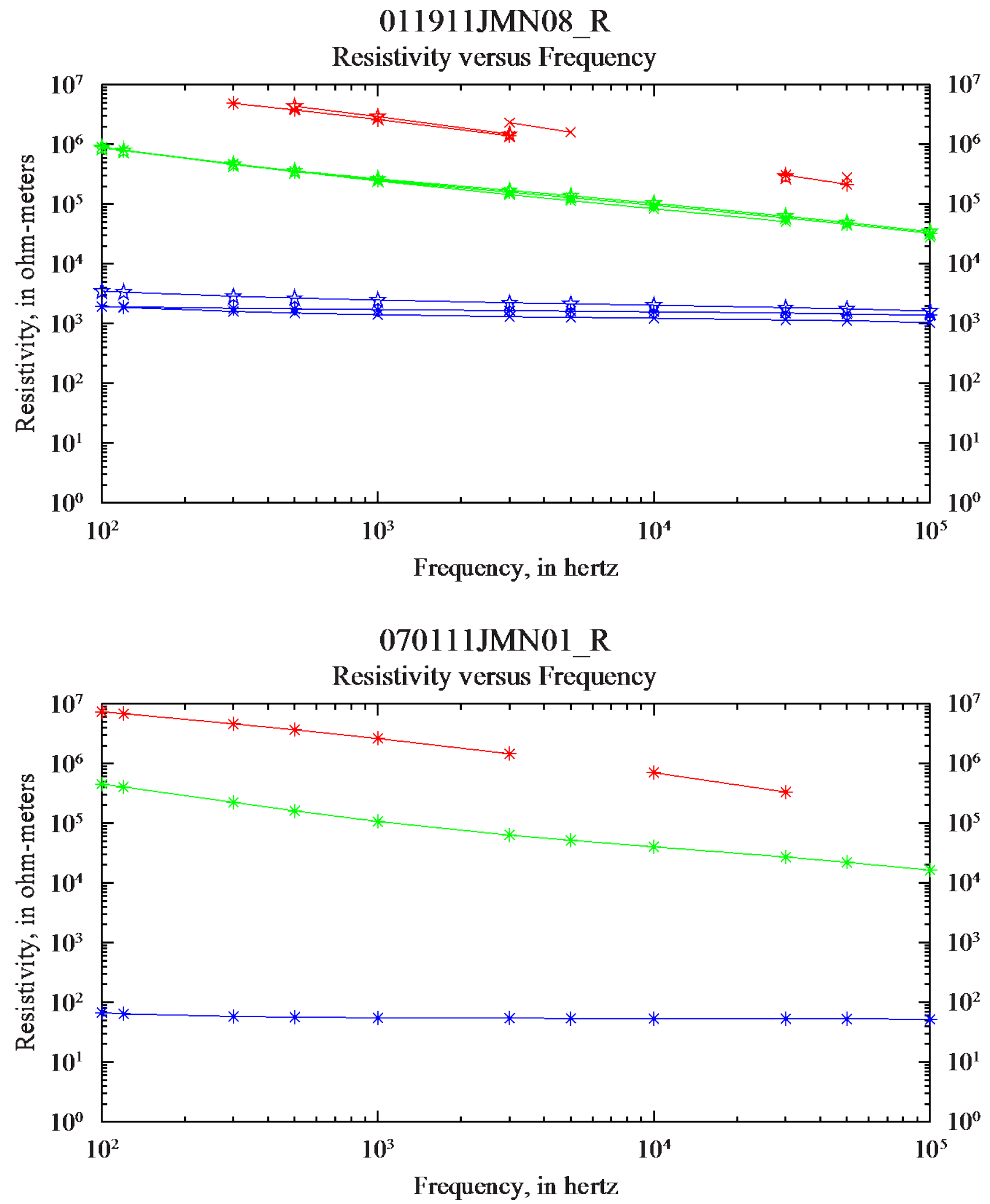

Dry measurement

Humid measurement

Submerged measurement
* Datum point indicating first sample

is Datum point indicating second sample

$\times$ Datum point indicating third sample 

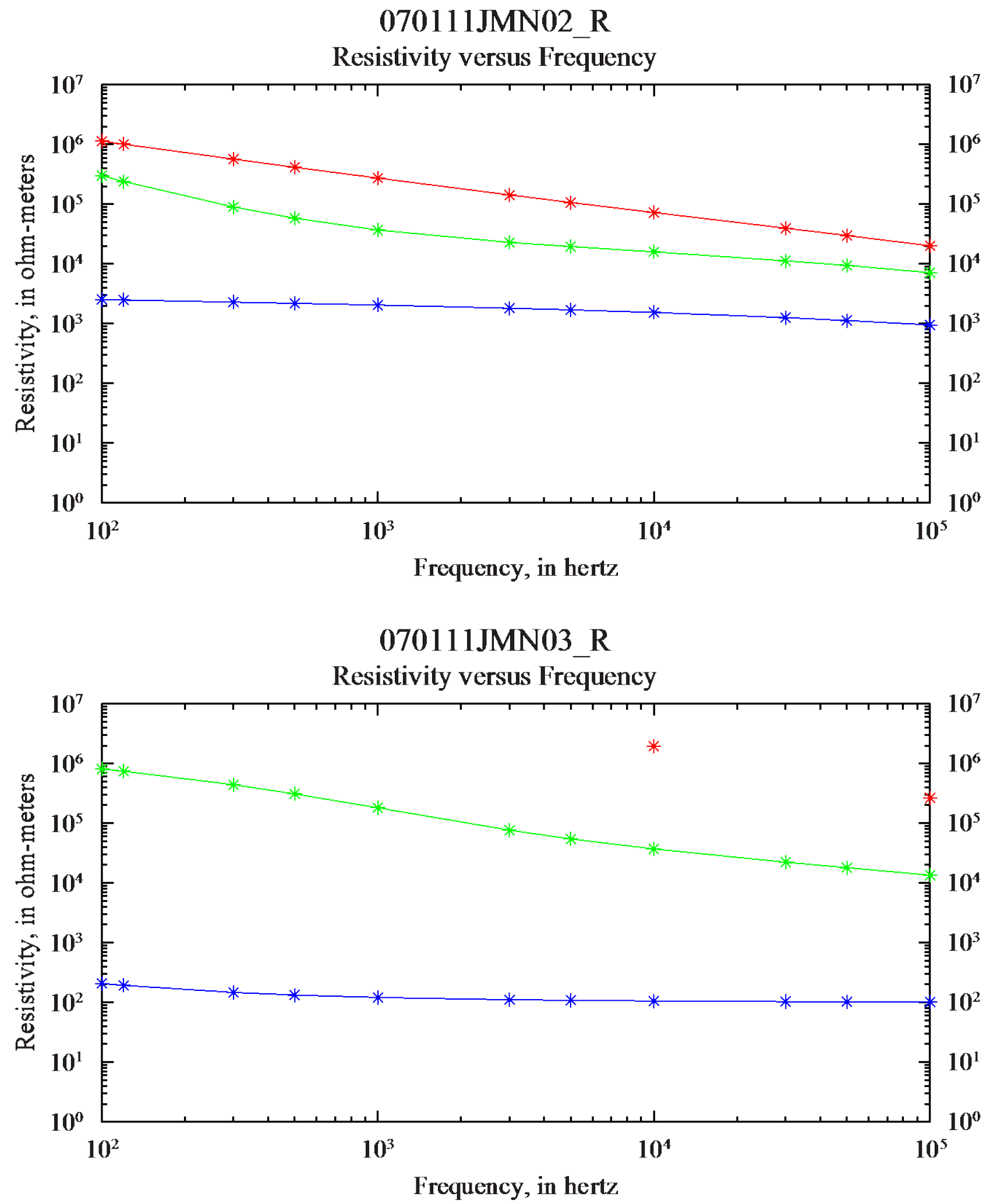

Dry measurement

* Datum point indicating first sample

Humid measurement

- Submerged measurement 

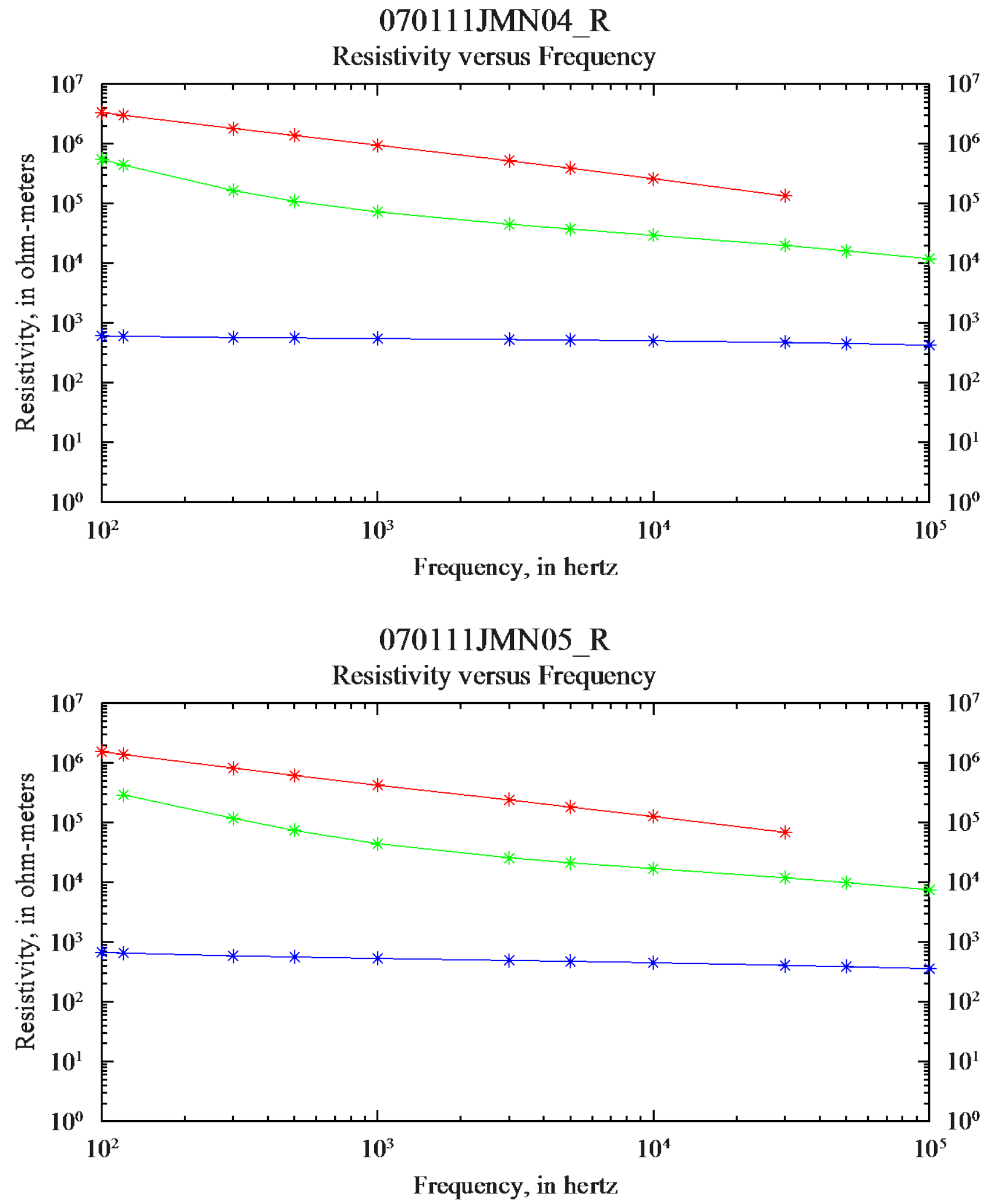

Dry measurement

* Datum point indicating first sample

Humid measurement

- Submerged measurement 

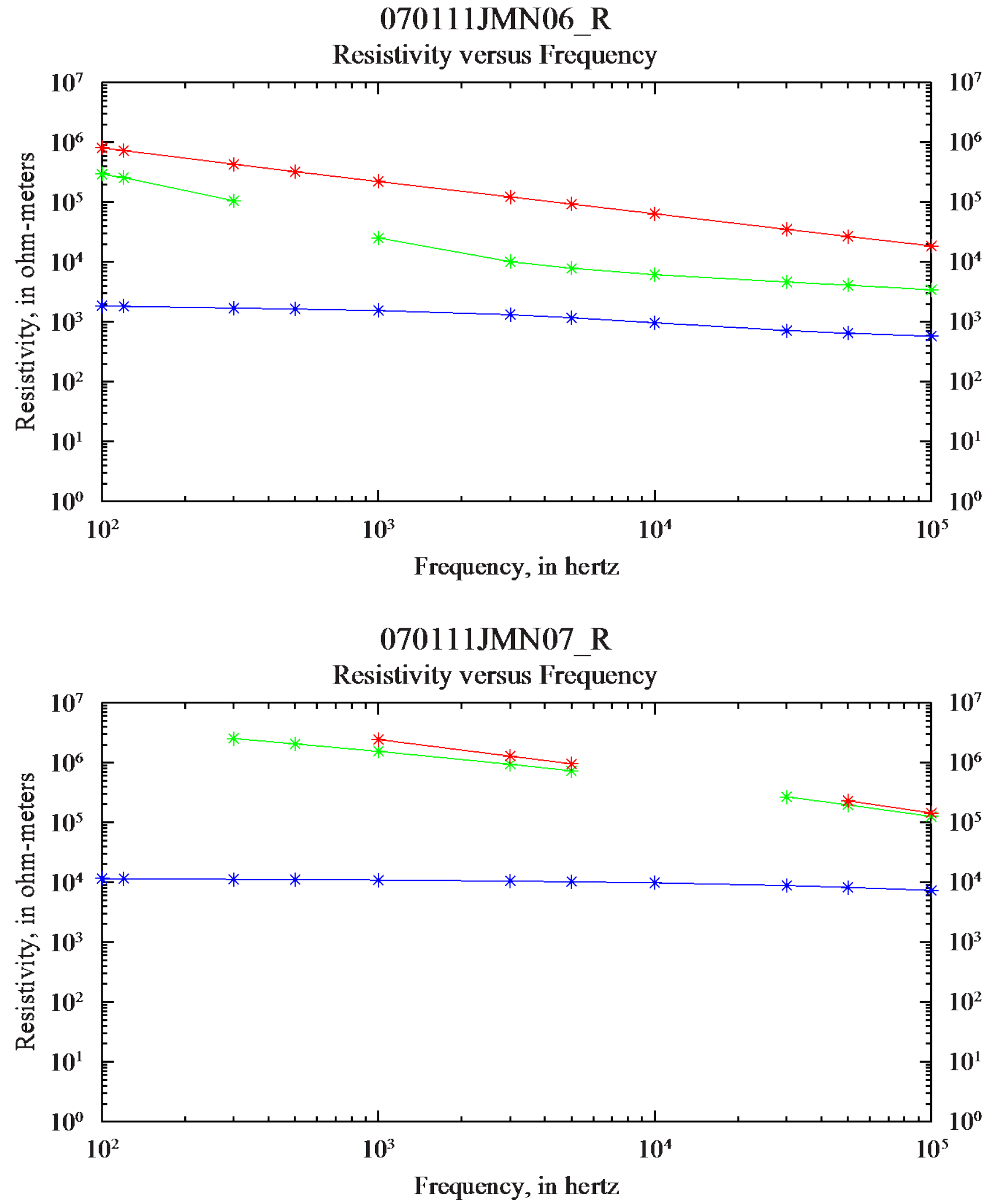

Dry measurement

* Datum point indicating first sample

Humid measurement

- Submerged measurement 

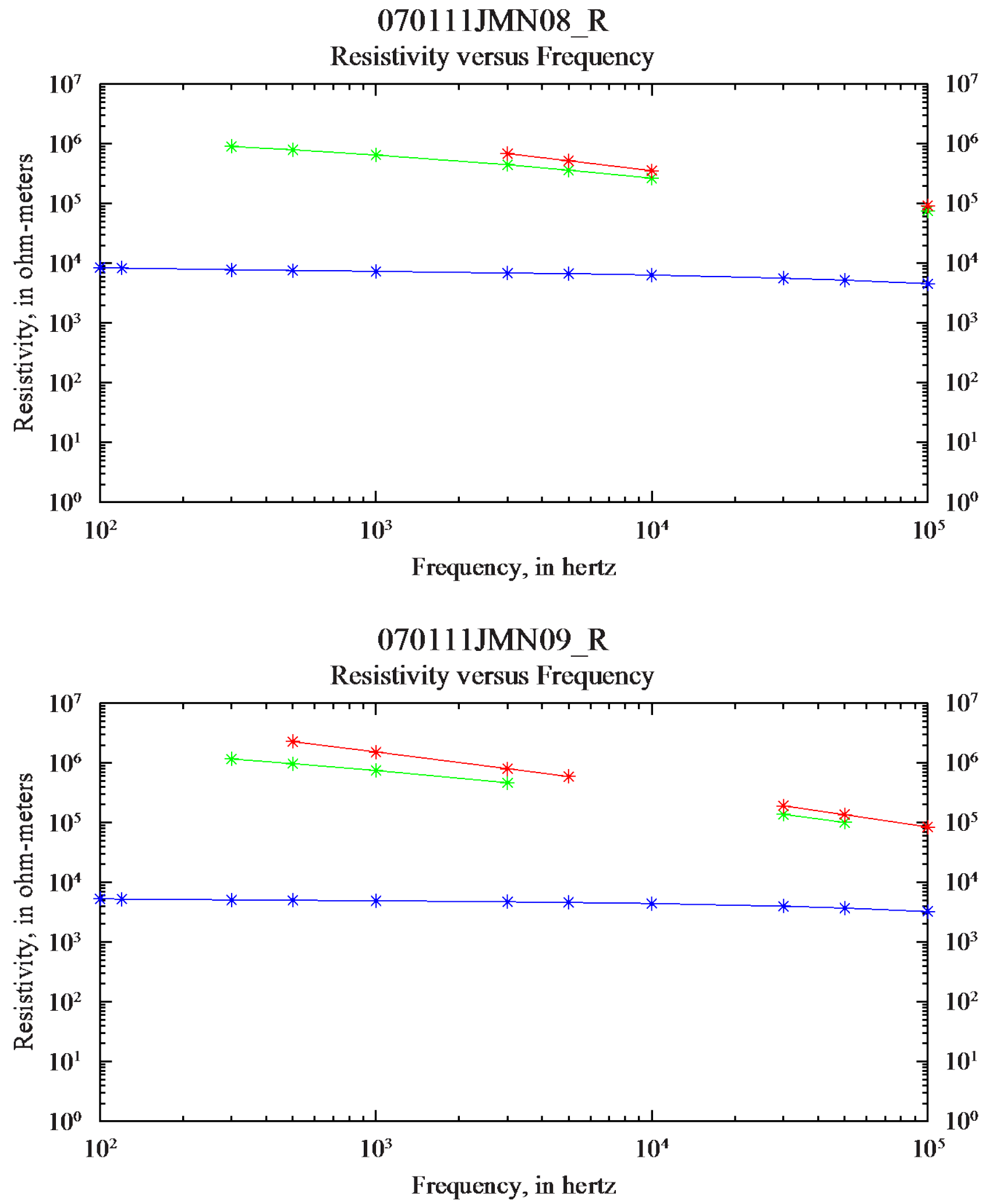

Dry measurement

* Datum point indicating first sample

Humid measurement

- Submerged measurement 

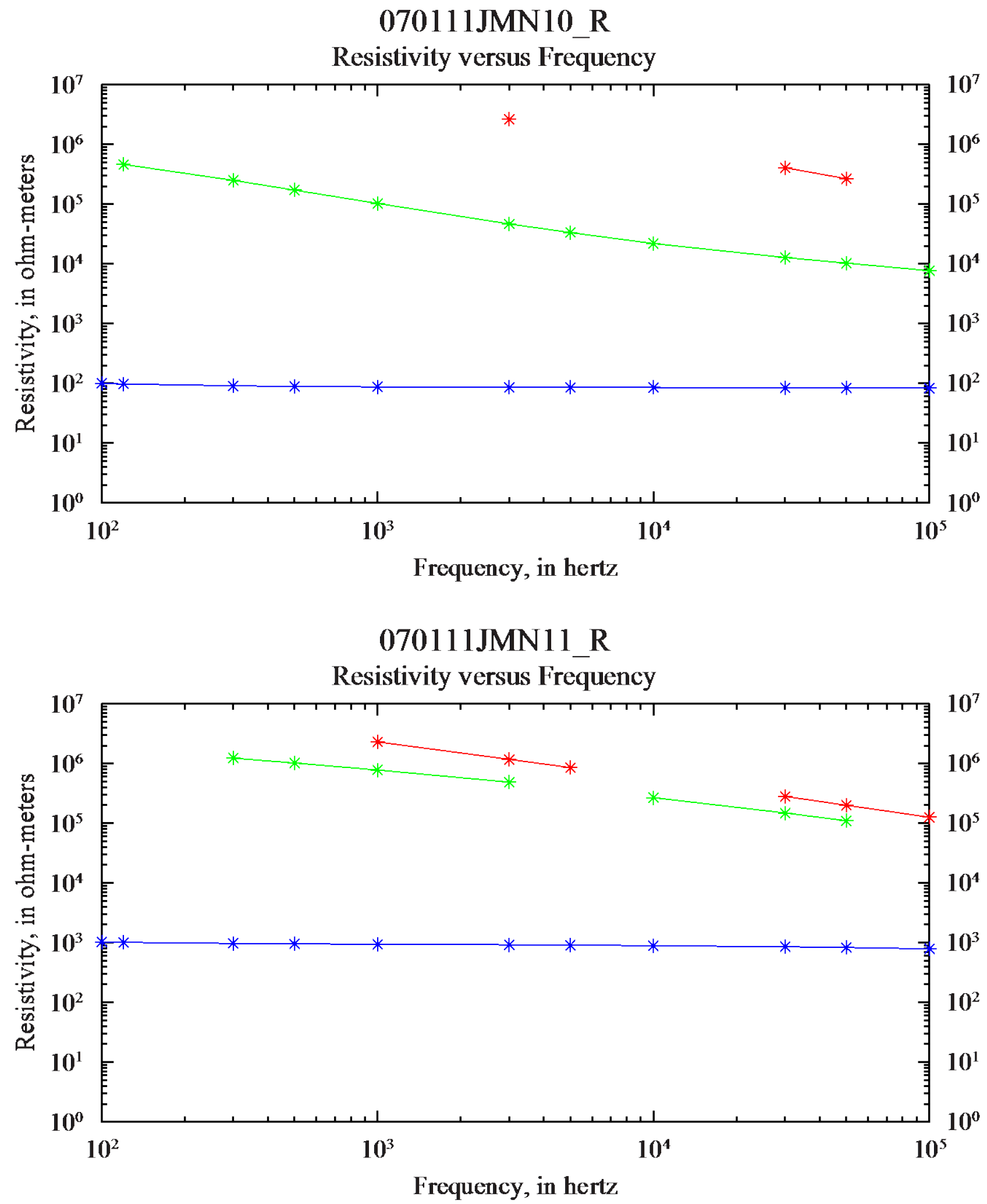

Dry measurement

* Datum point indicating first sample

Humid measurement

- Submerged measurement 

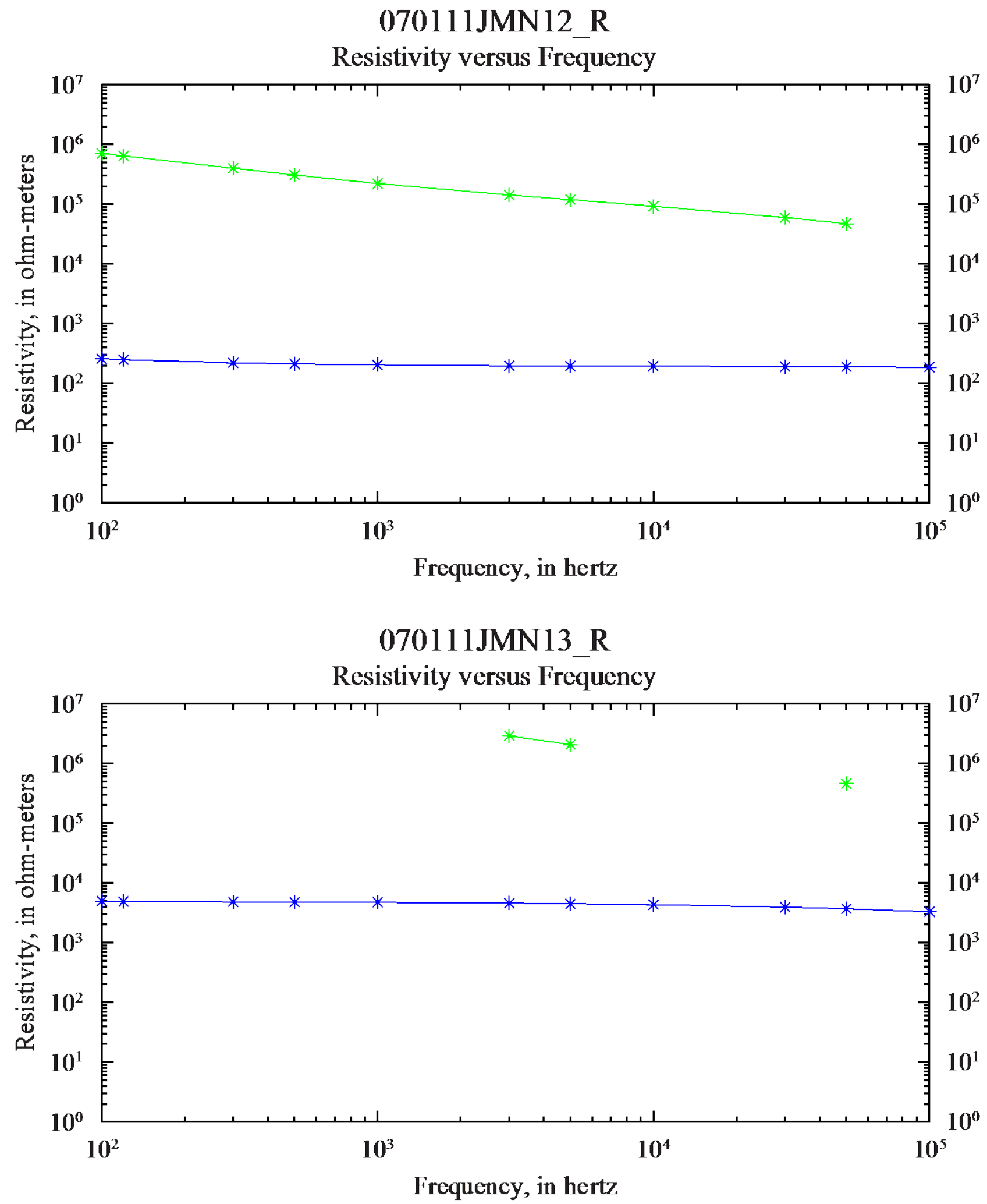

* Datum point indicating first sample

Humid measurement

Submerged measurement 

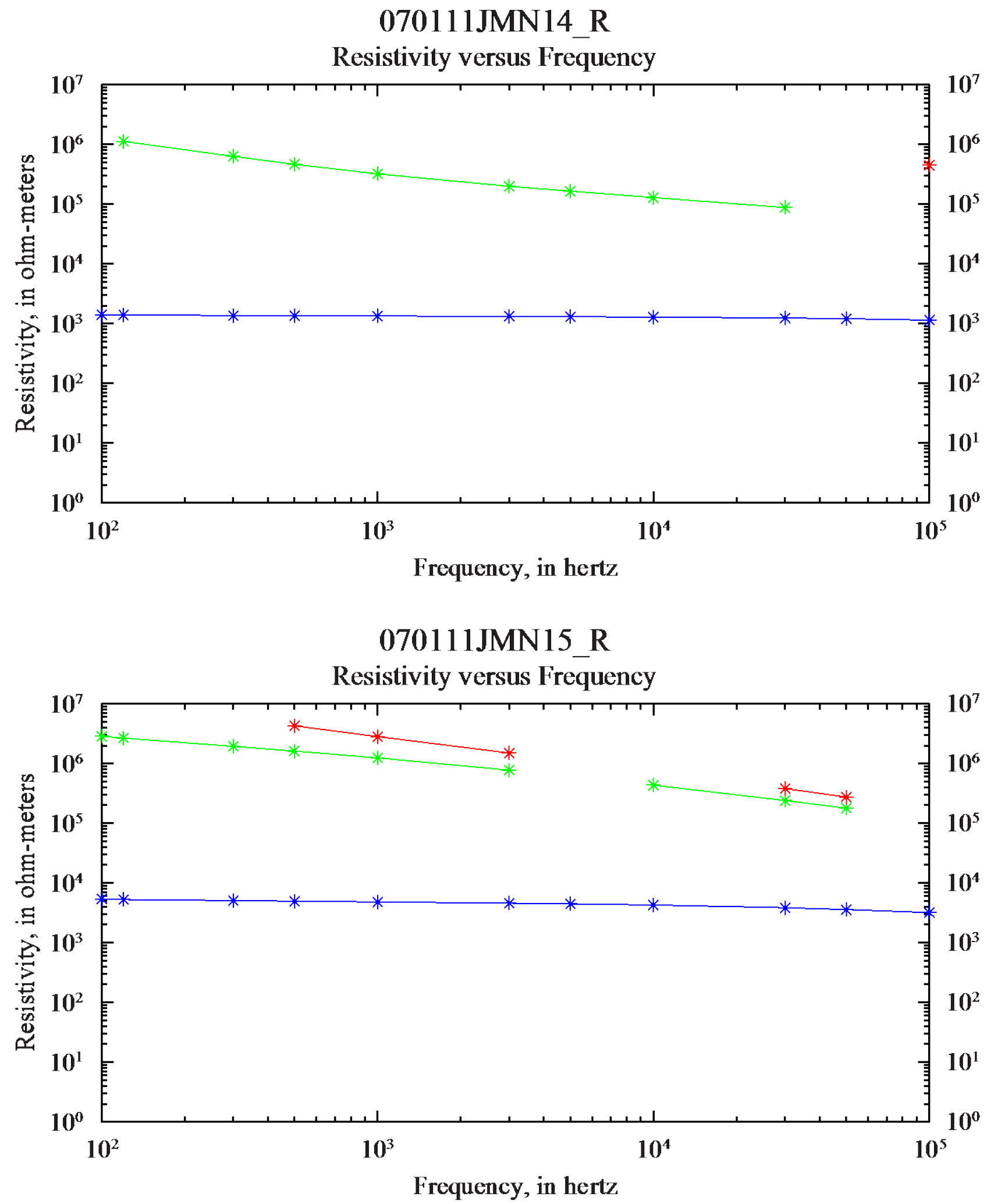

Dry measurement

* Datum point indicating first sample

Humid measurement

- Submerged measurement 

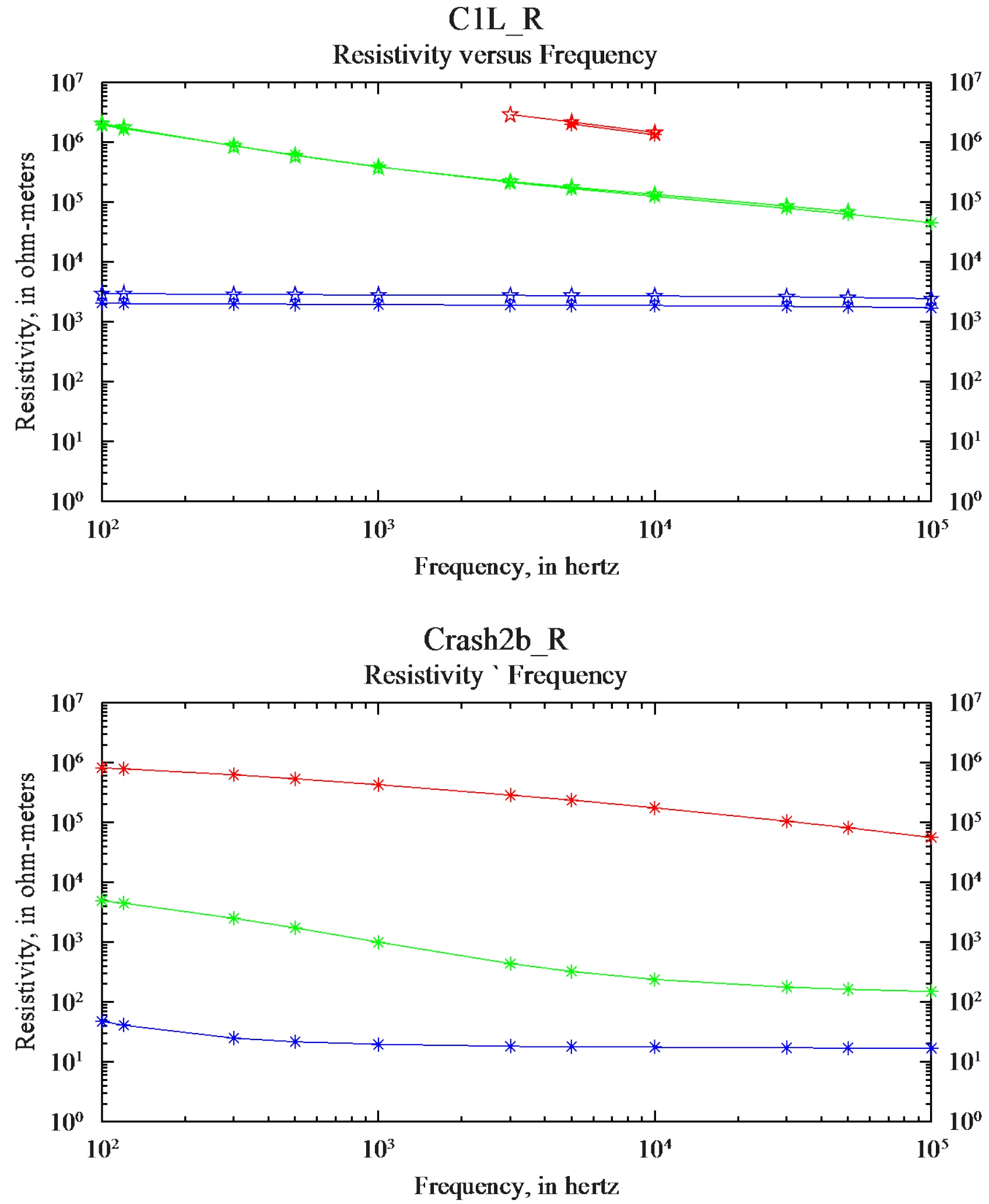

Dry measurement

Humid measurement

* Datum point indicating first sample

is Datum point indicating second sample

- Submerged measurement 

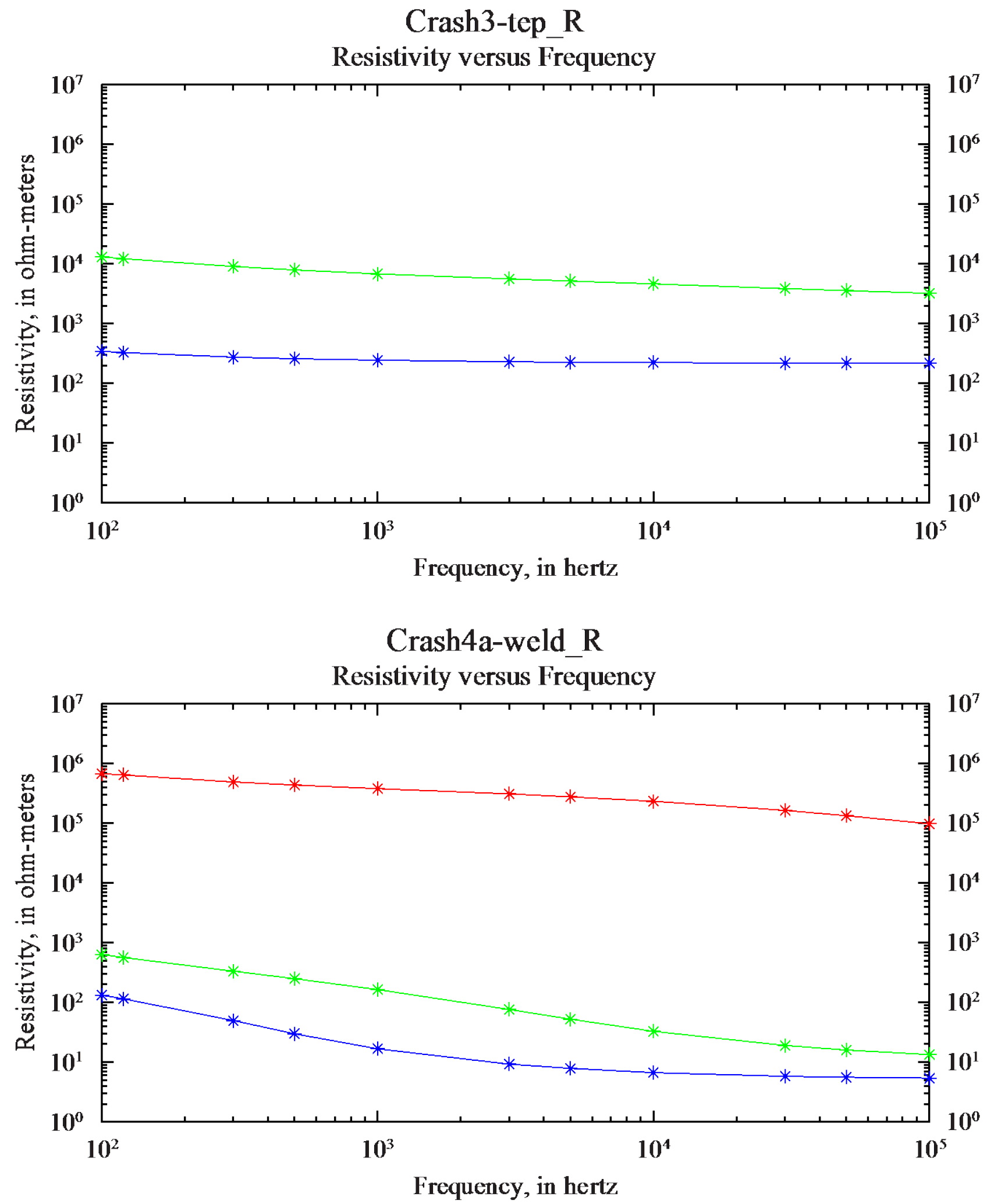

Dry measurement

* Datum point indicating first sample

Humid measurement

- Submerged measurement 

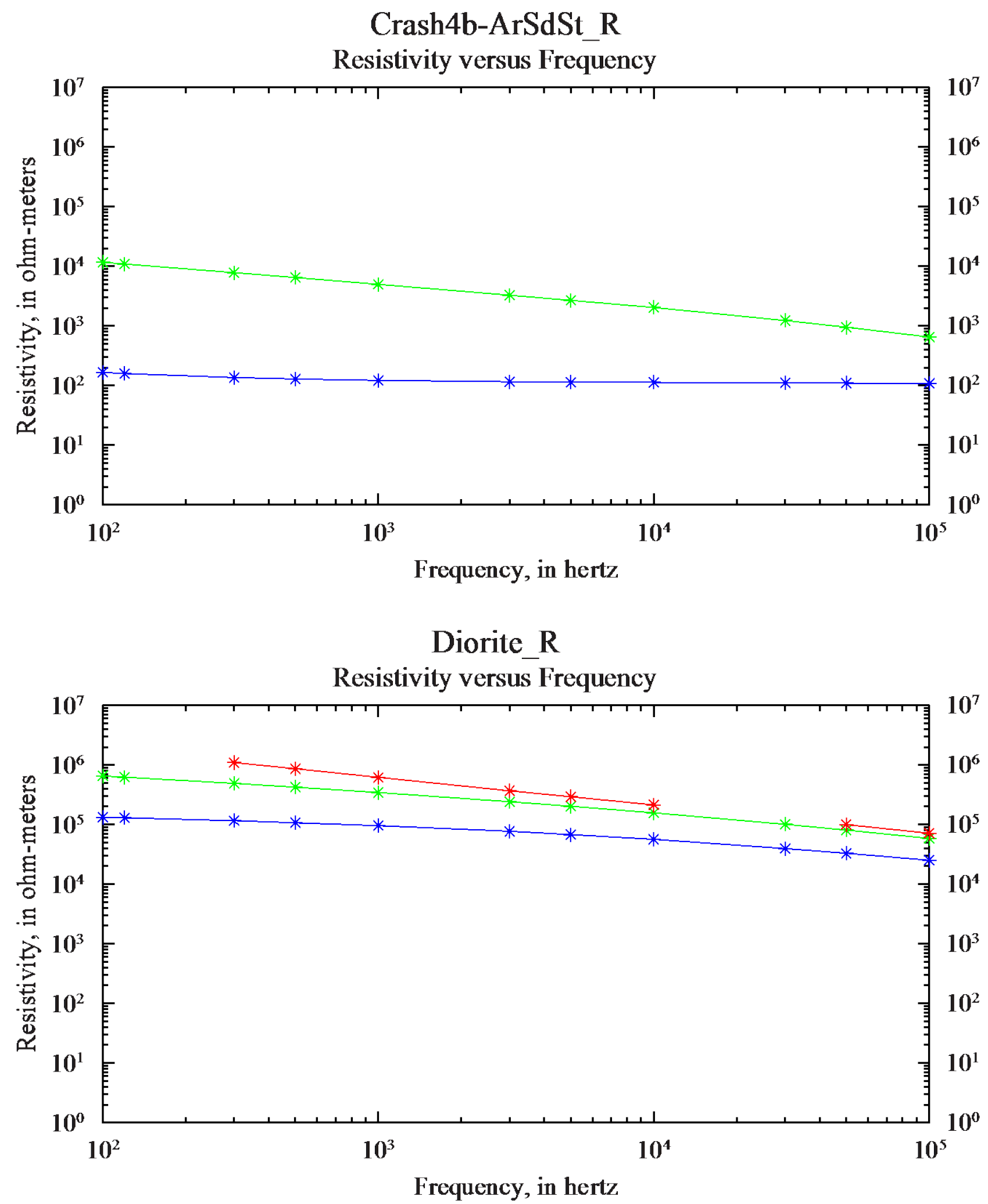

Dry measurement

* Datum point indicating first sample

Humid measurement

- Submerged measurement 

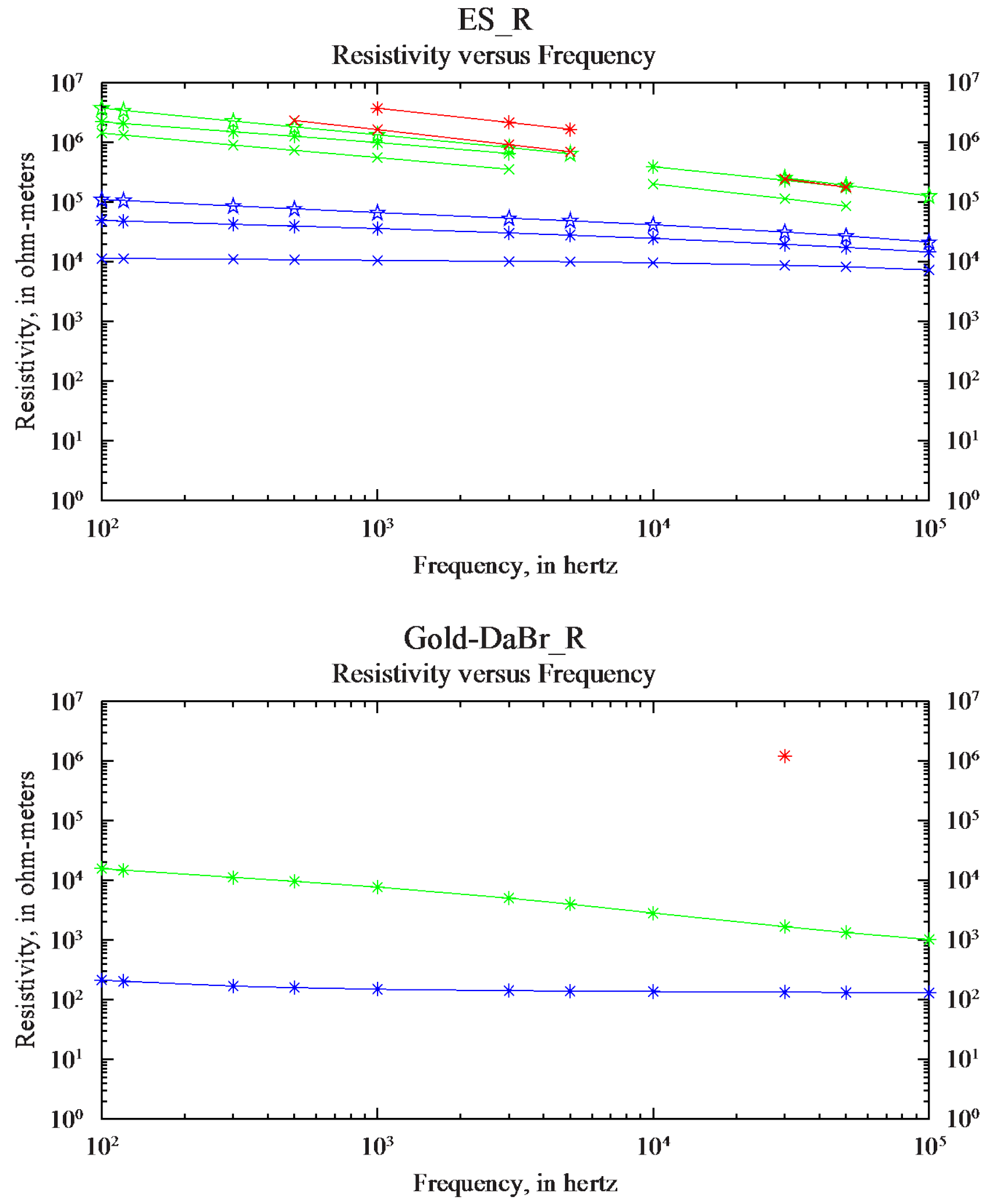

Dry measurement

Humid measurement

- Submerged measurement
* Datum point indicating first sample

Datum point indicating second sample

$\times$ Datum point indicating third sample 

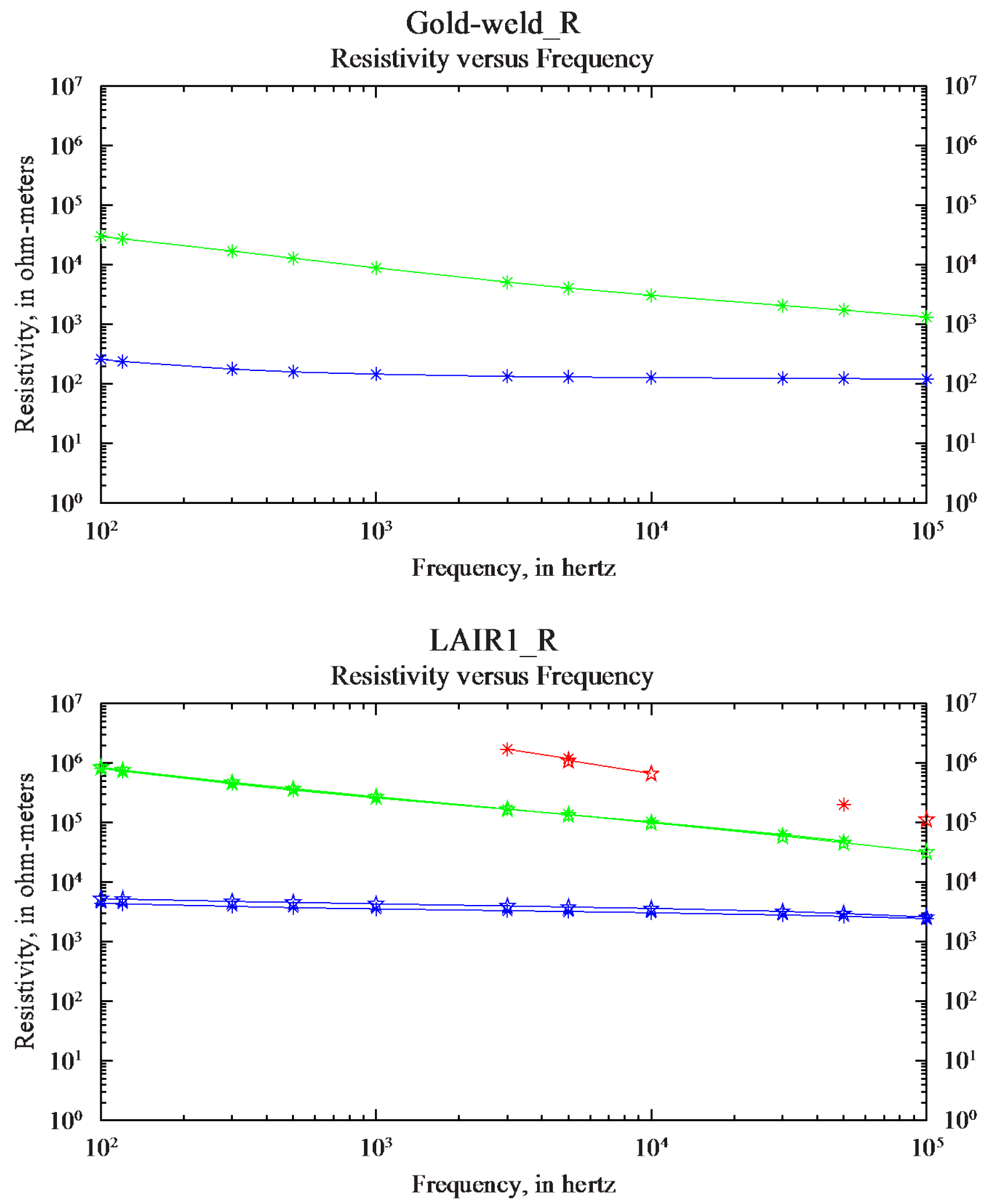

Dry measurement

Humid measurement

* Datum point indicating first sample

is Datum point indicating second sample

- Submerged measurement 

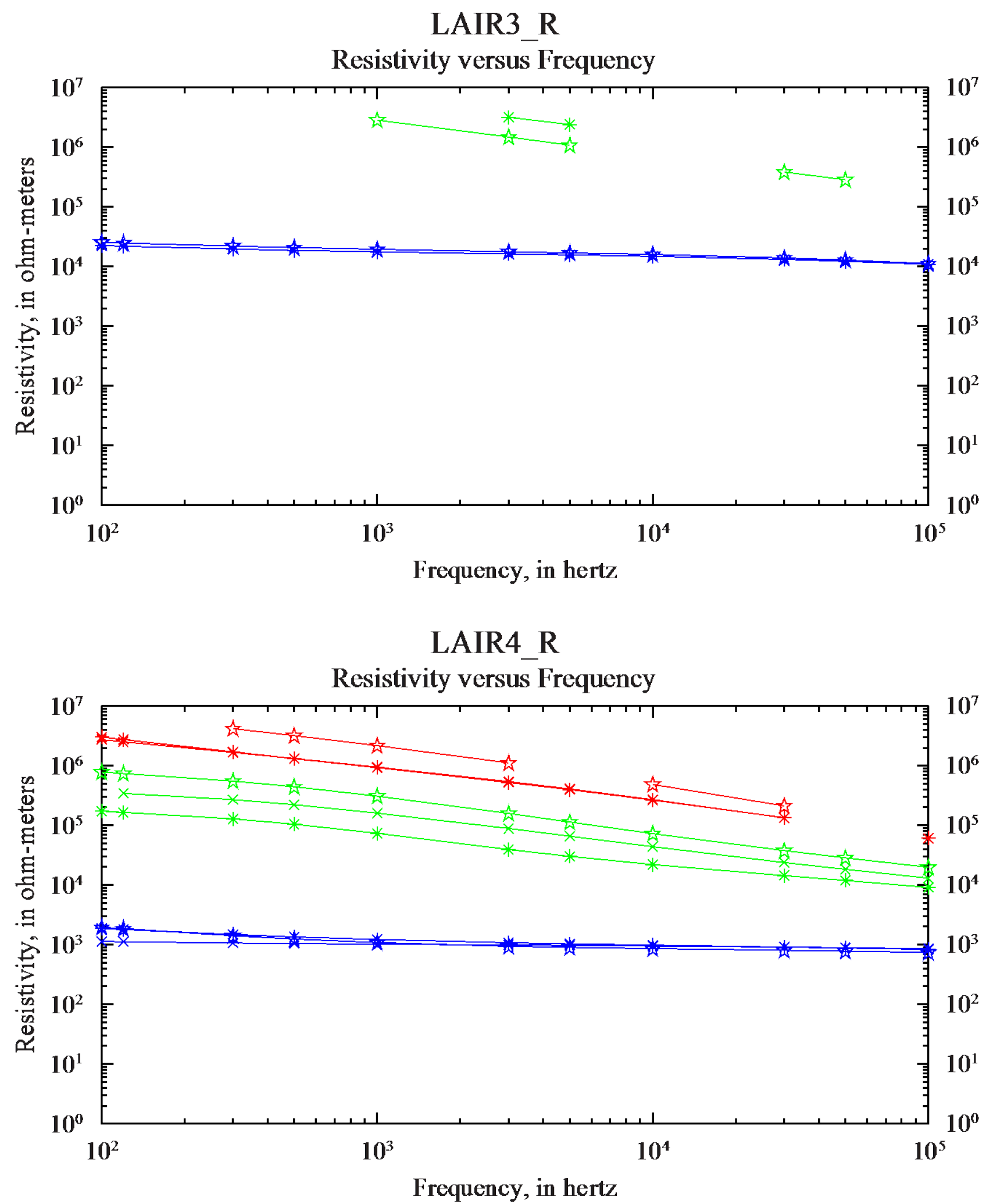

Dry measurement

Humid measurement

- Submerged measurement
* Datum point indicating first sample

is Datum point indicating second sample

$\times$ Datum point indicating third sample 

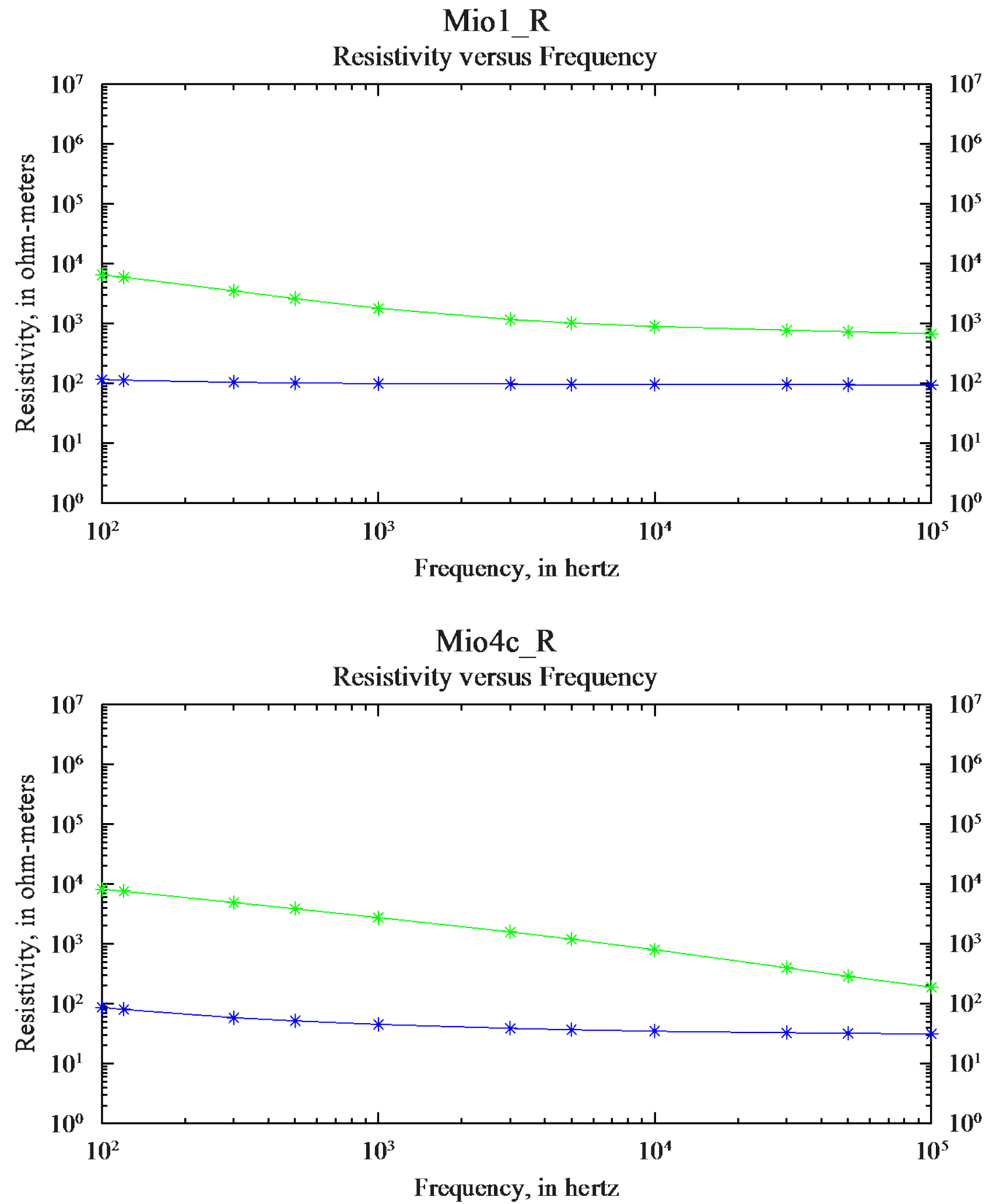

* Datum point indicating first sample

Humid measurement

Submerged measurement 

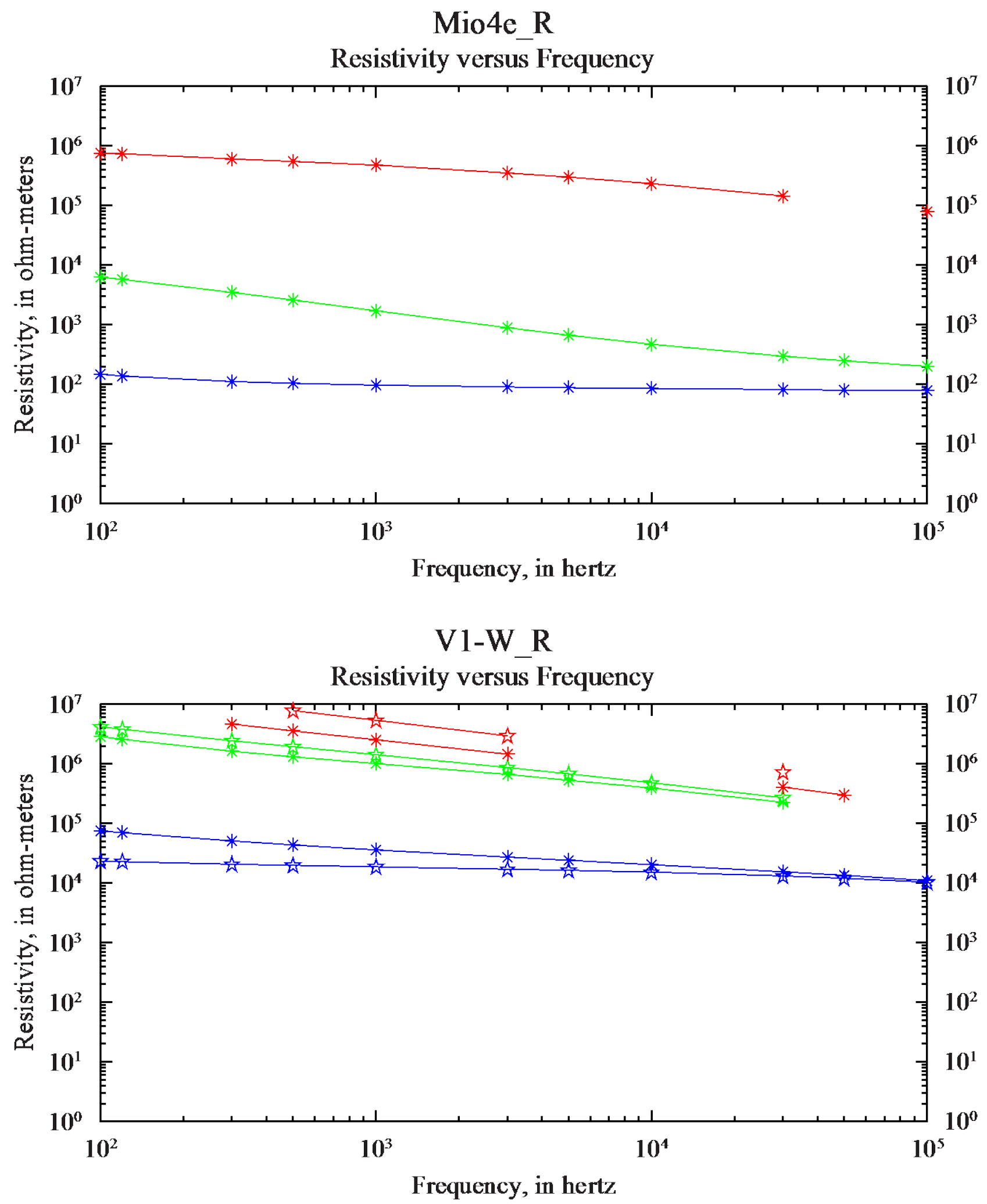

Dry measurement

Humid measurement

* Datum point indicating first sample

is Datum point indicating second sample

- Submerged measurement 


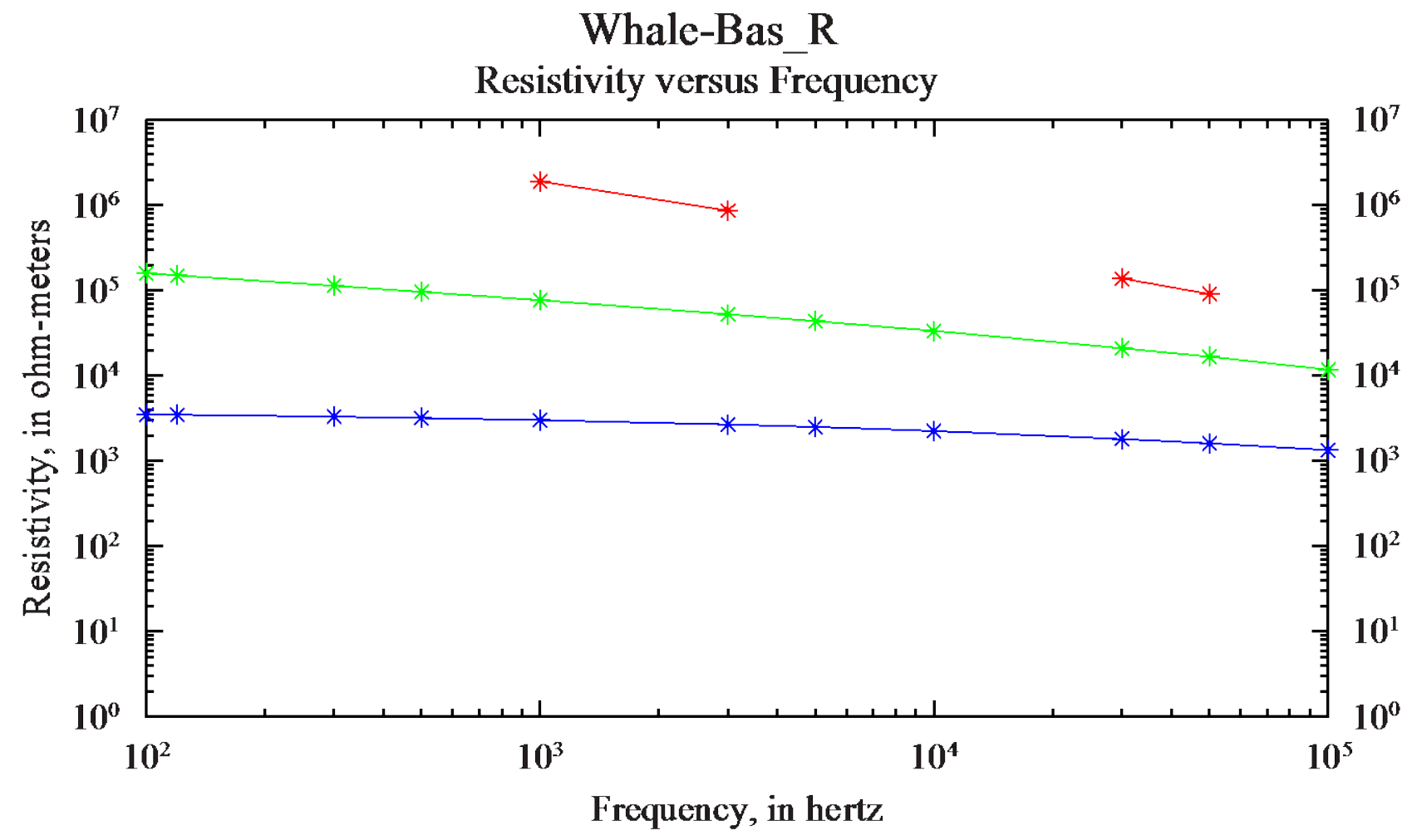

Dry measurement

* Datum point indicating first sample

Humid measurement

- Submerged measurement 


\section{Appendix D. Surface Sediment Resistivity Versus Frequency}

Figures, one per sample, showing sample resistivity, in ohm-meters, versus frequency, in hertz. Each curve represents a different degree of saturation. 

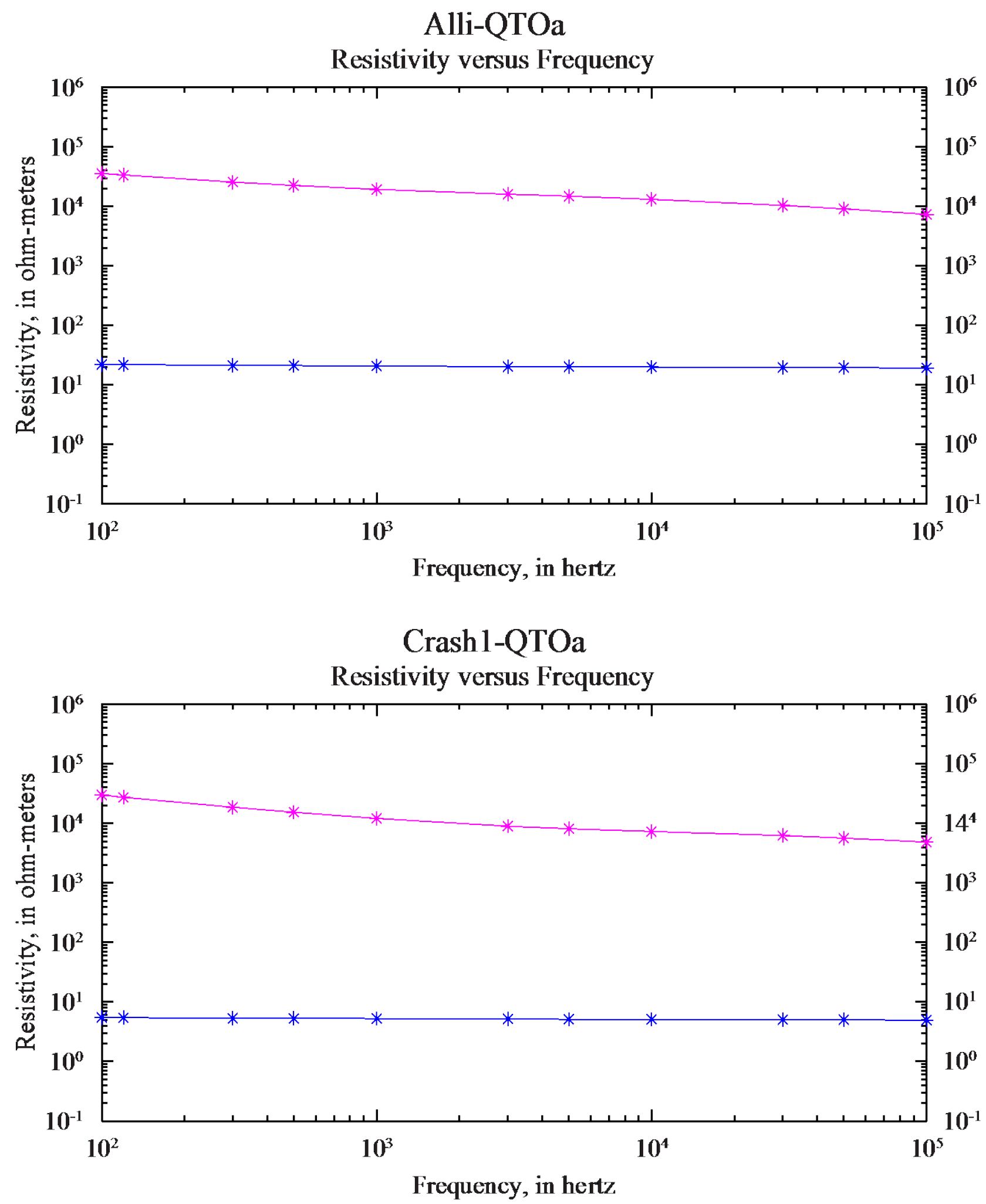

As-received measurement

- Water-added measurement

* Datum point 


\section{Crash2a}

Resistivity versus Frequency

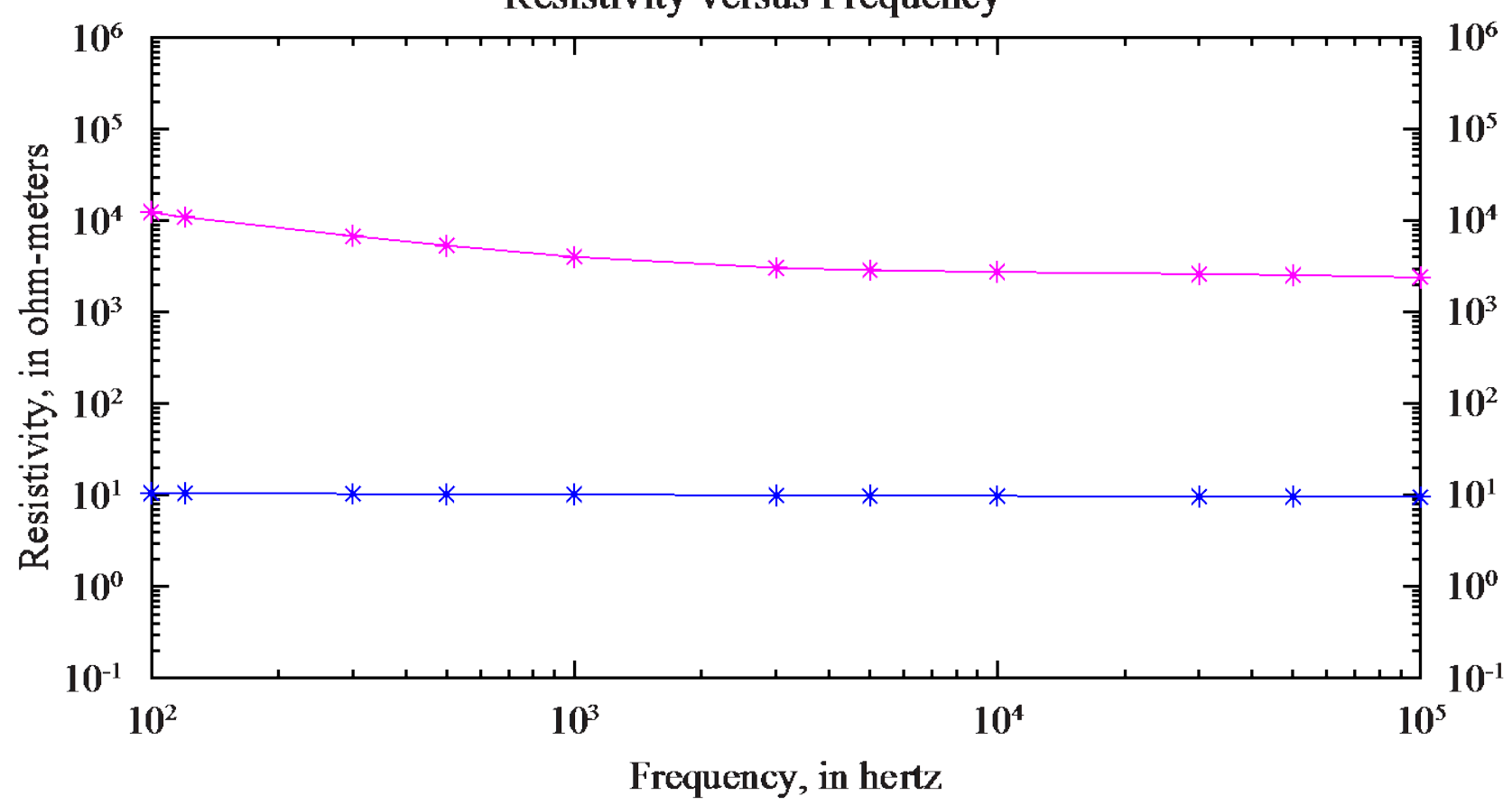

Crash3-tep

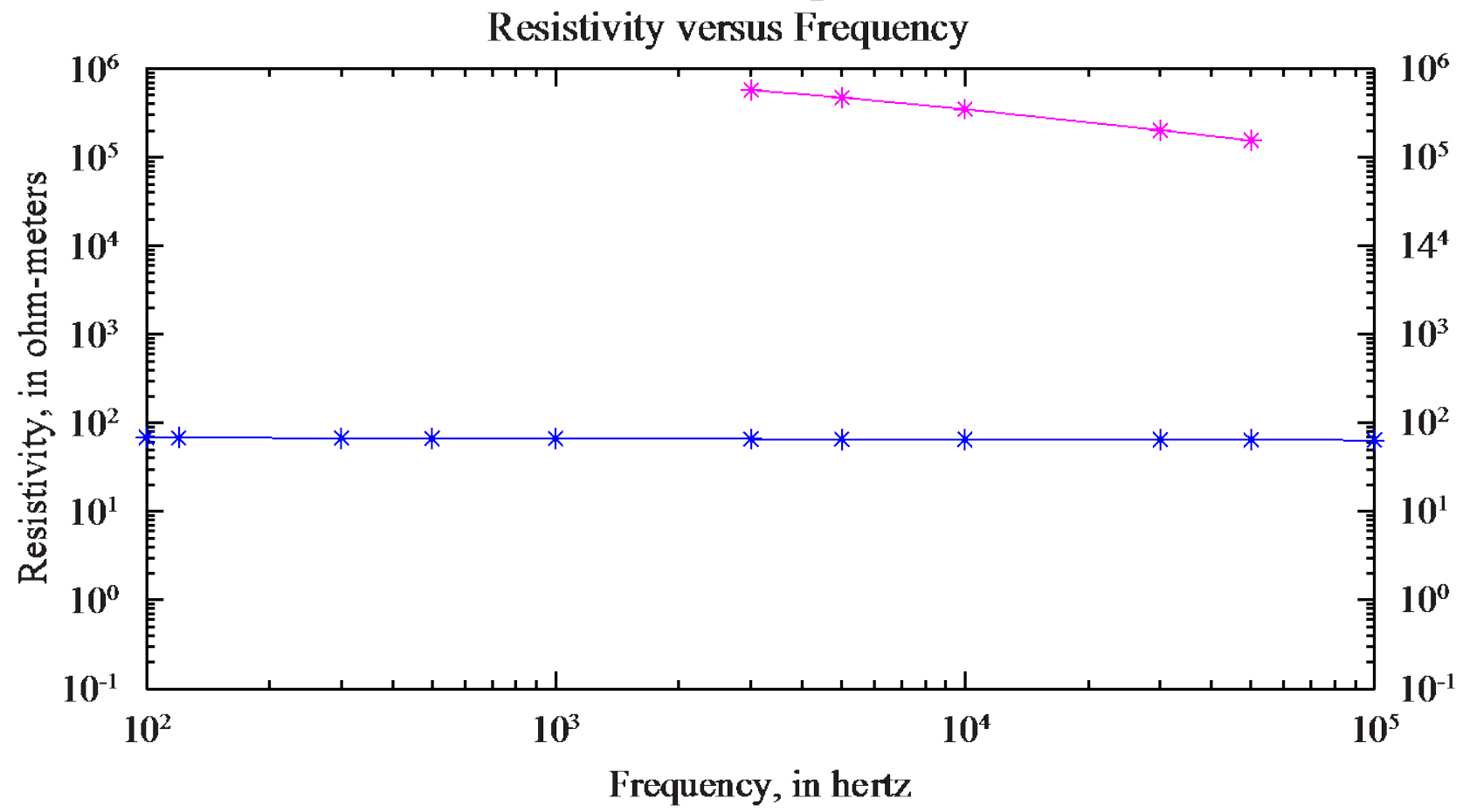

As-received measurement

- Water-added measurement

* Datum point 


\section{GoldTuft}

Resistivity versus Frequency

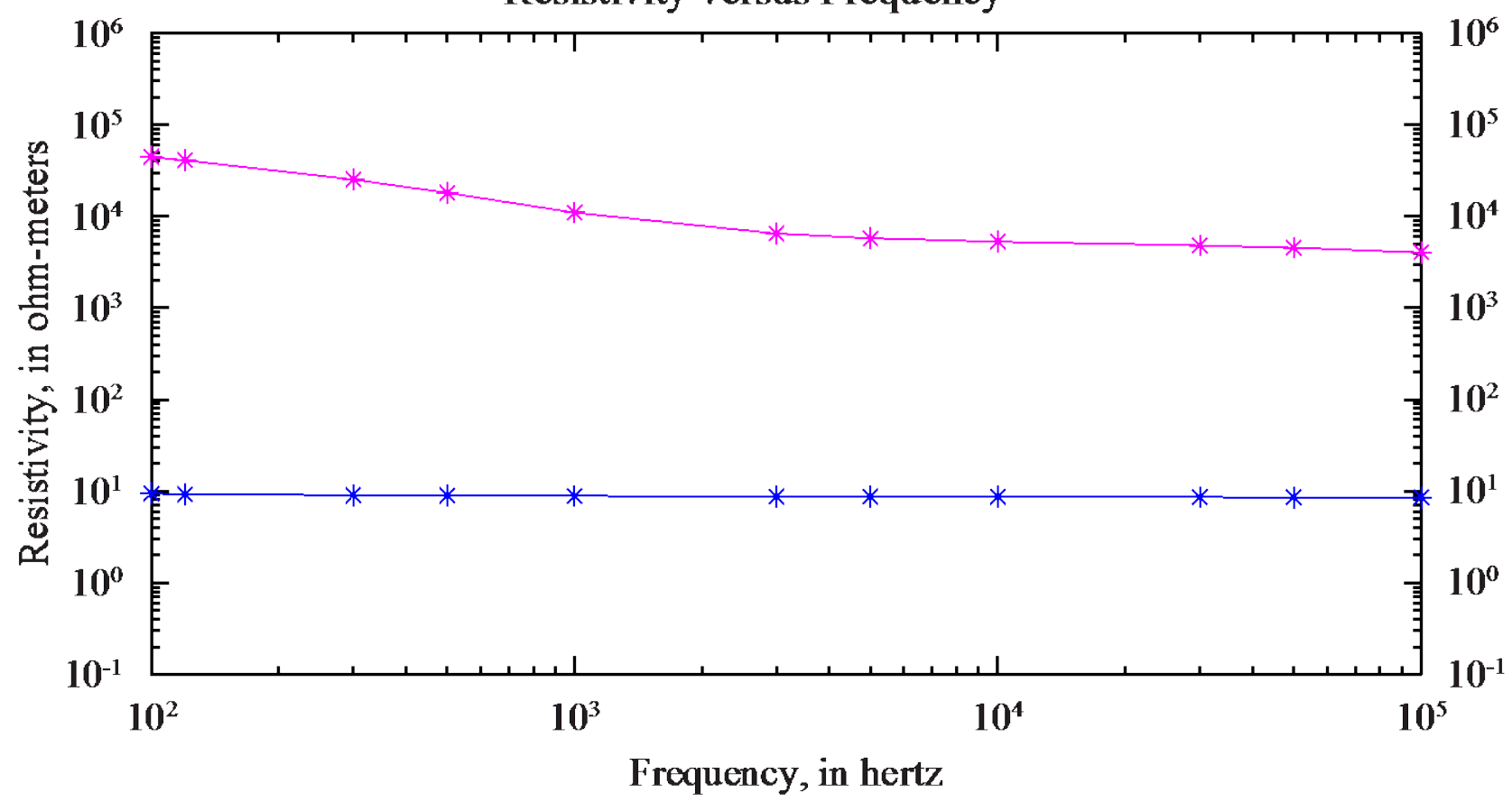

\section{GWdis}

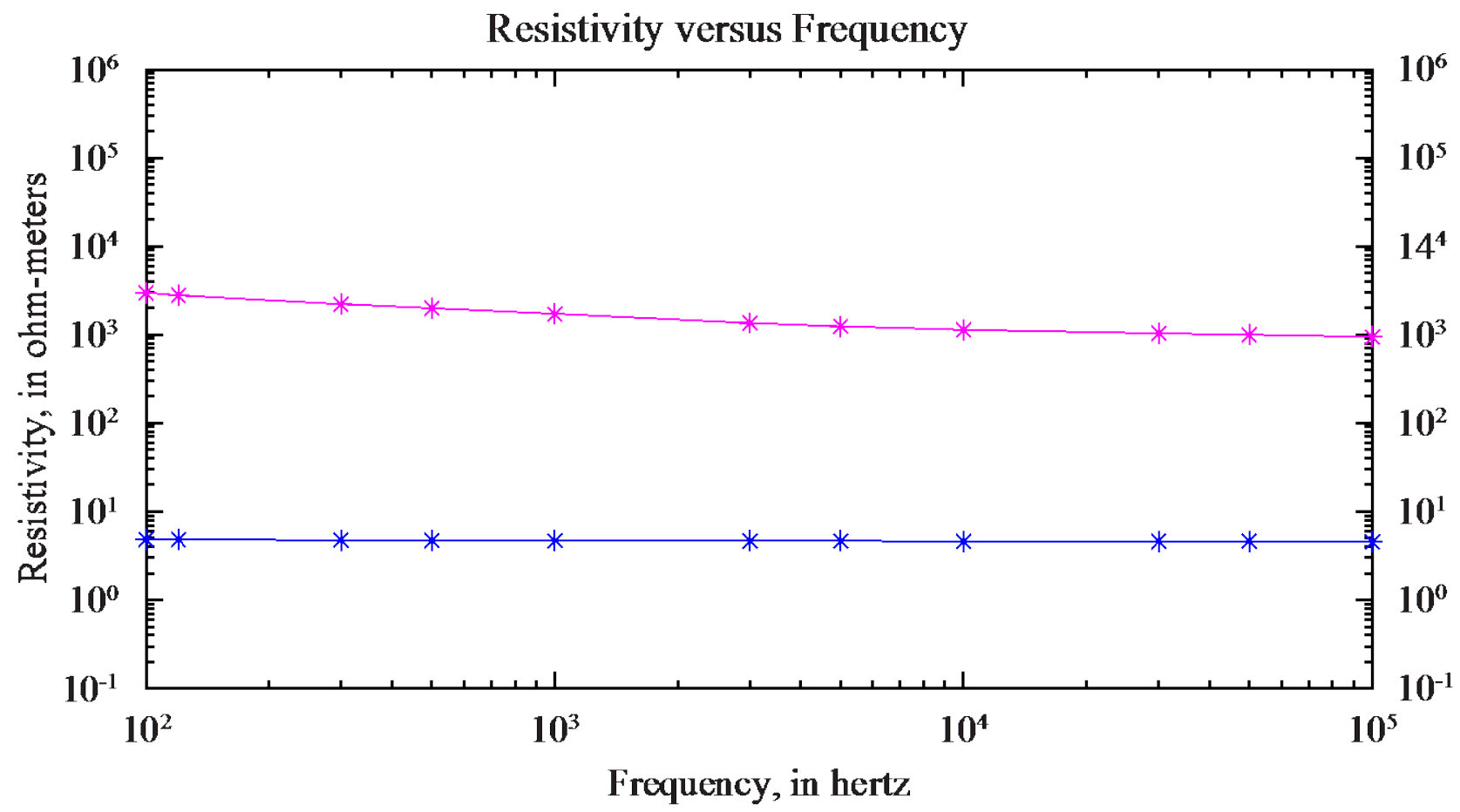

As-received measurement

- Water-added measurement

* Datum point 

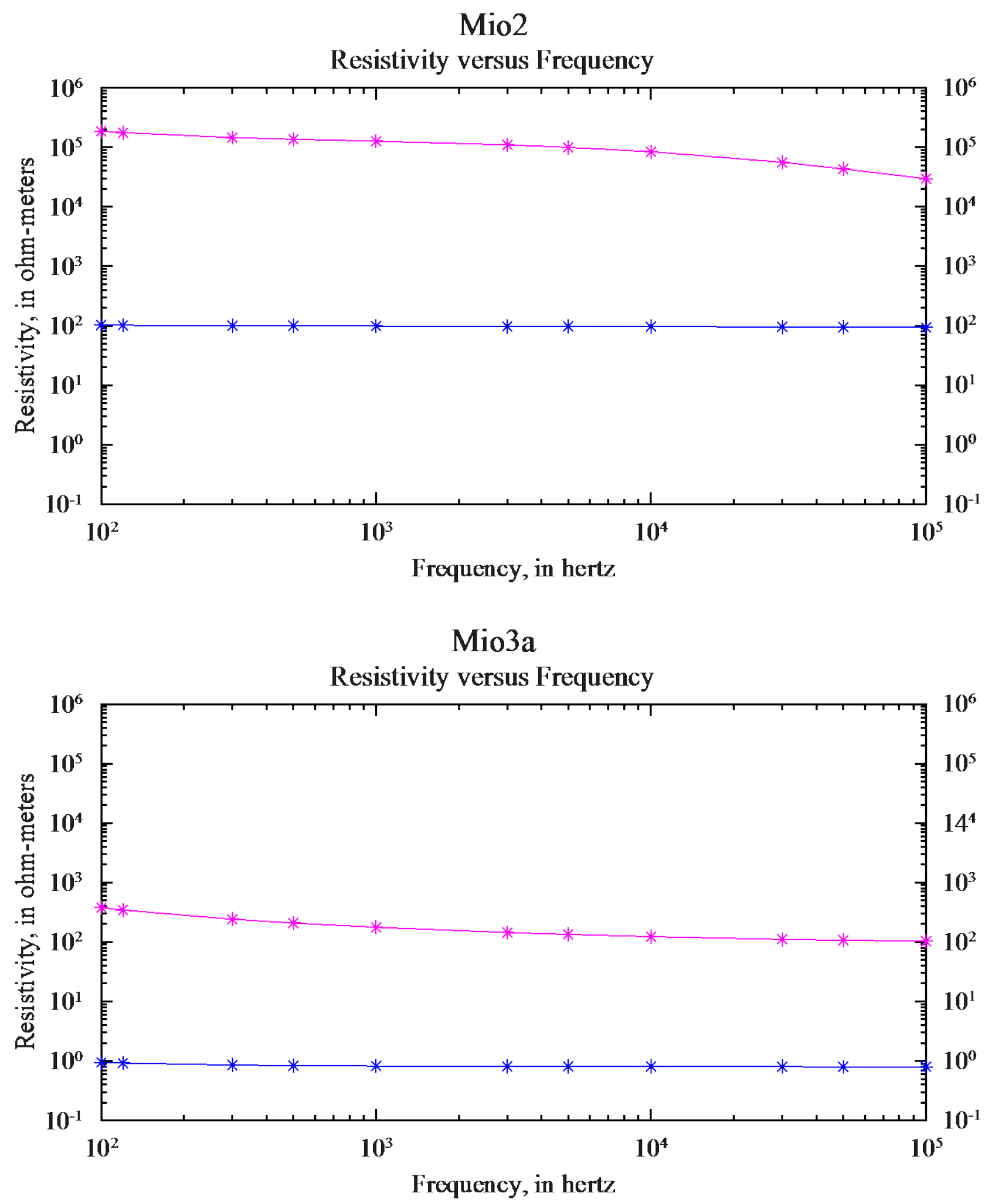

As-received measurement

- Water-added measurement

* Datum point 

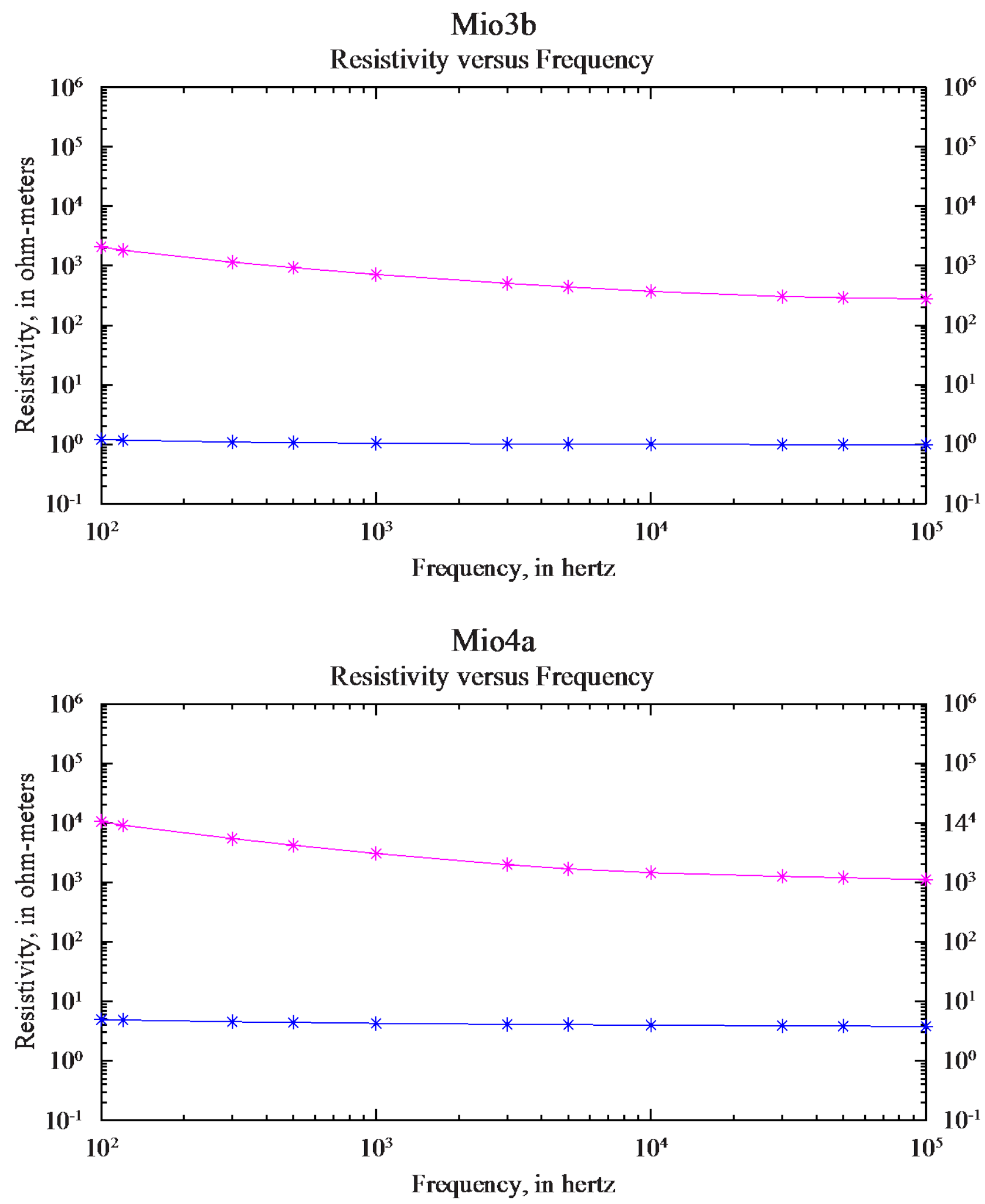

As-received measurement

- Water-added measurement

* Datum point 

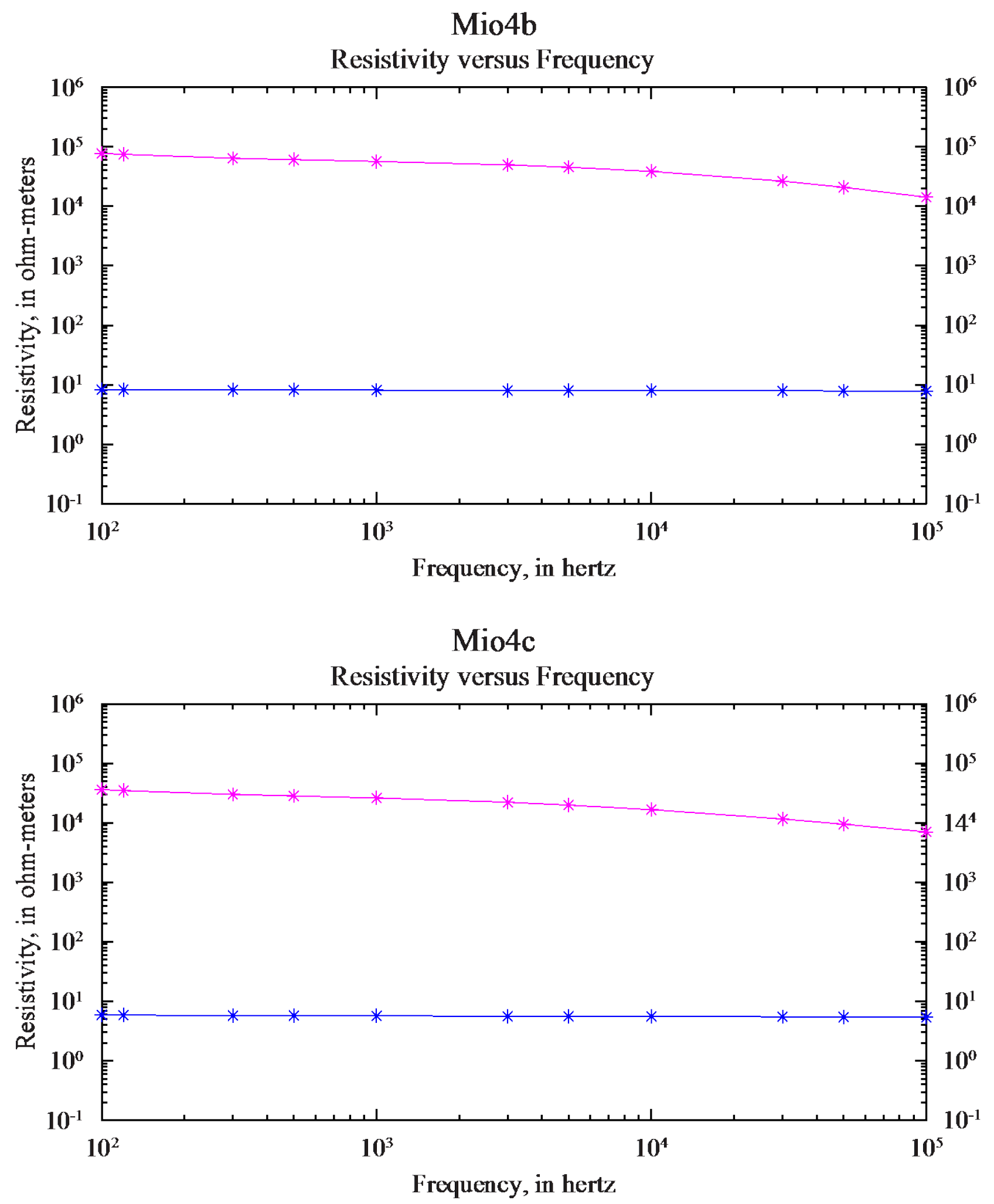

As-received measurement

- Water-added measurement

* Datum point 

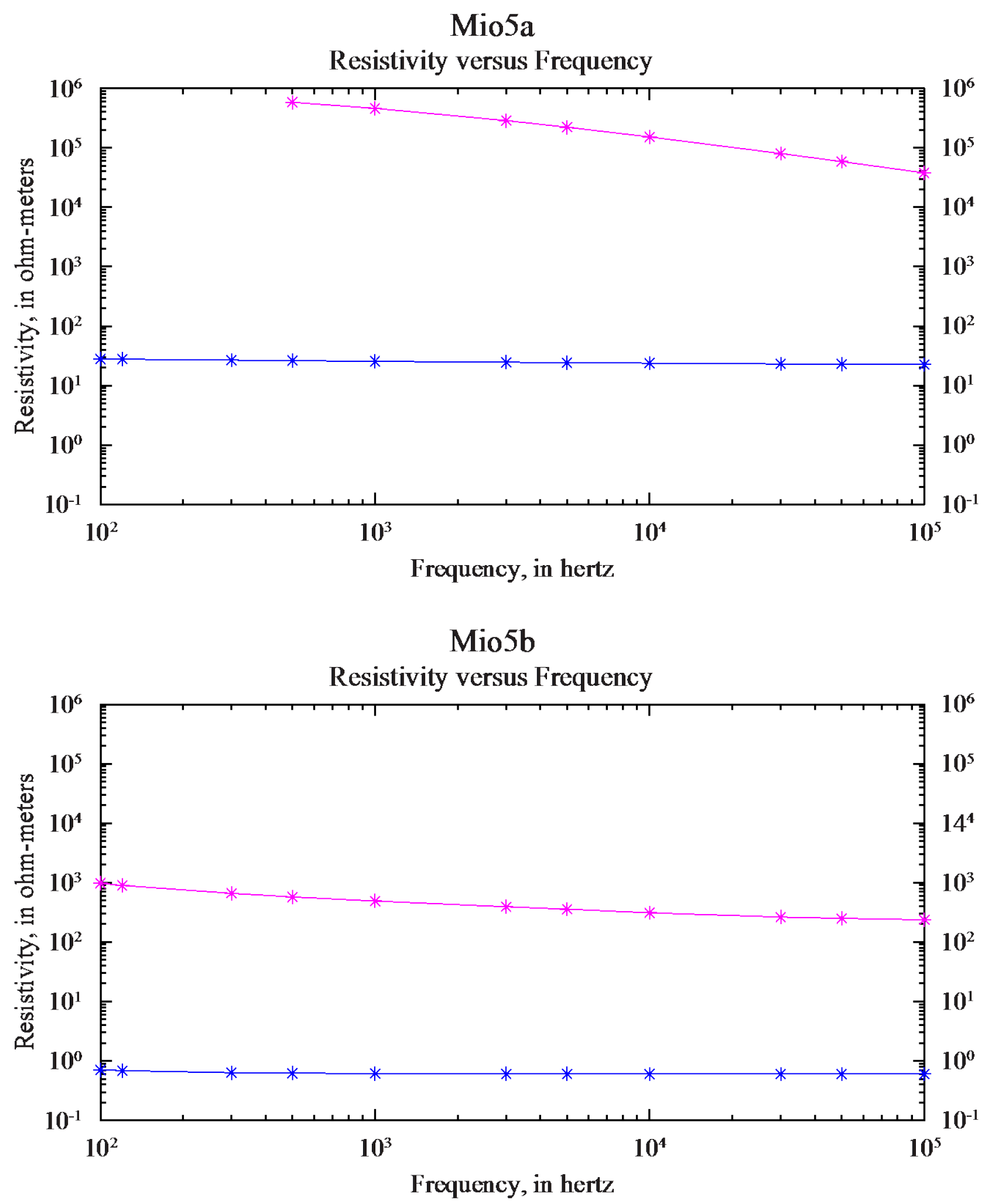

As-received measurement

- Water-added measurement

* Datum point 

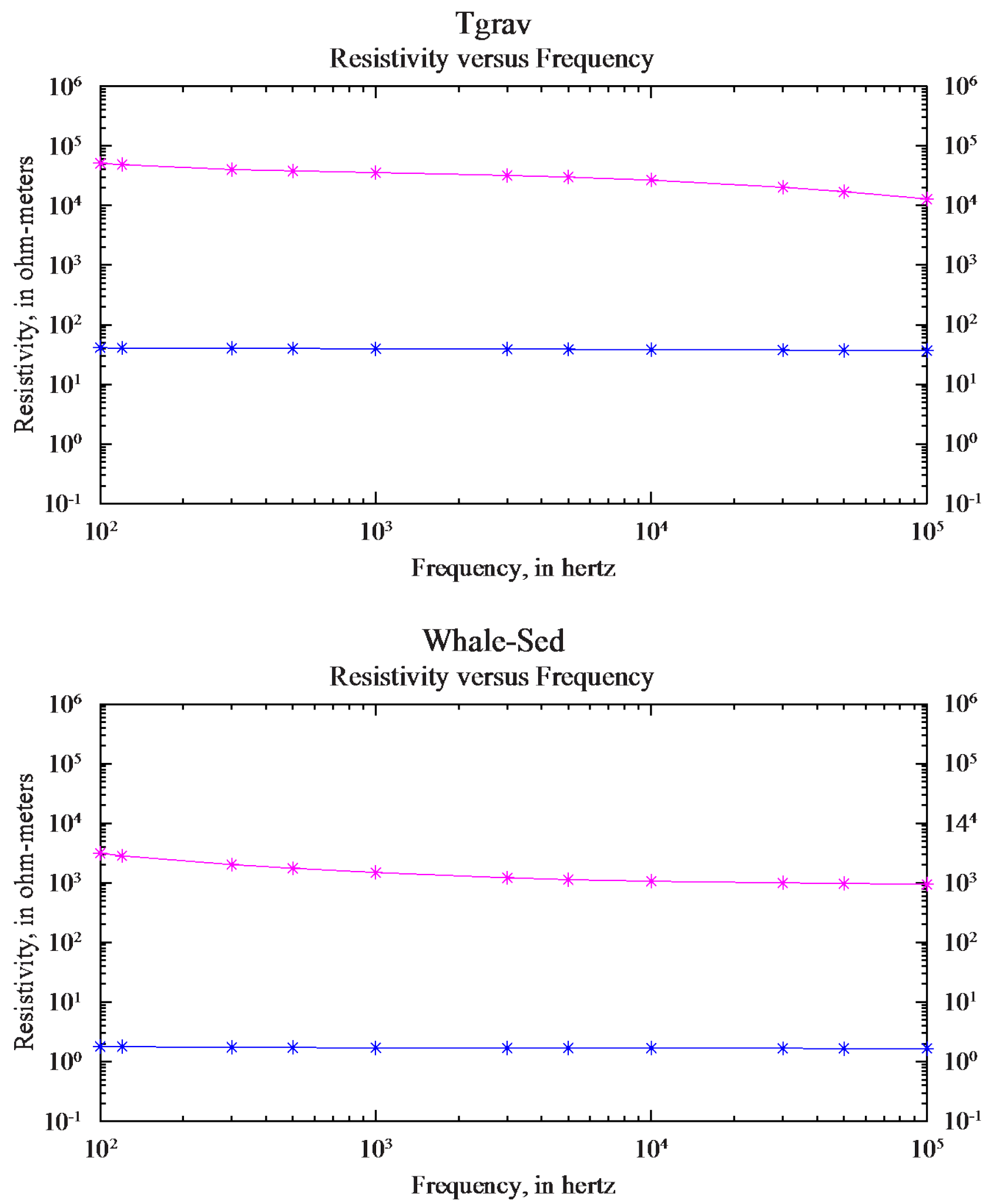

As-received measurement

- Water-added measurement

* Datum point 


\section{Appendix E. Laboratory Borehole Resistivity Comparison to TEM and Downhole Resistivity Logs}

Figures showing consolidated and unconsolidated core sample resistivity data, in ohm-meters, in comparison to the nearest inverted TEM resistivity sounding and long-normal resistivity borehole data. Depth is relative to the land surface. 
BLA5

Depth versus Resistivity

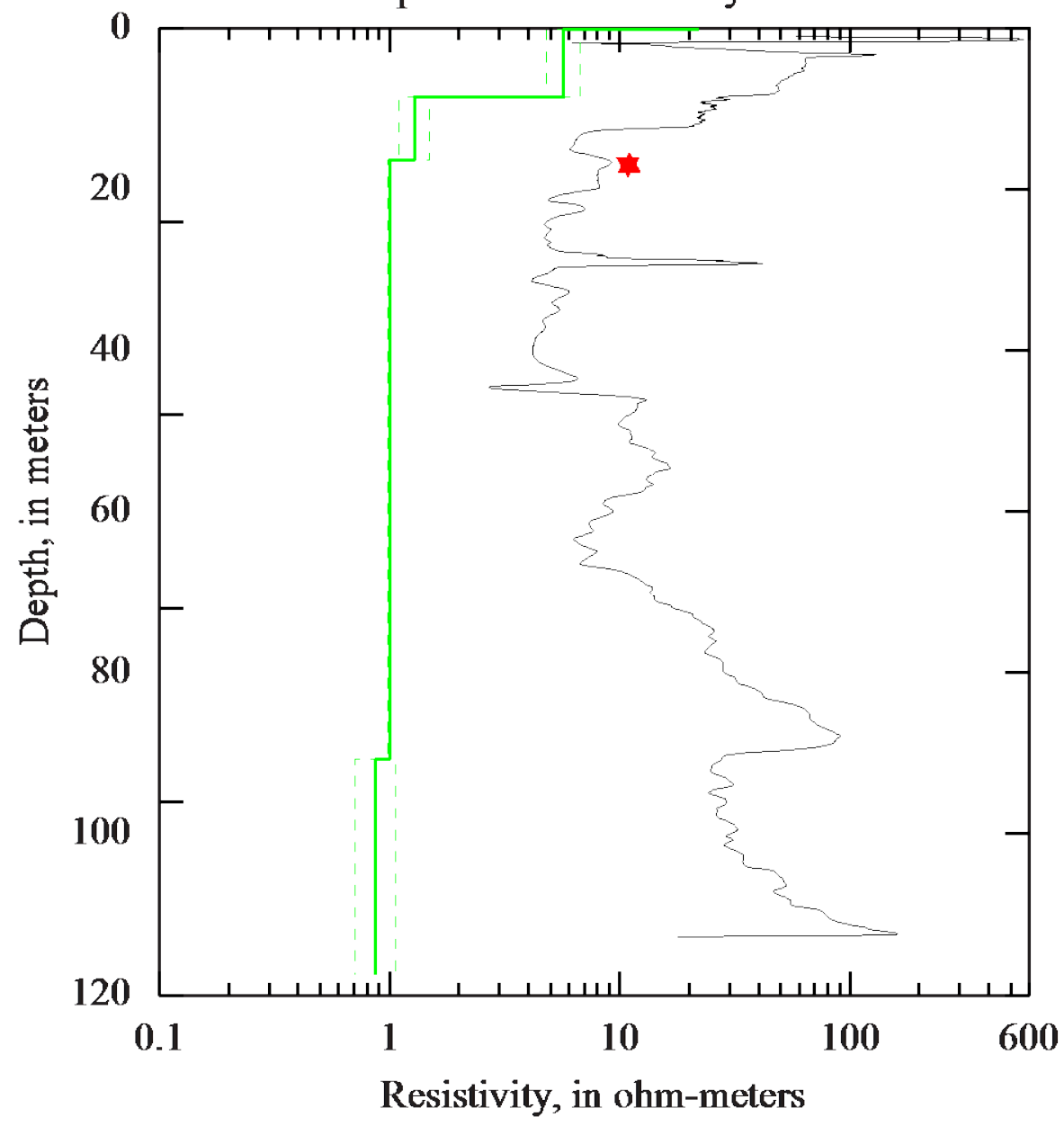

As-Received sample

$\triangle$ Top of core sample

$\nabla$ Bottom of core sample

- BL6 TEM sounding

Resistivity error bounds on TEM sounding

- Borehole long-normal (64 inch) resistivity log
CCT1

Depth versus Resistivity

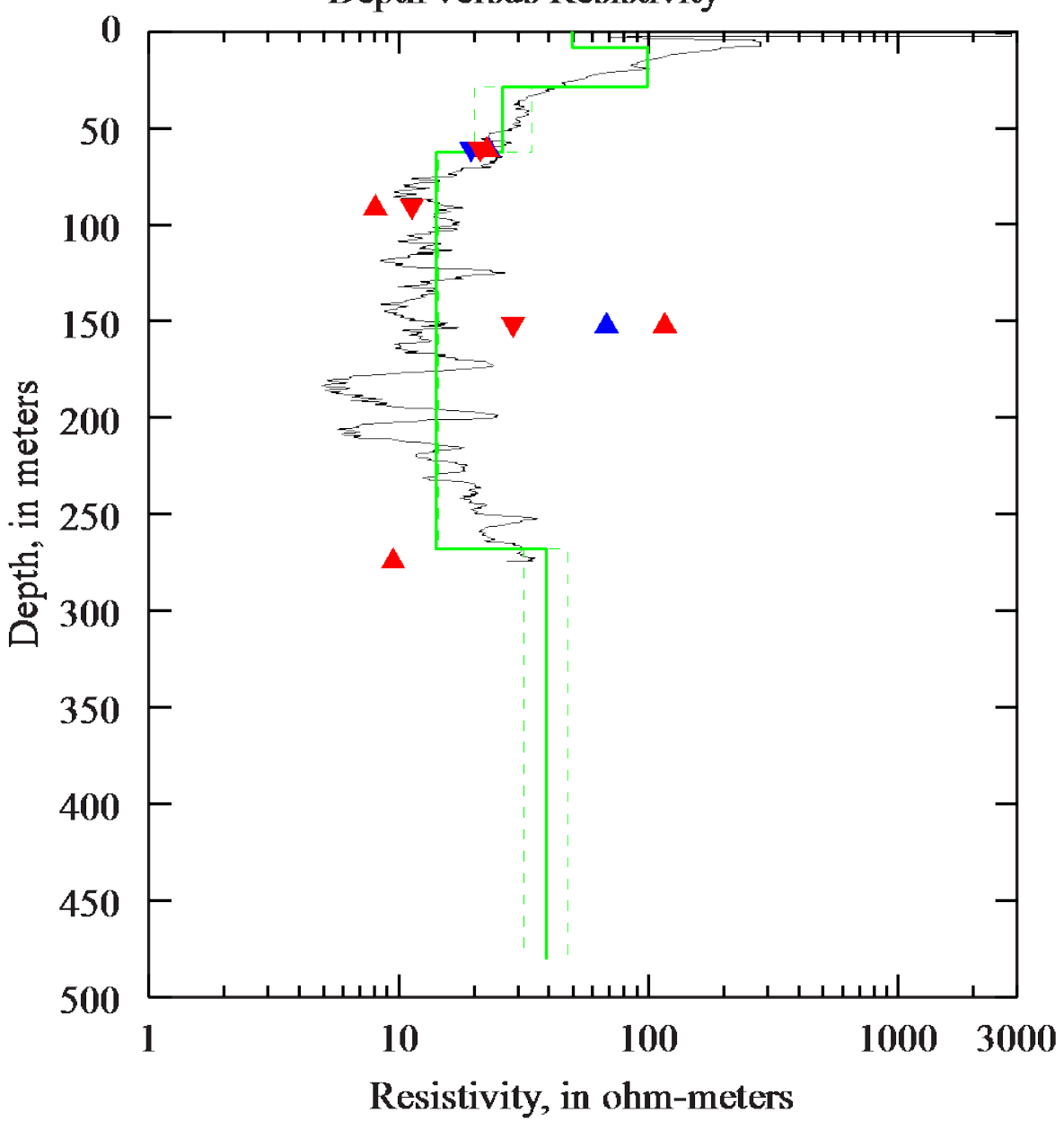

As-Received sample

Water-added sample

$\triangle$ Top of core sample

$\nabla$ Bottom of core sample

- CC1 TEM sounding

Resistivity error bounds on TEM sounding 
CRTH1

Depth versus Resistivity

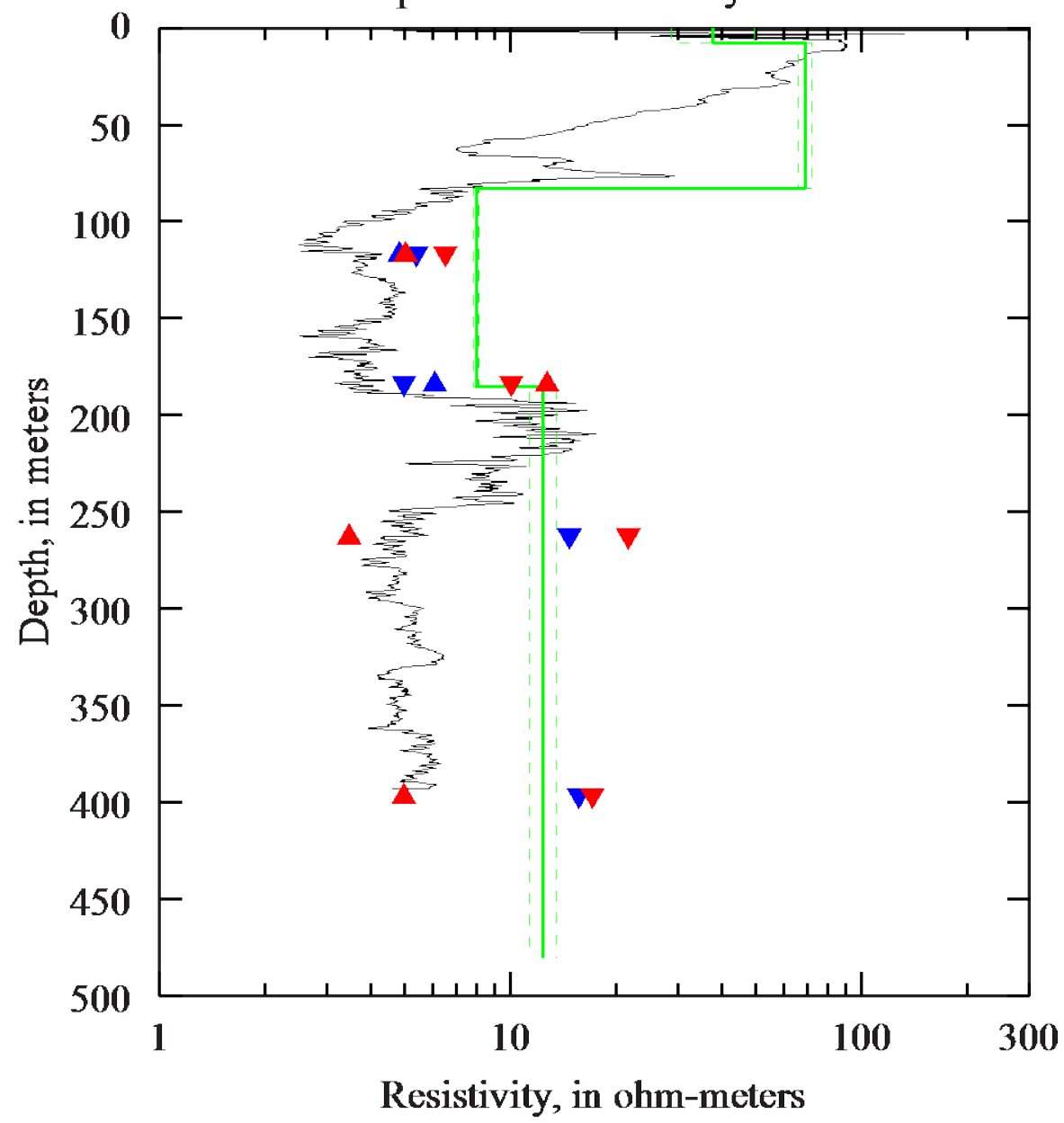

As-Received sample

$\triangle$ Top of core sample

Water-added sample

$\nabla$ Bottom of core sample

- CR6 TEM sounding

Resistivity error bounds on TEM sounding

- Borehole long-normal (64 inch) resistivity log
CRTH2

Depth versus Resistivity

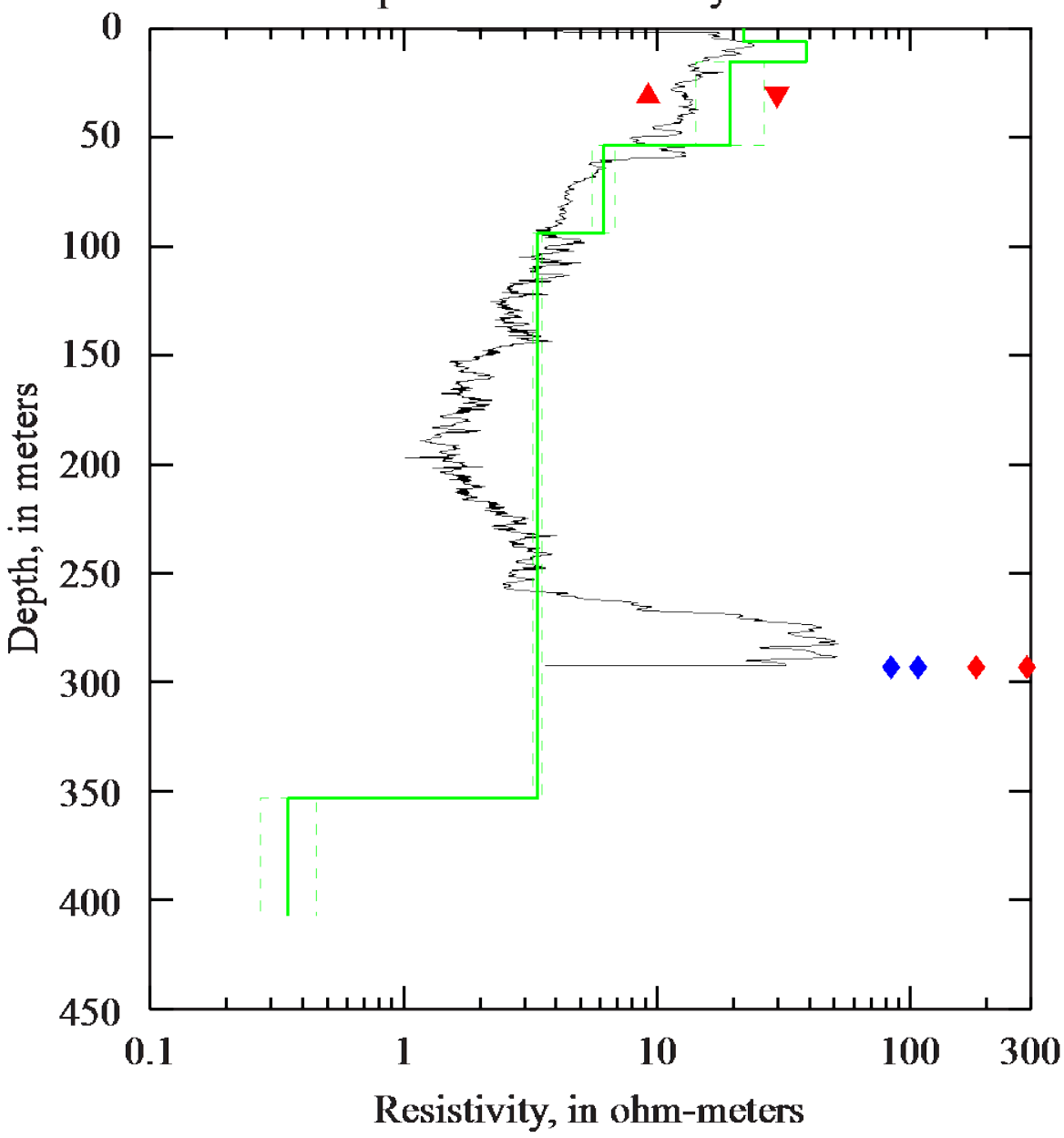

As-Received sample

$\triangle$ Top of core sample

$\nabla$ Bottom of core sample

$\diamond$ Core rock sample

- CR2 TEM sounding

Resistivity error bounds on TEM sounding 
GOLD1

Depth versus Resistivity

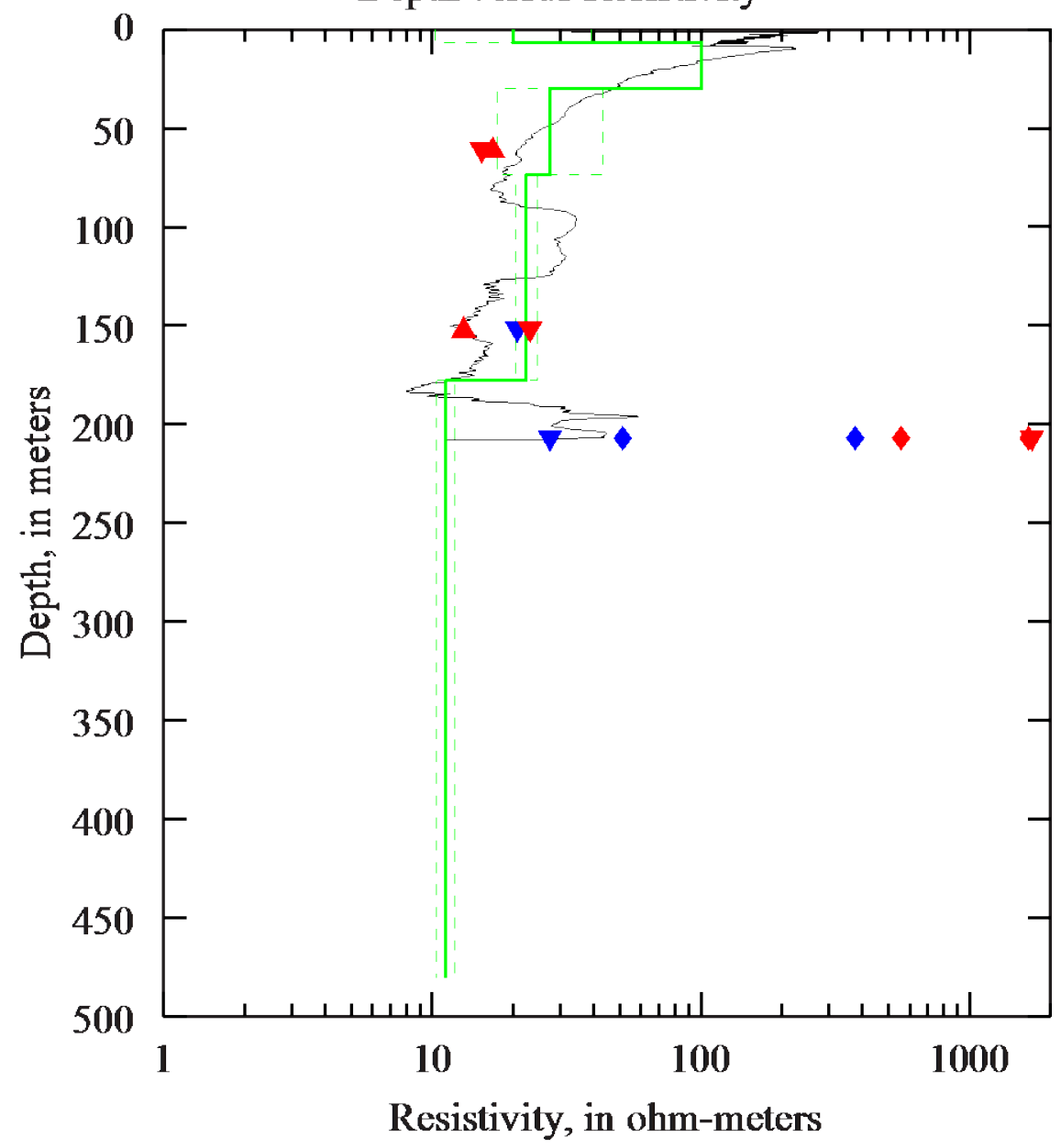

As-Received sample

$\triangle$ Top of core sample

- Water-added sample

$\nabla$ Bottom of core sample

$\diamond$ Core rock sample

- AU3 TEM sounding

Resistivity error bounds on TEM sounding

- Borehole long-normal (64 inch) resistivity log

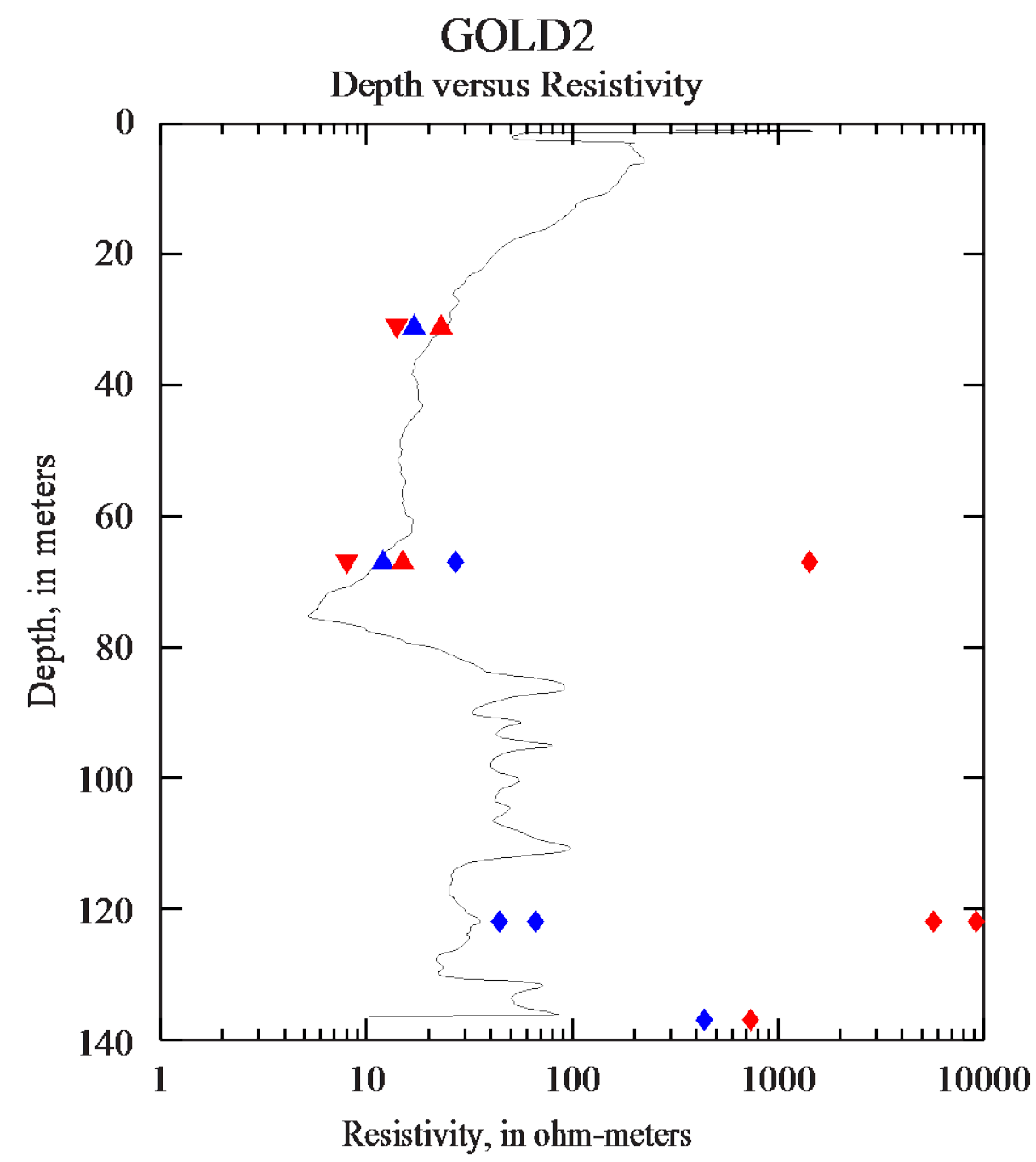

As-Received sample

- Water-added sample $\triangle$ Top of core sample

$\nabla$ Bottom of core sample

$\diamond$ Core rock sample 
LL04

Depth versus Resistivity

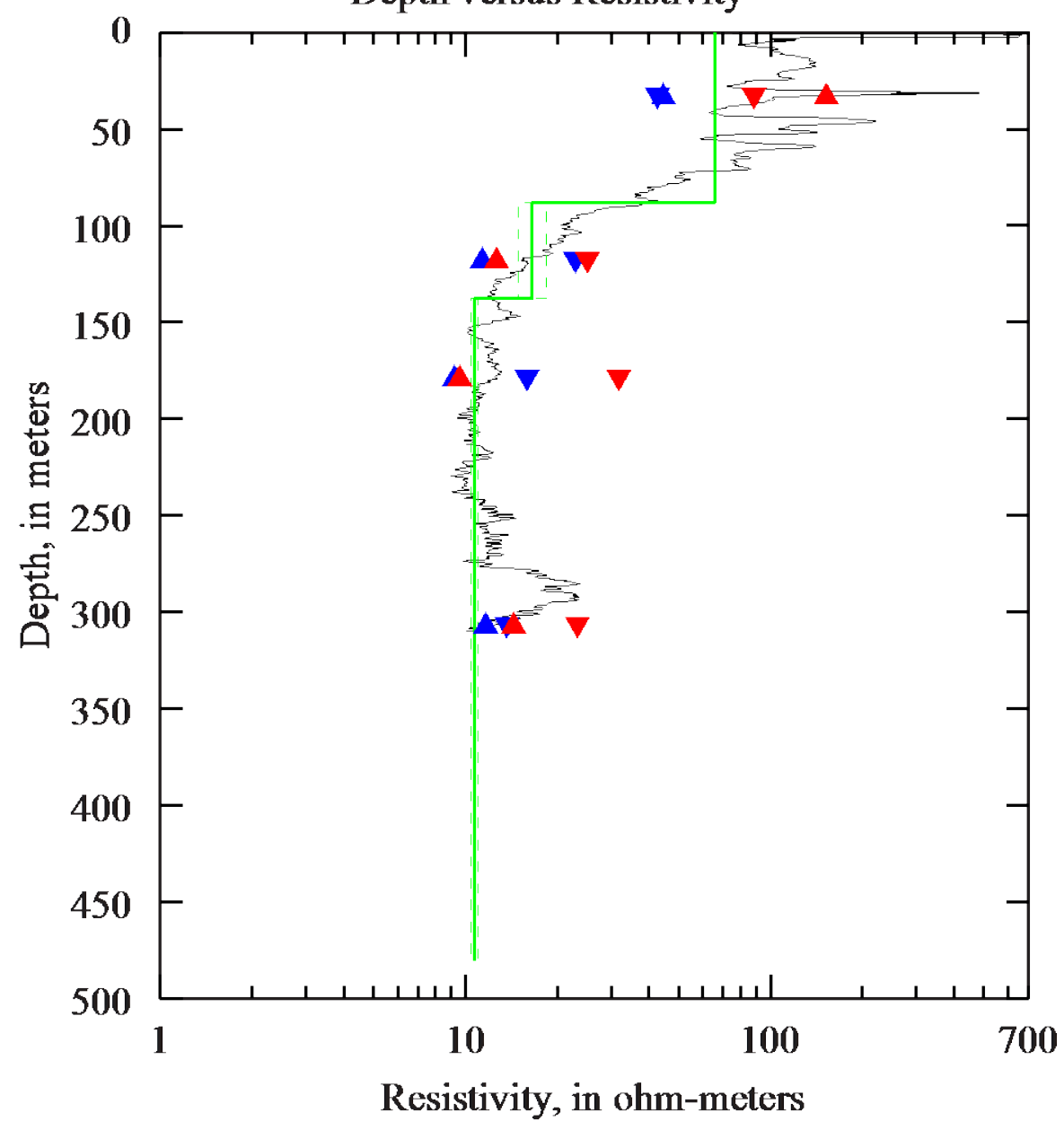

As-Received sample

- Water-added sample

$\triangle$ Top of core sample

$\nabla$ Bottom of core sample

- LN2 TEM sounding

Resistivity error bounds on TEM sounding

- Borehole long-normal (64 inch) resistivity log
NELT1

Depth versus Resistivity

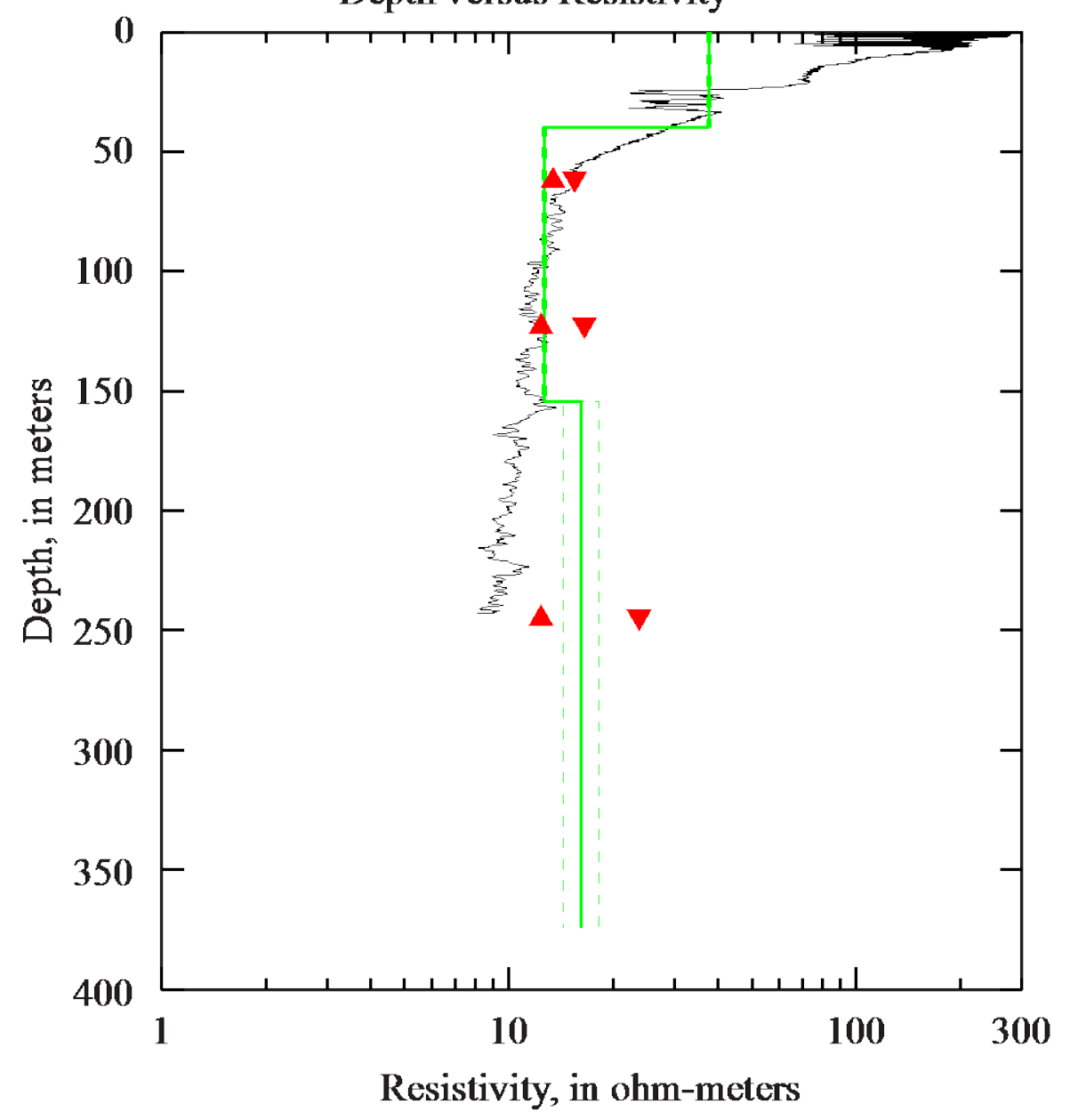

As-Received sample

$\triangle$ Top of core sample

$\nabla$ Bottom of core sample

- NL03 TEM sounding

Resistivity error bounds on TEM sounding 
NELT2

Depth versus Resistivity

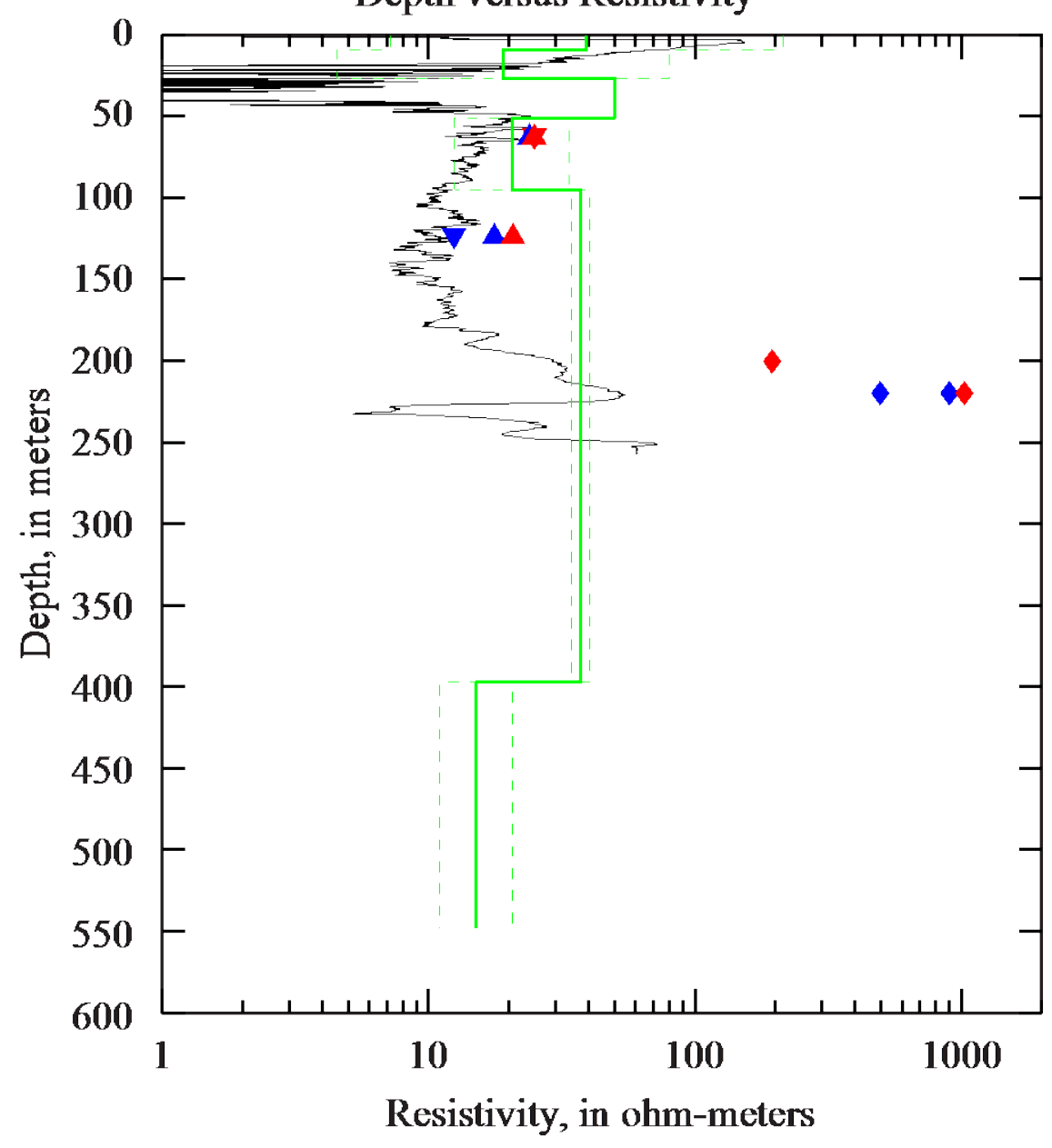

As-Received sample

Water-added sample

- NL14 TEM sounding

Resistivity error bounds on TEM sounding

$\nabla$ Bottom of core sample

$\diamond$ Core rock sample
NELT3

Depth versus Resistivity

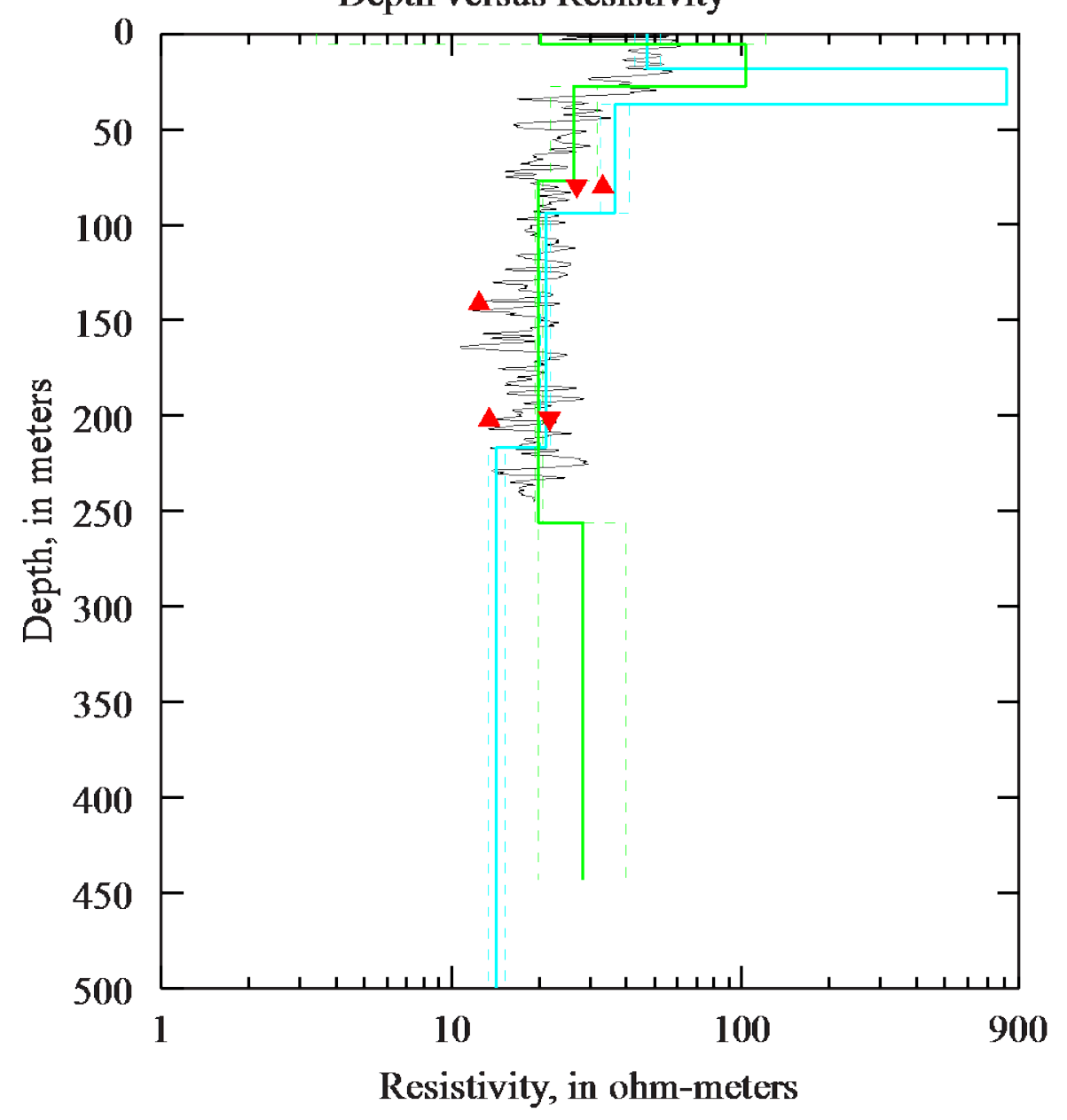

As-Received sample

$\triangle$ Top of core sample

- Water-added sample

$\nabla$ Bottom of core sample

- NL11 TEM sounding

Resistivity error bounds on TEM sounding

- NL20 TEM sounding Resistivity error bounds on TEM sounding

- Borehole long-normal (64 inch) resistivity log

- Borehole long-normal (64 inch) resistivity log 
NELT4

Depth versus Resistivity

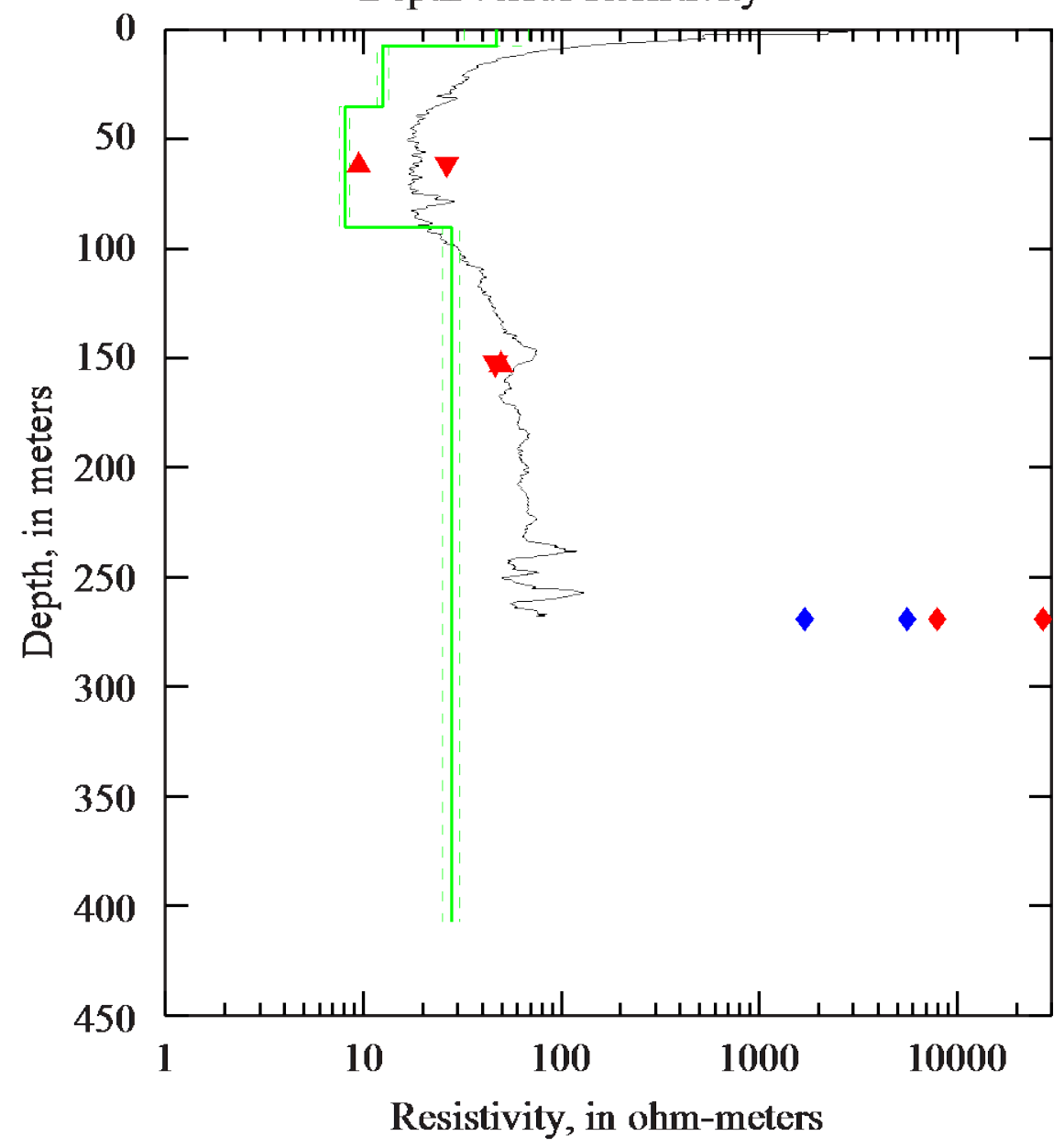

As-Received sample

- Water-added sample

- NL13 TEM sounding

$\triangle$ Top of core sample

$\nabla$ Bottom of core sample

$\diamond$ Core rock sample

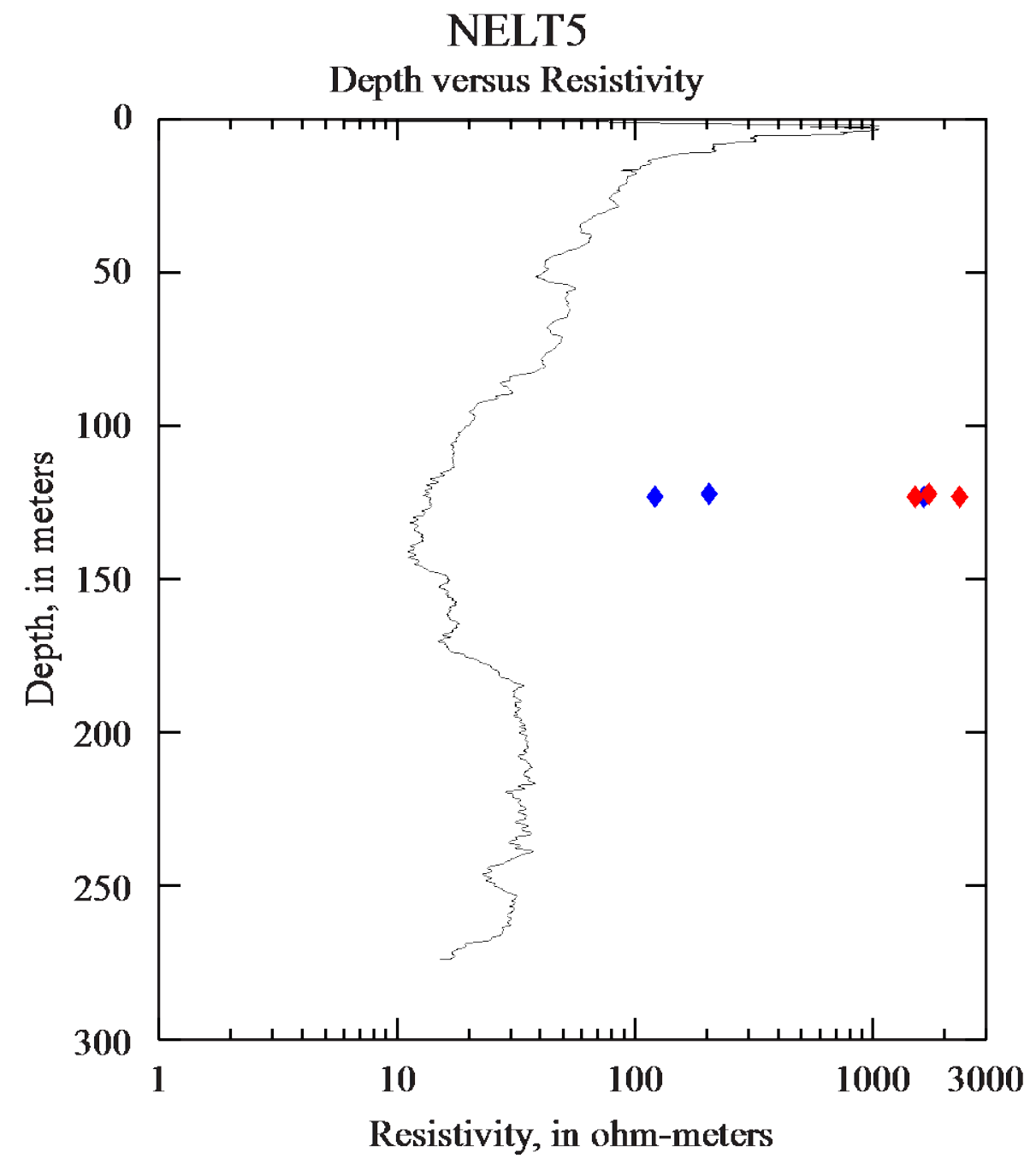

As-Received sample

- Water-added sample

Resistivity error bounds on TEM sounding

- Borehole long-normal (64 inch) resistivity log

- Borehole long-normal (64 inch) resistivity log 
NELT6

Depth versus Resistivity

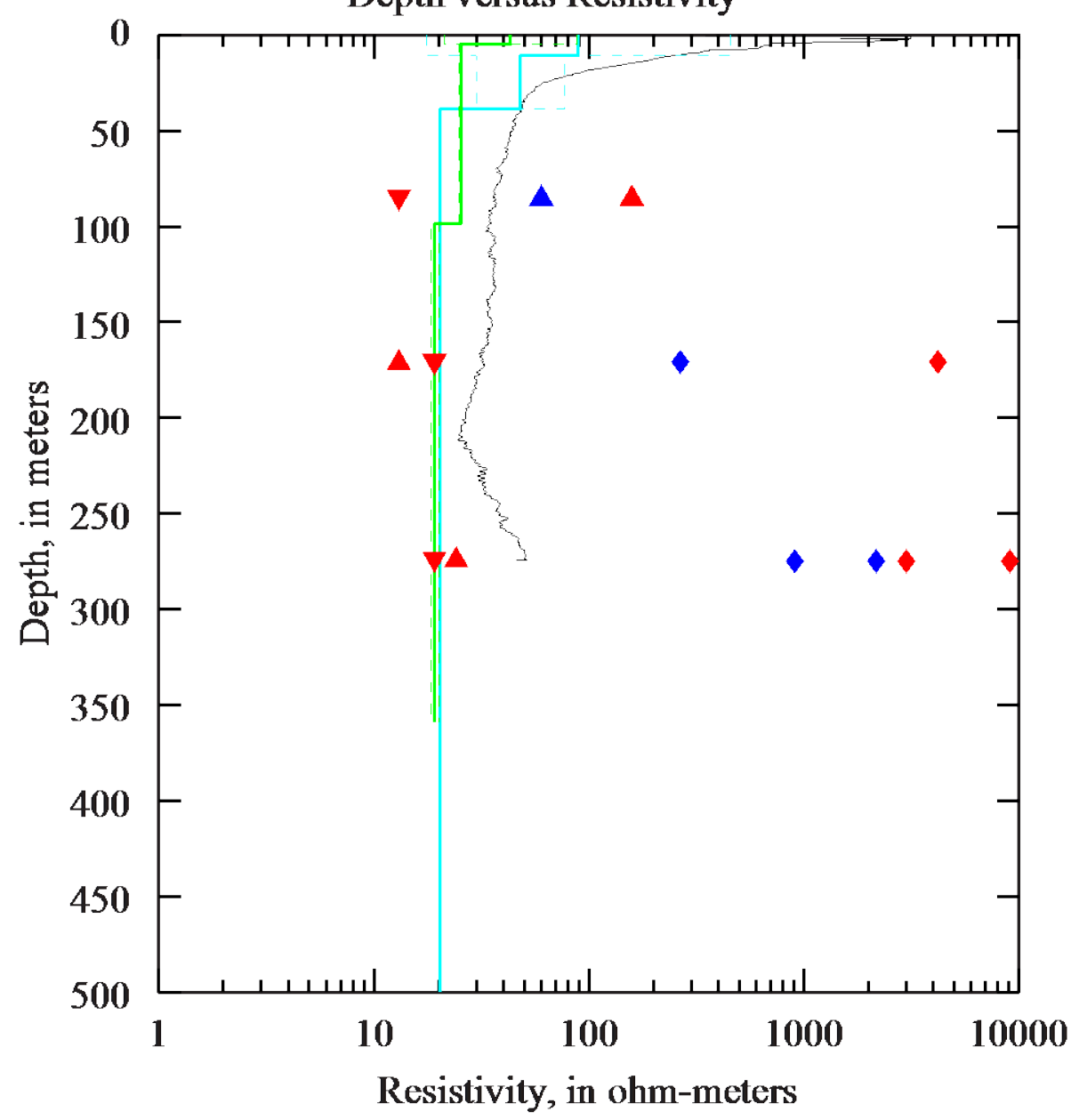

As-Received sample

$\triangle$ Top of core sample

Water-added sample

$\nabla$ Bottom of core sample

$\diamond$ Core rock sample

- NL04 TEM sounding

Resistivity error bounds on TEM sounding

- NL30 TEM sounding

Resistivity error bounds on TEM sounding

- Borehole long-normal (64 inch) resistivity log
NELT7

Depth versus Resistivity

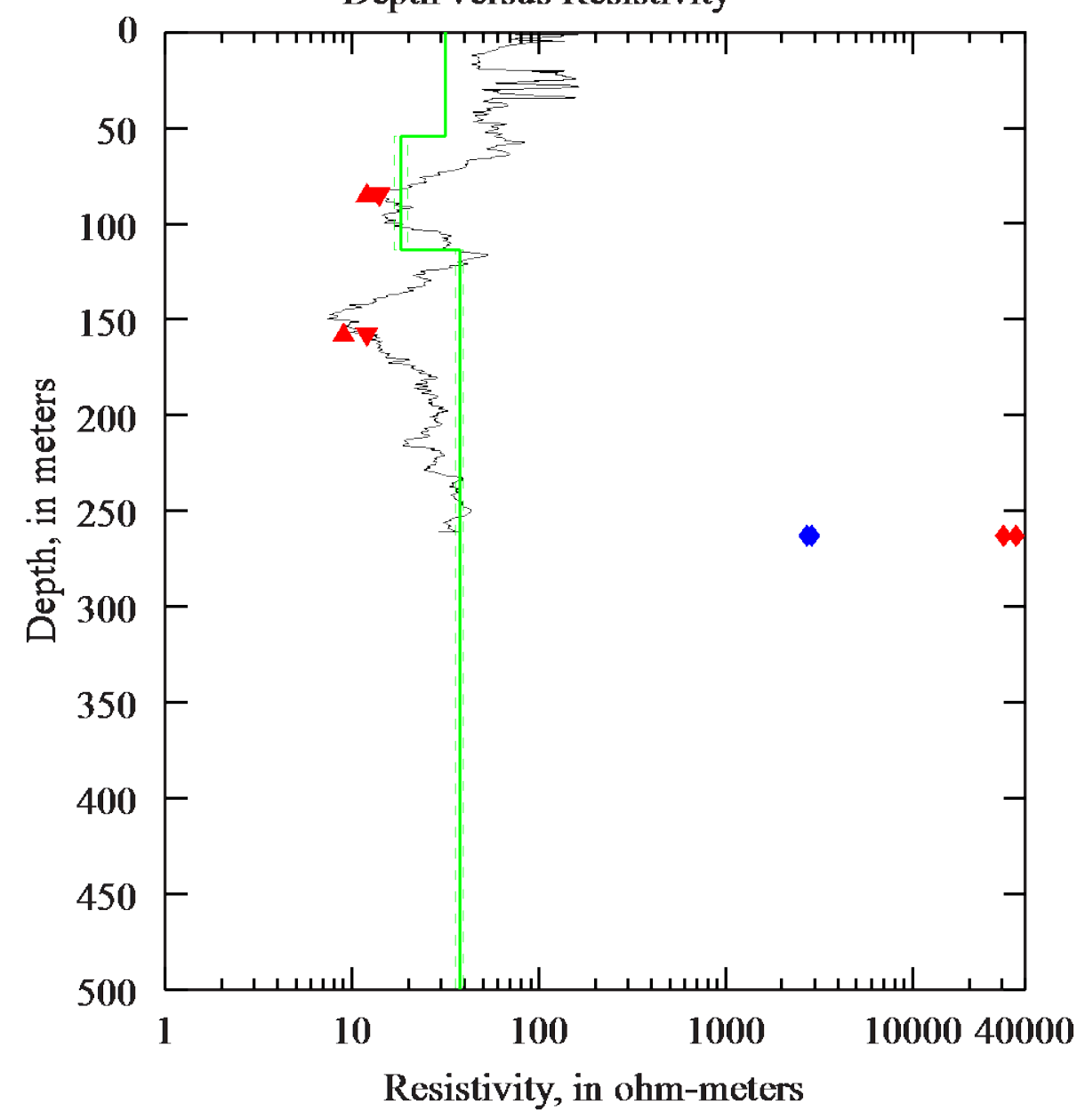

As-Received sample

Water-added sample

- NL18 TEM sounding

Resistivity error bounds on TEM sounding 


\section{Supplemental Data}

Data

The supplemental data include frequency-dependent resistivity, complex impedance magnitude, phase, and real and imaginary components of impedance. Frequency is specified in hertz, resistivity is specified in ohm-meters, phase is specified in radians, and all impedance values (magnitude, real, and imaginary components) are specified in ohms.

All of the processed data are presented in one of four spreadsheets in the supplemental data. The four spreadsheets have been broken up based on the origin and type of sample: core rocks

(SupplementA_CoreRock_spreadsheet.xlsx), core sediments (SupplementB_CoreSed_spreadsheet.xlsx), surface rocks (SupplementC_SurfaceRock_spreadsheet.xlsx), and surface sediments (SupplementD_SurfaceSed_spreadsheet.xlsx). In addition to the spreadsheets, there is a table for each group that contains sample locations and, for the rock samples, a brief petrologic description (SupplementA_CoreRock_table.xlsx, SupplementB_CoreSed_table.xlsx, SupplementC_SurfaceRock_ table.xlsx, and SupplementD_SurfaceSed_table.xlsx). Appendixes A, B, C, and D present each of these four groups and show the data on a resistivity versus frequency graph, one for each core segment or each sample.

The core-rock spreadsheet (SupplementA_CoreRock_spreadsheet.xlsx) presents the data separated out by borehole and then by sample. The data presented include as-received, dry, humid, and submerged resistivities; impedance; phase; and real and imaginary components of the complex impedance at each frequency.

The core-sediment spreadsheet (SupplementB_CoreSed_spreadsheet.xlsx) presents the data separated out by borehole and then by sample. The data presented include as-received and water-added resistivities; impedance; phase; and real and imaginary components of the complex impedance at each frequency. For each core segment, measurements are separated into top and bottom samples.

The surface-rock spreadsheet (SupplementC_SurfaceRock_spreadsheet.xlsx) presents the data separated by sample and, in a few cases, by subsample (for example, sample LAIR3 was slabbed twice, and two subsamples, LAIR3-a and LAIR3-b, were created). The data presented includes dry, humid, and submerged resistivities; impedance; phase; and real and imaginary components of the complex impedance at each frequency.

The surface-sediment spreadsheet (SupplementD_SurfaceSed_spreadsheet.xlsx) presents the data separated by sample. The data presented include as-received and water-added resistivities; impedance; phase; and real and imaginary components of the complex impedance at each frequency.

Additionally, appendix E compares the borehole geophysical logs to the laboratory measurements and time-domain soundings, one plot for each borehole.

\section{Supplement A}

CoreRock table (coordinates and description of samples) and CoreRock spreadsheet (containing all data). See FtIrwin_README.doc (in supplemental data folder) for additional details.

\section{Supplement B}

CoreSed table (coordinates and depth of samples) and CoreSed spreadsheet (containing all data). See FtIrwin_README.doc (in supplemental data folder) for additional details. 


\section{Supplement C}

SurfaceRock table (coordinates and description of samples) and SurfaceRock spreadsheet (containing all data). See FtIrwin_README.doc (in supplemental data folder) for additional details.

\section{Supplement D}

SurfaceSed table (coordinates of samples) and SurfaceSed spreadsheet (containing all data). See FtIrwin_README.doc (in supplemental data folder) for additional details. 